\title{
Alcohol Safety Countermeasures Program SPECIAL ANALTTICAL STUDY
}

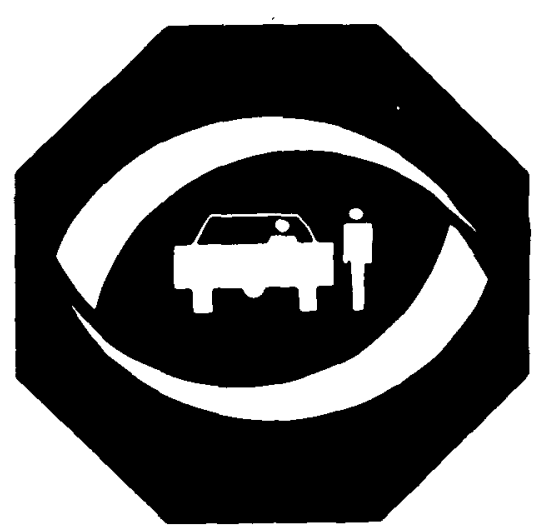

December, 1970

\section{U.S. DEPARTMENT OF TRANSPORTATION National Highway Safety Bureau}

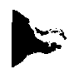




\section{r}

SPECIAL ANALYTICAI STUDY

ALCOHOL SAFETY COUNTERMEASURES PROGRAM

DECEMPER 1070

U. S. DEPARTMENT OF 'TRANSPORTATION

NETIONAL HIGHWAY SAFETY BUREAU 
ALCOHOL SAFETY PROGRAM

- Facts:

- Alcohol is involved in 50 percent of highway fatalities -more than 25,000 deaths; 800,000 crashes each year (Section II).

- Problem drinkers, not normal social drinkers, cause about two-thirds of these deaths, many to innocent victims, (Section II).

- Approximately 7 percent of the drivers a re problem drinkers and can be IDENTIFIED. Appropriate DECISIONS can be made by Courts and Licensing Agencies and ACTION taken to ensure they do not drink and drive (Section III).

Congressional Requirement:

- The importance of alcohol to highway safery was recognized by Congress, who included a requirement for a report on this subject in Section 204 of the Highway Safety Act of 1966. Public Law 89-564. In August 1968, the Secretary of Transpoxtation complied with this requirement by submitting to Congress a report on the relationship of consumption of alcohol and highway safety and potential countermeasures for reducing this problem.

DOT Action:

The 1968 Alcohol and Highway Safety Report provided a comprehensive review of research on the role of alcohol in highway crashes.

- This report details the DOT Countermeasures Program. NHSB has developed an action program featuring comprehensive Community Alcohol Safety Action Projects, (Secion IV); Bureau activities under: Section 402 assistance to the States, (Section V); Public Education, Community Support and Manpowes Development Programs, (Section VI); and Research, Development and Field Demonstration activities, (Section VII). 


\section{CONTENTS}

SUMNARY

Summary

Section I

PROGRAM BACKGROUND
The Problern Section II
NHSB A:cohol Safety Section III
Program Concept

\section{ELEMENTS OF THE ACTION PROGRAM}

Plan for Development of

Comprehensive Community

Section IV

Alcohol Safety Action Progratäa

Plan for State Assistance

Section V

Through 102 Annual Work.

Plans

Plan for Public Education and

Section VI

Manpower Development Program

Plan for Research and Development. Section VII Program

PROGRAM MANAGEMENT

Program Lvaluation

Section VIII

Resource Requirements

Section IX

Interagency Relationships

Section $X$

Management Plan and Organization

Section XI 


\section{SUMMARY}

The Highway Safety Act of 1966 requires the Secretary to make a thorough and complete study of the relationship between the consumption of alcohol and its effect upon highway safety and drivers of motor vehicles; and to report the results of the study to the Congress including any recommendations for legislation.

A comprehensive report was submitted to the Congress in August 1968 which concluded that:

The use of alcohol by drivers ane pedestrians leads to some 25,000 deaths and a total. of at least 800,000 crashes in the United States each year.

Alcoholics and other problem drinkers, who constitute but a smail minority of the general population, account for a very large part of the overall highway safety problem.

The Secretary indicated on July 22, 1969 , that he would initiate a comprehensive countermeasure program to reduce ajcohol-related highway death and injury. Previous to that NHSB officials testified before the House Public Works Committee outlining an alcohol countermeasure program. Furthermore, the National Lfighway Safety Advisory Committee on December 16, 1969, recommended to the Secretary that an alcohol and highway safety countermeasure program be given a high priority. The specific countermeasures suggested by the Committee included a number of those described belc.w.

The Problern

Research data indicate that about three-quarters of all drivers drink and that about 16 percent of these can be zlassified as heavy drinkers. At least five to seven million of these have a problem involving alcohol. Included in this group are alcoholics and heavy compulsive drinkers who are the priniary target group of the Buxe'u's countermeasure program. 
Available evidence indicates that this small group of problem drinkers can be distinguished from the large mass of social drinkers as the problem drinkers frequently have a history of traffic arests, particularly arrests involving alcohol. They also frequenty have a history of arrests for non-highway offenses. When they axe involved in fatal accidents they will bave blood-ulcohol levels (BAL) in excess of . 15 percent, far above the typical social drinker's level of 07 percent or less. Drinking in any amount lessens driver safety, and any driving after drinking is discoureged. However, generalized campaigns against drinking and drivang, because they appeat to aim at 75 percent of the drivers who on occasion do drive after some drinking, fail to gain strong public support. The National Standard on Alcohol and Highway Safety defines. 10 percent BAL as presumptive evidence of intoxication. At this level the risk of arivers causing a highway crash grows very sharply. As statud, pioblem drinkers who typicaily reach. 15 percent BAL and highex are a deviant, identifiable group who are a predominate factor in fatal and serious injury crashes. It takes about 11 one-ounce drinks after eating for a 180 pound man to reach the. 15 percent bluod alcohol level.

Present methods of dealing with the drinking driver center on law enforcement and the imposition of penalties against convicted drunken drivers. Little if ary effort is directed at keeping the known problem drinker from behind the wheel or regulating his driving behavior before he causes an accident. More specifically, the present approach is deficient in the following areas:

- Identification and control of the problem drinker.

- Inadequate apprehensions and prosecution

- Lack of specialized counseling services

- Lax enforcement of dxiving suspensions

- Misdirected public information campaigne which are aimed at the social drinker

ISSUE: Scope, direction, magnitude and scheduling of Department of Transportation Alcohol Countermeasures Program to reduce alcohol related highway death and injury.

\section{ASSUMPTIONS :}

Significant reductions in alcohol connested traffic crashes, deaths and injuries can be achieved through a well designed and properly implemented program, as inclicated by the experience of some European countries. 
- The Federal Government must exercise leadership in this field. States and communities have been dealing with the problem with 1 inited success. The Federal Government must provide direction and leadership for a new approach.

- An essential distinction can be drawn between the social drinker and the problem drinker. A program focusing on the latter can secure public support.

- Countermeasures directed at the problen drinker will have a significant deterrent effect on the heavy social drinker who can control his drinking/driving habits and who accounts for a substantial part of the alcohol-connected traffic deaths.

- Appropriate inter-agency coordination can be achieved to provide communty medical facilities required to treat known alcoholic drivers.

\section{ALTERNATIVES :}

1. Increased emphasis on alcohol countermeasures in ongoing highway safety programs.

2. Pilot demonstrations of individual countermeasures under controlled conditions, to ascertain cost-effectiveness and input-output ratios of individual measures.

3. Pilot demonstration of a comprehensive alcohol safety action program in one or more test locations, with expansion to follow after thorough test and evaluation of results in 4-5 years.

4. Continued research to refine countermeasures deferring major. programs unti]. measurements are derived finitely.

5. Immediate implementation of intensive Federally funded alcohol countermeasure programs in all states and major metropolitan areas in the nation.

6. Immediate implementation of comprehensive alcohol countermeasures programs, combining increased emphasis in State highway safety programs, intensified research and development, a national campaign of public education and information, and Federally funded alcohol safety action programs in several. selected $s$ tates, to be expanded into all states and into additional areas in key states and probl $12 \mathrm{~m}$ areas during the next $1-3$ years, in order to permit development of sound programs in the areas concerned and the build-up of Bureau staff capability to provide technical assistanc? and to manage and monitor the increasing level of effort. 
Alternative 1 is to be sought in any case, and this effort is undervay. However, because of statutory apportionments of the 1 imited Section 402 funds among states and jurisdictions and the need for states to make progress to reach conformance with all the national standards, as required by law, the resources available through section 402 are not, in themselves, adequate to undertake intensive comprehensive programs in any concentrated manner. Rather, effort under this alternative serves as a complementary program to provide the necessary supporting features of: comprehensive alcohol countermeasures programs, and to extend more widely portions of such programs.

Alternative 2 has the advantage of carefully controlled and measured experiments to determine which individual measures work best. However, the time frame is unacceptable, in that operational programs to attack the problem meaningfully would be delayed for a very considerable number of years. The problem exists now, in catastrophic form. Problem drinkingdrivers are involved in about 350 deaths every week, while social drinkers who drive after excessive drinking are involved in another 150 deaths. As the Secretary has pointed out, if two or three airliners were to crash each and every week of the year because of a single known cause, there would be drastic and jmmediate action. The death toll caused by abusive use of a]cohol is about quadruple that of Americans in the Viet-Nam war. Despite the merits of cortrolled research over several years to verify results, we cannot afford the luxury of such delay when faced with an immediate problem of major magnitude.

Altemative 3 has essentially the same merits and disadvantages of alternative 2, with the added advantage that countermeasures in combination wi11 be more effective than when applied singly. However, the problem of such inmediacy and scope that major national visibility and impact are essential to achieve meaningful results in the near future. To gain such major visibility and impact, it is necessary to launch a major program in many locations and to expand it as rapidly as can be managed effectively.

Alternative 4 , like altemative 1 , must be continued regardless of other efforts, but for the reasons stated major programs cannot be deferred. There has been more than enough research in the United States over the last two decades to delineate the problem and to point to necessary correctives. We know what must be done. While research will be pursued to refine countermeasures and to develop new countermeasures, this is an area where most definitely we canuot continue an approach of research only, leading inevitably to need for stili more research. Thexe are promising efforts underway and in prospect, which will sharpen countermeasures being implemented. This is a contimuing process, but action operational programs are feasible now and need not and cannot await further research. 
Alternative 5 is very much to be desired, in that it would lead to the earliest major reduction in deaths and injuries. However, alcohol countermeasure programs must be carefully developed, designed, managed, and monitored. The initial 9 projects were carefully developed, over the course of several months, with leading experts in the field. Capability, organization, and the requisite coordinative efforts are not yet in being in most areas, and must be developed. In addition, to ensure that Federal funds are well expended needs management and monitoringo practical considerations of staff build-up and training time, as well as the periods required to acquire the necessary capability and conditions in the field locations, preclude immediate start-up of comprehensive programs in all locations.

Alternative $G$ is the preferred alternative, combining the better features of the other alternatives, with consideration to the fact that the problem is here and now but tempered by practical factors of order $1 y$ build-up and proper preparation and management.

Under the preferred alternative, the National Highway Safety Bureau Progran is designed to assist the states in developing measures for controlling problem drinkers. These measures must ensure that their driving privilege and/or their drinling is regulated in a way which will minimize the risks of accidents until. such time as they receive treatment or counseling which is successful in alleviating their drinking and driving problems. These measures rill inciude several of the functional program areas now covered by the highway saliety standards such as driver licensing, vehicle rcgistration, police trafic services, and traffic court procedures, and will

specify steps for the states to implement. The countermeasures include:

- Identification of problem drinkers who are unfit to operate a motor vehicle.

- Evaluation by licensing agencies on an individual basis, with the advice of a medical advisory board, to determine whether the licenses of such drivers should be revoked, or limits placed on the times and places where driving will be permittec.

- Increasec efforts to apprehend the drunk driver, to prosecute more vigorously and to impose appropriate penalties. 
- Special counseling courses for the problem drinker who drives, and (through the Department of Health, Education and Welfare) provision for treatment of convicted alcoholic drivers, to provide courts with more effective alternatives to standard sentences involving prison or fines.

- Community efforts to assist the problem dinker who drives to find alternate means of transportation.

This priority effort must be an attack on all available fronts, exploiting every available program resource. Therefore, it will be carried out by means of:

- Comprehensive start-up action programs at the local level. in selected communities

- State-wide programs funded under Section 402 of P. I. 89-564

- A public elucation campaign on alcohol and highway safety which points out the dimensions of the alcohol/ highway sefety program and which distinguishes between social and problem driakers

- A researci and development program which provides new, more: effective countermeasures for community use

This program envisages:

- A special alcohol program to assist the States in regulating the times and conditions of driving by problem drinkers and supporting State efforts to readily identify drivers with alcohol violation records

- High priority accorded to alcohol projects within the State and Community Highway Safety Grant Program

An increased alcoholic treatment program undertaken by the Department of Health, Education and Welfare 


\section{Contents of this Report}

This report reviews the established facts on the relationship of excessive drinking to highway fatalities and injuries and describes major elements of the Bureau's proposed program, and delineates the funding and management requirements to carry out the program.

Overall, the development of a national countermeasure program for alcohol safety can be divided into the four major steps indicated below, which will proceed in large measure concurrently:

1. Research, development and field demonstration of counterneasures

2. Public education and manpower development efforts

3. Comprehensive alcohol safety action programs (ASAP) projects at the local level

4. Assistance to the States under Section 402 of the Highway Safety Act́

A final stage following these four steps will be sustaining alcohol safety programs funded by the States.

Research and Development - The decade of the sixities produced the basic research which clearly demonstrated the role of excessive drinking in highway safety with particular focus upon the problem drinker. As a result of this research, new countermeasures were proposed and testing of these proposais has begun. With the research basis for a national countermeasure effort well underway, the time has arrived for action programs at the State and community level.

Public Education and Manpower Development -- The first element of the action program must be a national program to educate the public on the true nature of the drinking driving problem: that it is the problem drinker who is p:imarily responsible for injuries and fatalities due to alcohol; and that an effective countermeasure program can be mounted. In addition to ach ieving public support, training programs for the personnel who will manage alcohol safety programs at the community level must also ke initiated. Guidance and orjentation material must be developed for enforcement, court, and other personnel. 


\title{
SECTION II
}

\author{
THE PROBLEM
}

\section{A. FINDINGS OE REPORT TO CONGRESS}

The National Fighvay Safety Act of 1966 required that the Secretary of Transportation submit to the Congress a repoxt on the role of alcohol in highway accidents. This report (submitted in October 1968) reviewed studies covering over two thousand fatally injured drivers and indicated that just under one-half were intoxicated at the time they lost their lives. Overall, the report concluded that "the use of alcohol by drivers and pedestrians leads to scme 25,000 deaths in a total of at least 800,000 crashes in the United States each year." The basis for this finding is summarized in the following paragraphs:

The Importance of Chemical Tests

The development of chemical methods for determining the concentration of alcohol in the blood has been crucial to objective determination of the relationship between blood alcohol and fatal accidents. Until such tests were developed, detemination of intoxication was a matter of interpreting somexhat equivocal behavioxal signs such as slurred speech, staggering gait, etc. Even experts, such as physicians, could not agree when a person was intoxicated based on these signs. Chemical tests, however, provide objective criteria of intoxication which in turn permit quantitative field studies of the role of alcohol in fatal accidents. The criterion of intoxication adopted by the National Highway Safety Buxiau, and by States complying with the National Standard in their drinking-driving laws, is one-tenth of one percent by weight in blood (.10 percent).

Blood Alcohol in Drivers Responsible for Fatal Accidents

Using this objective definition (. 10 percent), data such as those presented in figure $2-1$ have been collected. This figure summarizes the relationship between blood alcohol level and highway fataliries. Data for three groups are presented. The first bar relates to drivers stopped on the roads at times and places of fatal accidents (usually evenings, particularly weekend evenings), who were requested, on a voluritaxy basis: to take a breath test. When this is done, it is found that approximately 2 percent of drivers have blood alcohol levels above 0.10 percent. J.hat is, one in fifty drivers on the road at these times and places is intoxicated. If, on the other hand, blood alcohol 
measurements are taken from drivers fatally injured in accidents which were judged not to be their fault, it is found that approximately 12 percent of these drivers have blood alcohol levels indicating intoxication. Finally, if measurements are made of blood alcohol levels of drivers fatally injured in accidents where they were juaged to be at fault the percentage of intoxicated drivers rises to over one-half $(53$ percent). Thus, while only 2 percent of the drivers on the road are intoxicated, they account for over one-half of the "at fault" drivers in fatal accidents. Clearly, intoxication plays a major role in the causing of fatal accidents. Moreover, these data relate only to the driver himself. While mary of these accidents are single vehicle accidents in which only the intoxicated driver was killed, many others involve multiple vehicle accidents in which a passenger or innocent driver was also injured or killed. Thus, these at-fault, intoxicated drivers take with them many inrocent non-drinking drivers, passengers and pedestrians.

\section{Extremely high BAI's Typical of "At Fault" Drivers}

More detailed sindy of these intoxicated drivers further illuminates the type of individual who causes these fatal accicients. Figure 2-2

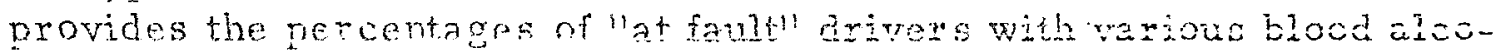
hol levels for various age groups from 14 to 60 . These data come from a recent study of fatally injured drivers in Baltimore. Considering the age group between 25 and 39 , it can be seen that approximately 75 percent had been drinking before their fatal accident. Of these, about 7 percent had blood alcohol levels betwecn 0.09 and 0.10 . Another 8 percent had blood alcohol levels between 0.10 percent to 0.3 .4 percent, while all the rest, almost 60 percent of the "at-fault" drivers, had blood-alcohol levels above 0.15 percent. This level represents (as will be seen in the following paragraph), a level of consumption so excessive that it raises a question whether the individual has a problem regarding his drinking. As can be seen in Figure $2-2$, $i$ is individuals with bloodalcohol levels above this point ( 0.15 percent) that account for most of the fatally injured drivers who were at fault arnong those who had been drinking at all. This is true for all age grouph, with the possible exception of young drivers between ages 14 and 24 and drivers over the age of 60. These: two age groups may represent categories which require special treatment since they appeax to be involved in fatal accidents at lower blood alcohol. levels than is typical of the mass of drivers between 25 and 60 years of age. 


\section{Significance of High Blood Alcohol Levels}

The significance of very high blood alcohol levels (above 0.15 percent) can be better understood from examination of figure $2-3$. In this figure, the number of one ounce drinks of 86 proof whiskey required to reach a 0.15 percent blood alcohol level is shown as a function of the individual's weight. As can be seen, a 180 pound man would require 11 drinks to reach this level if he is drinking vithin two hours after eating. If the drinking occurs before eating then these figures should be reduced by about one-third. In either case, it can be seen that an excessive quantity of alcohol must be ingested in order to reach this very high blood alcohol level. This amount of alcohol is so very high that it suggests that the individuals concerned have a drinking problem. These drinking habits are obviously deviant from the majority of social drinkers in the United States. This conclusion is strengthened by stuciles of blocd alcohol levels which result from normal cocktail parties. These studies have indicated that the great majority of jndividuals who attend cocktail parties do not achieve blood alcohol levels above 0.07 pes:cent.

Further Fvidence That Divers in Fatal Accidents Represent a Deviant Group

The hypothesis that individuals who demonstrate these very high blood alcohol levels (above 0.15 percent) represent deviant drinkers is strengthened by exarnination of the previous records of convicted drinking drivers (most of whom are above these levels when arrested). Figure 2-4 gives the result of one such study in the State of Oregon. In this study, 35 percent of the arrested driaking drivers had previous drinking driving arrests, while 58 percent had either a drinking driving arrest or some other kind of alcohol celated arrest. Moreover, more than one-third had a prior criminal record. Other indications of maladjustment we::e shown by past commitments to mental hospitals, welfare assistance because of alcoholism, etc. Thus, the overall picture presented by this study is that these individuals have a drinking pro- . blem which is reflected in a number of social, legal and financial difficulties. 
Methods of Recognizing Problem Drinkexs Who Drive

Overall, what percentage of arrested driuking drivers, or drinking drivers involved in crashes, could be identified by these signs (previous arrest, hospital admissions, social agency contacts, erc.)? Figure 2-5 which represents the results of the siudy by Dr. Waller in Oakiand, California, indicates that in the gromp he studied, over 80 percent of the individuals axrested for driving while intoxicated had some previous contact with the Police Department or a community social agency, and over 70 percent of those involved in fatal accidents or hit and rum crashes had such prior contacts. Thus, there is a good basis for believing that these signs of social maladjustment, when taken together with high alcohol consumption levels, could serve to identify individuals with high potential for involvement in fatal and serious alcohol-related accidents.

Based on such data, the Bureau has proposed that problem drinkers could be recognized through two or more of the signs summarized in figure 2..6. First, the individual may demonstrate at the time of his arrest a blood alcohol level above 0.15 percent. This' is not only 50 percent abnve the recommended definition for intoxication, it is far above that of the average social drinkex. A second indicator is a previous arrest, for either a driving or a non-dxiving offense involving alcohol. Of particular significance, also are "drunk and disorderly" arrests and criminal arrests related to alcohol.

A third symptom is the presence, in the individual's records, of contacts with social and/or health agencies, either specifically for treatment of alccholis or as a result of an application by their families for: aid because of desertion or unemployment due to drinking problems. A fourth sign may be developed through a medical examination. A medical diagnosis: of alcoholism is difficult in the early years of the excessive drinking pattern, but as the physiological changes resulting from the progresisive deterioration from alcoholism develop, the medical signs of alcoholism such as a distended liver become easier for the physician to diagnose. As part of the redical examination, psychological tesis and interviews can be conducted which can uncover psychological dependence upon alcohol, to aid in making a diagnosis.

Finaly, interviews with family members, employers and associates often uncover information related to heavy drinking, loss of time on the job, maxitial sroblems and other signs of social-psychological difficulties relate to excessive drinking. Evicience from research on the drinking-driving problem suggests that where two or more of these 
signs are present, the individual has a high probability of being involved in a fatal or serious driving accident. Therefore, countermeasures should be developed which result in limiting the driving by such individuals, unit such a time as the drinking problem can be overcome.

\section{B. DEFICIENCIES IN PRESENT ENFORCEMENT OF DRINKING DRIVING LAWS}

Figure 2-7 illustrates the typical enforcement system in operation in the States at this time. This system flows from the arrest of the individual while driving under the influence of alcohol; through the adjudication of his case; his conviction; sentencing, with the resultant license restriction; and, in some cases, followup action to ensure that the individual does not drive during his period of restriction. While. this system provides, on a conceptual basis, for effective enforcement of drinking-driving restrictions, as actually implemented the system has many deficiencies. These deficiencies are described in the following section. Fach point is keyed to figure $2-7$.

Inadequate Detection of Problem Drinkers

At present, problem drinkers enter the recoxd system almost entirely through arrests for driving while under the influence of alcohol. The coordination of information between the courcs and the licensing agencics on individuals convicted of non-traffic alcohoi offenses (drunk and dis orderly, etc.) is frequenty ineffective. Thete is no provision for reports on alcoholics to be received from gorermment supported social agencies or medical facilities which commoriy treat alcoholics. Furthermore, even for those problem drinkers who actively drive while intoxicated the probability of apprehension is low. Research data indicate approximately two percent of drivers on the road at times and places of fatal accidents are intoxicated, yet one estimate of the probability of arrest of an intoxicated driver is or: the order of one in 1,000.

Limited Availability of Chemical Tests

There is general scientific agreement that a chemical test is the best approach for prisecuting intoxicated drivers. The NHSB Standard 8 on alcohol safety requires such tests. Despite tris, seven States have no chemical test laws and thirty-one do not have a definition of intoxication consistent with the NHSB standard. Even where appropriate laws exist adequately trained personnel and the necessayy equipment for giving the test may be lacking. 
Restrictions on Use of Chemical Tests

Most present implied consent statutes heve no provision for making a chemical test until after the police officer has arrested the driver. This results in the failure to apprehend many drinking drivers since a. driver must break some traffic law before there is a possibility of being apprehended for driving while intoxicated. A screening test systen is needed which is constitutional and which would permit testing suspected drivers without requiring that they be formally charged with driving while intoxicated. Even those charged with DWI may, in a number of States with implied, consent laws, still avoid taking the test and the consequent loss of license because of excessive safeguards in the law. In some States the driver can, for example, refuse to acquiesce to a chemicai test until advised by counsel. By the time his lawyer arrives it is too late to make a valid test. Other States require that the driver be offered breath, blood and urine tests and some drivers can escape by electing a method which is not available to the police in his locality.

\section{Failures to Prosecute DWI Drivers}

Becanse of tha strichess of the pendities assessed for driving while intoxicaced, in many States (some, for example, require automatic license revocation police are reluctant to aryest and charge indiviauals with driving while intoxicated and juries are reluctant to convict DWI drivers because of their concem for the hardships and possible loss of livelihood of these individuals if deprived of their driving privilege. A strong penalty system which will be effective in deterring drinking drivers is needed, but it rnust be one for which police are willing to make the DWI charge and for which juries axe willing to convict the DWI driver.

\section{Ineffective Penalties for DWI}

Fines and jail sentences which are standard penalties for driving while intoxicated are probably of little or no effect with the problem drinker or alcoholic. These latter individuals are unable to control their drinking no matter what the penalties. Therefore, they rust be prevented from drinking or driving in a more direct fashion thar through fear of jail sentence or fines. 
Inadequate Treatment Programs for Problem Drinkers

A number of court systems have attempted to refer alcoholics and problem drinkers to community medical facilities and social service organizations, including such non-government agencies as Alcoholics Anonymous. To date, there has been little or no attempt to evaluate the results of these efforts. What data are available are not encouraging. However, there are several preliminary programs using the protective drug Antabuse in conjunction with other treatment programs which have demonstrated encouraging results. Since a sufficientevel of Antabuse in the blood system will directly prevent drinking, court motivated use of Antabuse may turn out to be an effective method of preventing drinking and driving by alcoholics and problem drinkers even though it will not of itsclf "cure" alcoholism.

Lax Enforcement of Driving Suspensions

The most used and most popular penalty for drinking and driving is lie revocation or iuspension of the driving license. Indeed, as stated above, a number of States make suspension of the driver's license a mandatory penalty for dirivig while intoxicated. Write fed of ius of the driving privilege may have an important deterrent effect on the social drinker, it is probably ineffective on the alcoholic and probiem drinker because this individual continues to drive anyway. The probability of his detection is very low. Most States fail almost entirely to take any practical steps to enforce the driviag liconse devocatior. A recent study in California indicated that two-thirds of all drivers with revoked permits were arrested (some as many as ten times or morc) during periods when their driving privilege was revoked. Despite repeated apprehensions, arrests and convicions the State was apparently unable to prevent these individuals fro:n driving.

\section{POSSIBILITIES FOR REDUCING FATAI, AND SERIOUS INJURIES DUE TO ALCOHOL}

Reducing this problem is difficult but not impossible. The possibilities for sjgnificant reduction in the number of drinking drivers involved in fatal accidents is indicated by the experiencs in several European countries in which stringent programs in alcohol safety are in force. In Sweden, for example, it appears that only $10-20$ percent, rather than 50 percent of $f$ tally injured drivers are impaired by alcohol at the time of the accident. In Britain, deaths and jnjurics between 10 p.m. 
and $4 \mathrm{a} . \mathrm{m}$. (the time when most alcohol related accidents occur) were reduced by 3.3 percent as a result of an intensive alcohol safety campaign in 1968. This reduction has persisted over a two-year period. The British program was directed at all drinking drivers, through the use of the intensified enforcement procedures involving roadside breath tests. As a result of the research data presented in this section, the NFISB proposed a program which would involve not only increased enforcement on the highway, similar to that used by the British, but would also involve a continuing program of intensive countermeasure activities directed at the problem drinker who drives. This program would ensure not only that he is apprehended on the road, but that he is handled effectively by the courts, brought into treament, and kept of the road until that treatment is effective.

With this program it should be possible to achieve not only the kind of reduction produced in Britain by their more intensive enforcement on the highway, but in the long run a more sizable reduction as a result of keeping problem drinkers off the road. We have for too long accepted the inevitability of deaths duc to alcohol. In part this had been due to the general assumption that the problem centered on the great mass of social drinkers, and the failure to recognize the unique importarce of the small number of problem drinkers. The American pubiic looks back to the ineffective enforcement of prohibition and assurnes that no adequate solution is available. However, if we understand that the reduction of this highway safety problem does not involve majox modification of the present drinking habits of the rajority of the population but focuses on a small minority, then we are on our way to an effective system of control. 


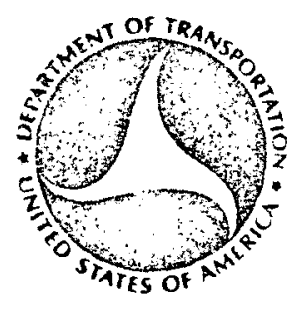

Finure 2-1

Action Program: Alcchol Safety Countermeasures BLOOD ALCOHOL ABOVE 0.10\% AND FATAL ACCIDENTS

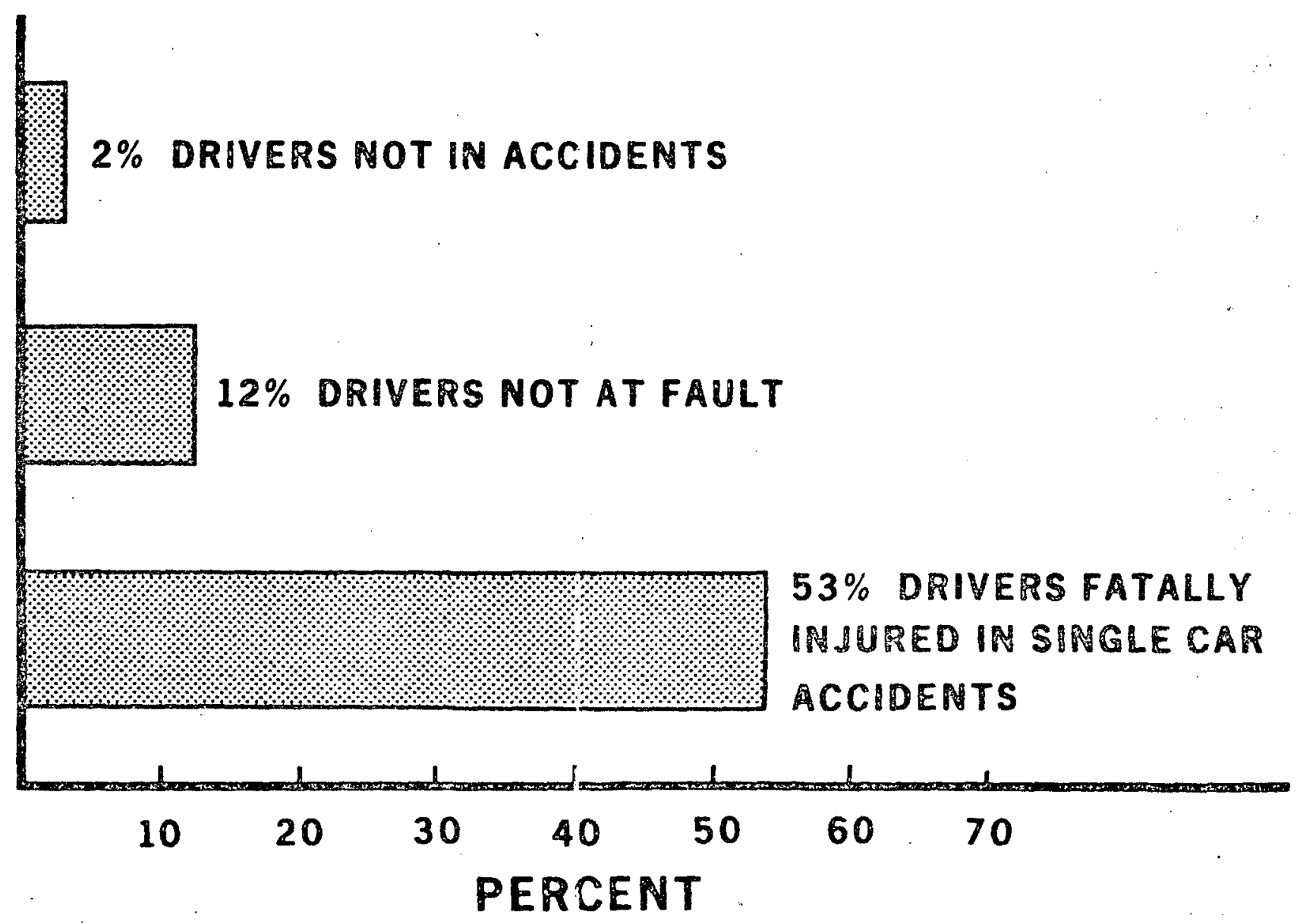


Figure 2-2

\section{BLOOD ALCOHOL LEVEL IN FATALLY INJURED DRIVERS AT FAULT AND NOT AT FAULT}
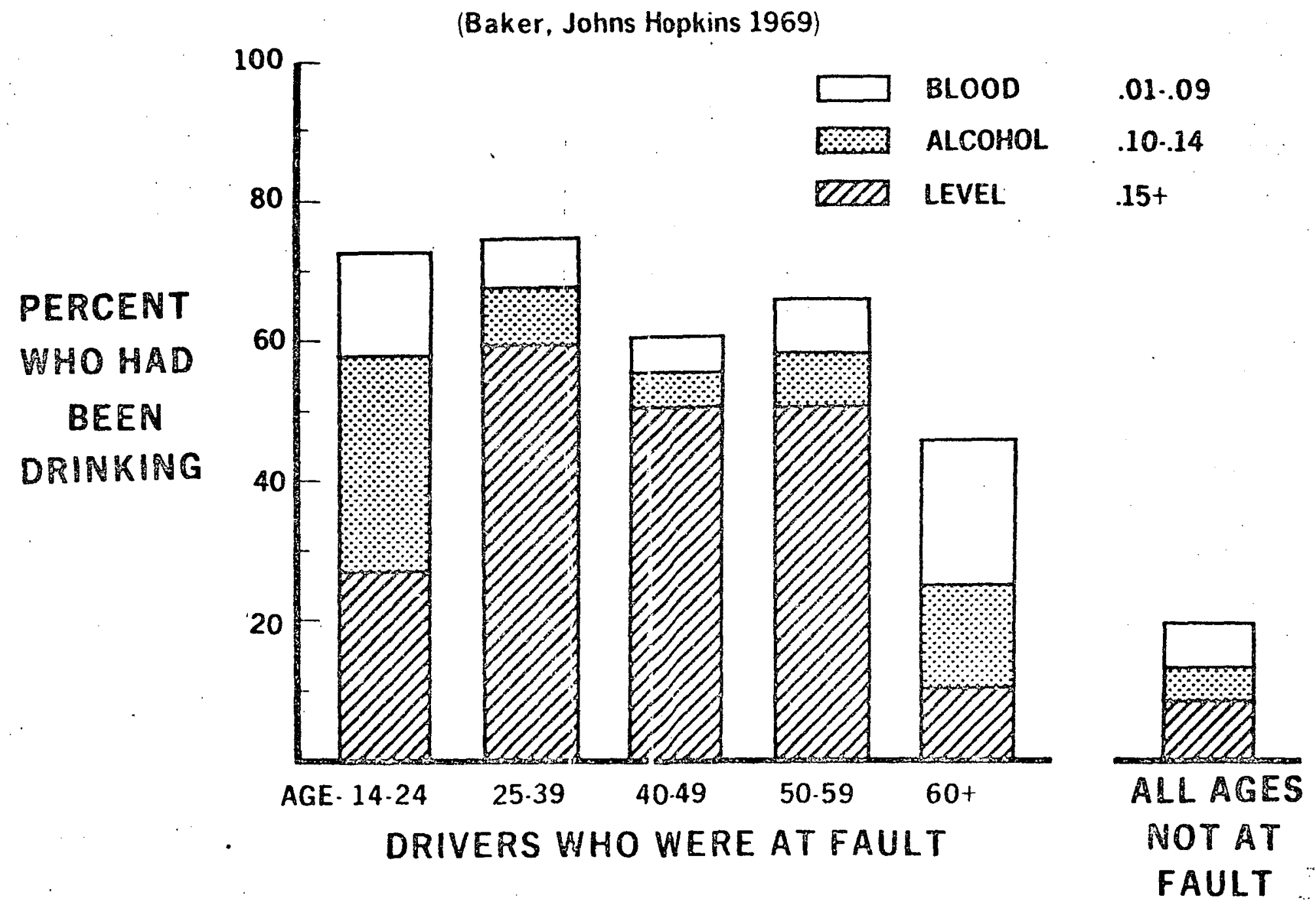
Action Program: Alcohol Safety Countermeasures

\section{EVIDENCE THAT A PERSON WITH BLOOD ALCOHOL. OVER .15\% IS A SERIOUS PROBLEM DRINKER}

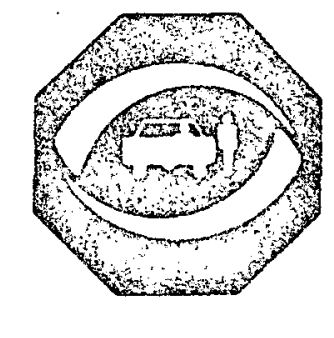

The Number of 1 Ounce Drinks of . 86 Proof Whisky Required to Reach a

Blood Alcohol Level of $0.15 \%$ Within Two Hours of Eating.
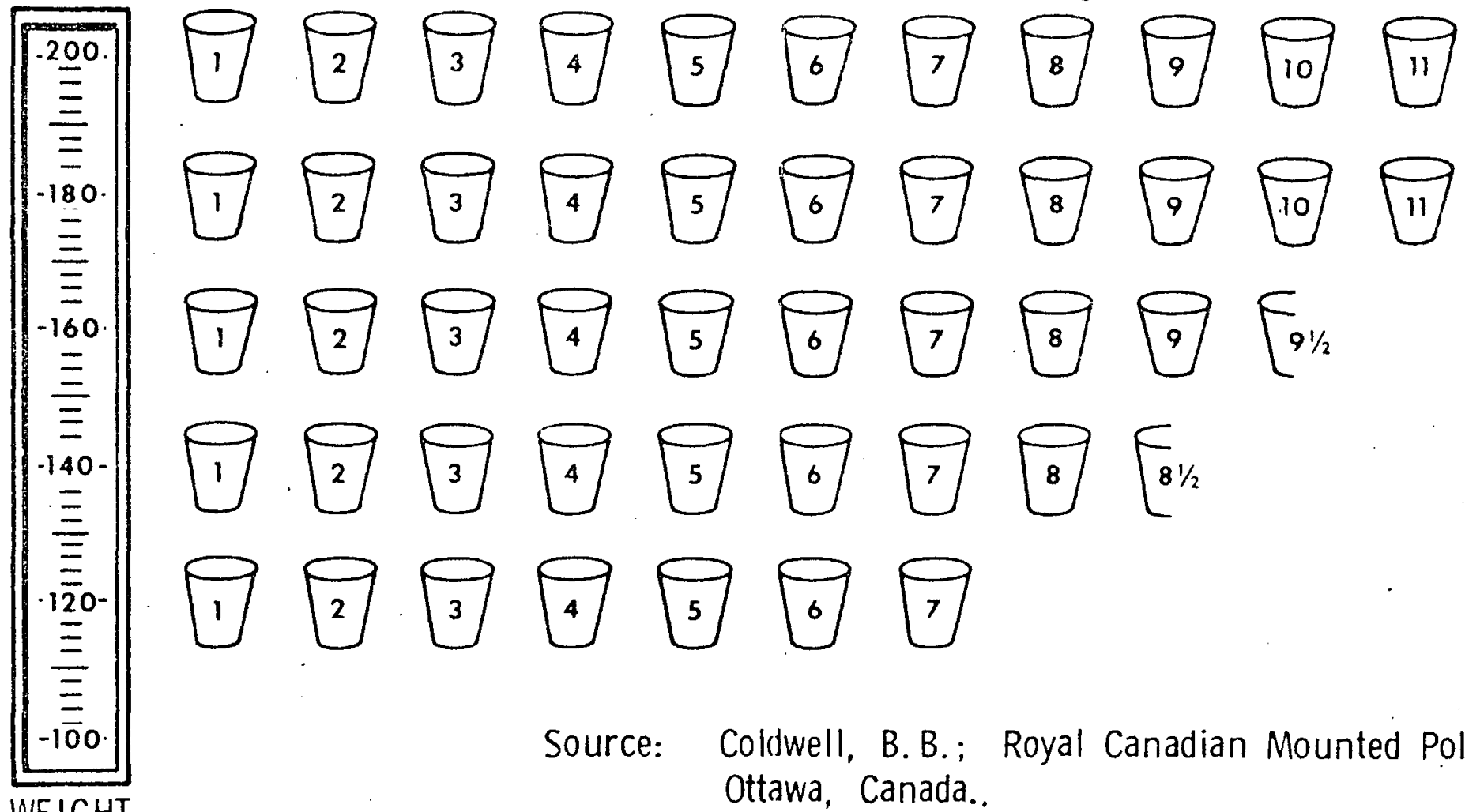

12
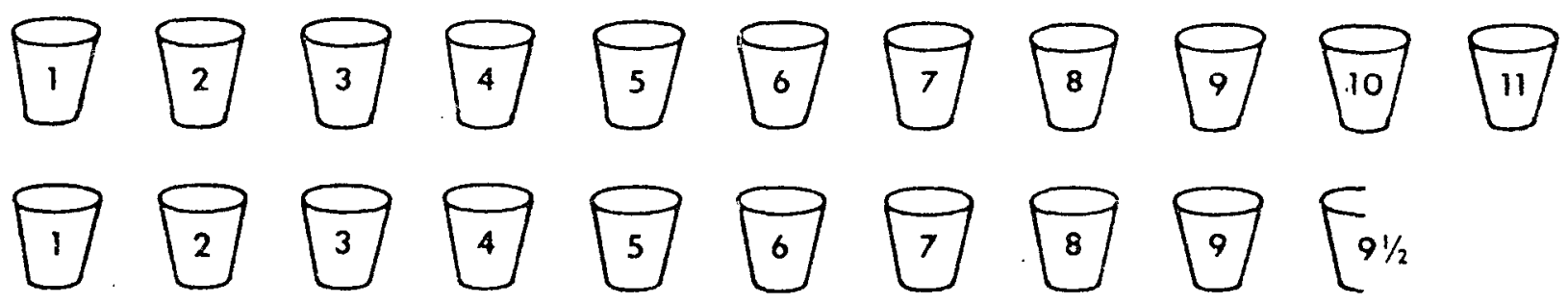

$F_{91 / 2}$
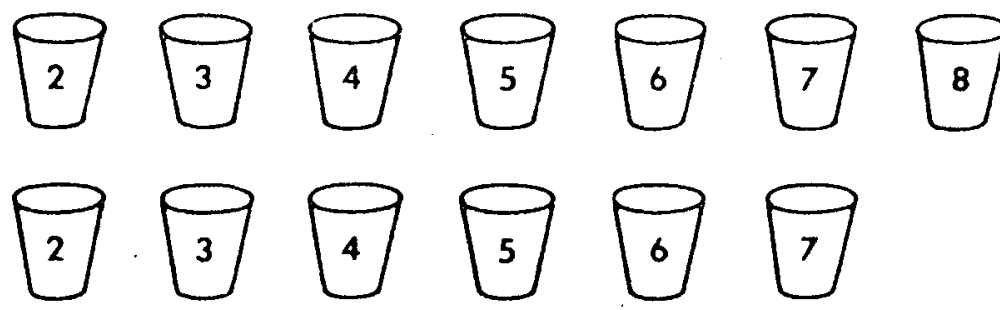

$E_{81 / 2}$
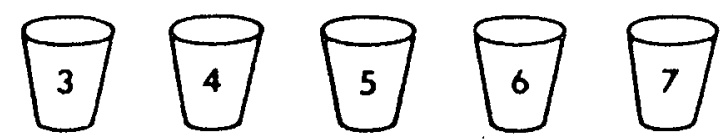

Source: Coldwell, B. B.; Royal Canadian Mounted Police, Ottawa, Canada.. 


\section{PRIOR RECORDS OF CONVICTED DRINKIISG DRIVERS}

\section{[FRON OREGON STUDY OF DRIMKIAG DRIVERS, OREGON DEPARTARENT OF TRAMSPORTATIOA]}

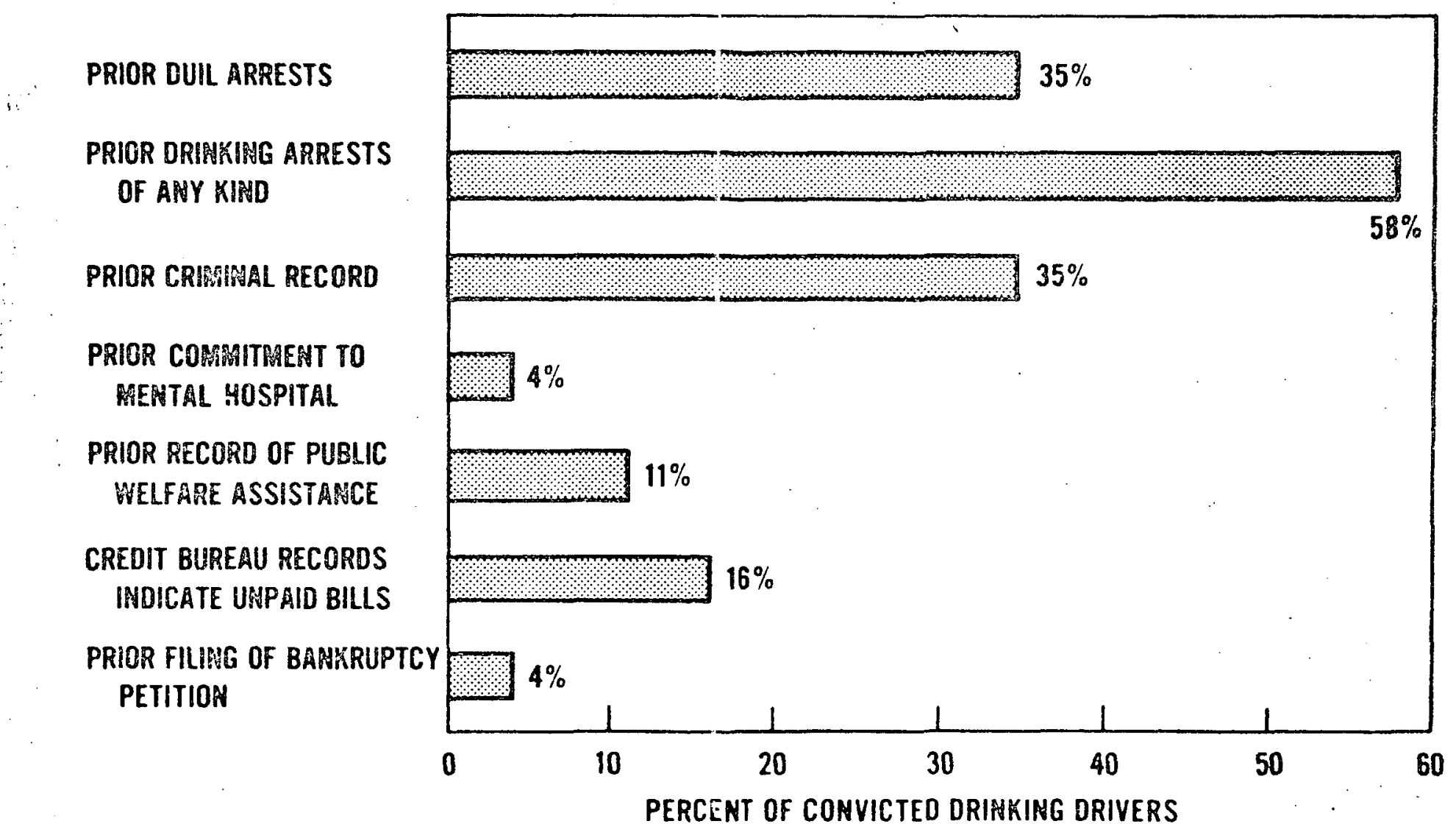




\section{PERCENTAGE OF MFEN KNOWN TO POLICE DEPARTMENT}

\section{AND/OR TO COMMUMNITY SERVICE AGENCIES PRIOR TO ARREST OR CRASH INVOLVEMENT}

[WALLER, J.A., OAKLAND, CALIFORNIA]

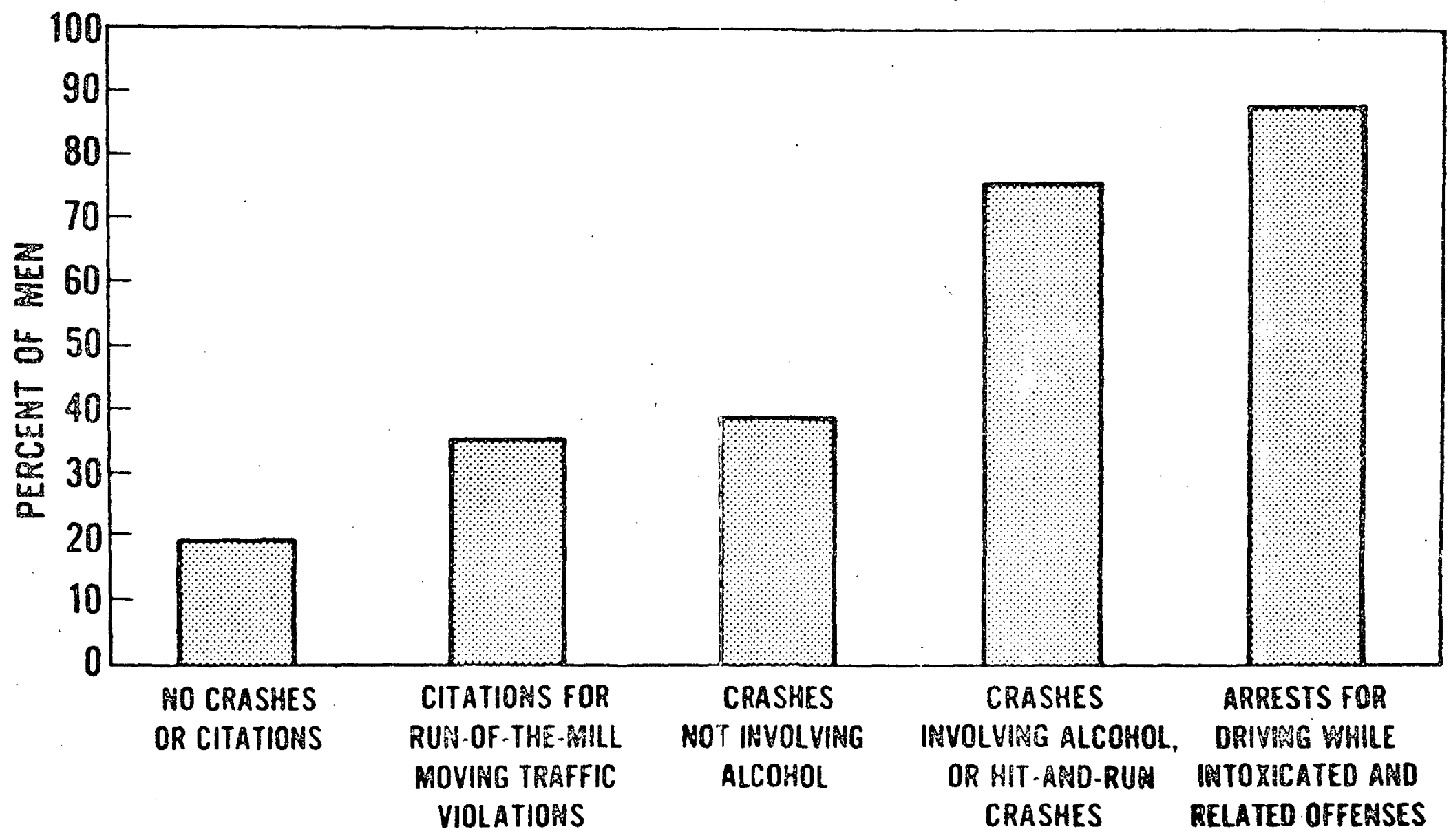


Figure $2-6$

RECOGNIZING PROBLEM DRINKERS

PROBLEM DRINKERS DEMONSTRATE TWO OR MORE OF THE FOLLOWING:

- BLOOD ALCOHOL LEVEL GREATER THAN . 15 PERCENT

- ONE OR MORE PREVIOUS ARRESTS INVOLVING ALCOHOL

- PREVIOUS CONTACTS WITH SOCIAL AGENCIES AND MEDICAL FACILITIES BECAUSE OF PROBLEM DRINKING

- iviedichi sigís OF ALCOHOLISMi (CIRRHOSIS) PRESENT

- PSYCHOLOGICAL DEPENDENCE ON ALCOHOL DEMONSTRATED

- FAMILY MEMBERS AND ASSOCIATES F.EPORTING INDIVIDUAL HAVING LOSS OF TIME FROM JOB, MARITIAL, ETC. DIFFICULTIES BECAUSE OF PROBLEM DRINKING. 


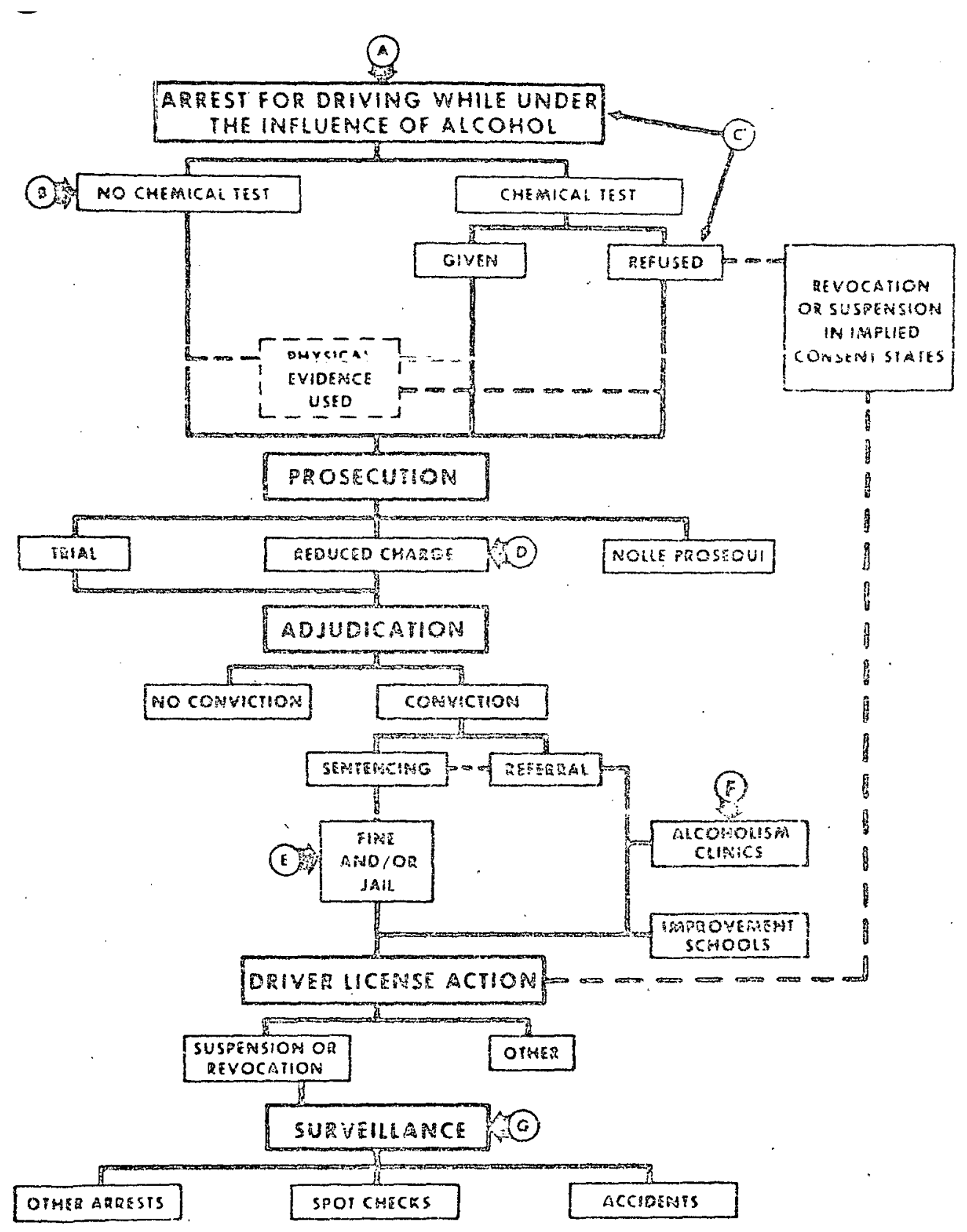

\author{
Figure 2-7

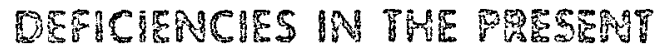 \\ METHOSS OF COATROLHAS PME

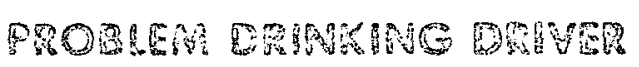 \\ A. Inadequate Identification of Drinking Orivers \\ C. Lirnited Ayailabiliky or Chemical rests \\ C. Restrictions on Use of Chemical Tesis \\ D. Faiiures to Prosecute DWI Drivers \\ E. Ineffective Penalities for DWI \\ F. Inadequate Treatment Programs for \\ Problem Drinkers \\ G. Lax Enforcement of Driving Suspensions
}


SEC'TION III

NHSB PROGRAM CONCEPT

\section{A. OVERVIEW}

Based on the foregoing data the NHSB has developed a proposed countermeasure program. While these countermeasures include some standard procedures such as strengthening enforcement activities on the highway; they differ from previous alcohol safety programs in that they focus primarily on identifying the problem drinker and taking action to remove him from the road until his drinking problem has been overcome. While the focus is on the problem drinker, it is expected that many of the countermeasures will also be effective in detering social drinkers who drive when they should not, so that the program will have impact on all elements of the drinking driving public who presently contribute to death and injury on the lighway. For example, there will be increased enforcement efforts on the highway in an atternpt to achieve some of the impact produced in Britain by their new alcohol safety law. The NHSB program goes beyond the British experiment, however, in emphasizing special. handing of problem drinkexs after they have been apprehended and convicted, and in proposing special efforts to identify problem drinkers through means other than highway infractions. This program would overcome many of the shortcomings of present enforcement efforts in the United States, described in the previous sectior.

Special efforts will be made with respect to youthful drivers who frequently abuse alcohol. to very great extents. As indicated in Figure 2-2, fatally injured at.-fault drivers under age 25 have somewhat lower blood alcohol levels than do older drunk drivers. And while the disease of alcoholism is typically clearly discemible in the mid-thirties, some studies show that nearly half of fatally injured at-fault drunk drivers are under age 30 . Whether or not pre-alcoholic, these under-thirty drivers in most cases show many of the same indications of a problem with alcohol, as demonstrated by previous arrests and other factors. When identified, they can be rehabilitated in the early stages of the progression from problem drinking to alcoholism, with good prognosis.

The NHSB Alcohol Sifety Program has been broken down into three categories: first, the problem drinker must be Identified; second, Decisions must be made as to the nature and extent of his drinking problem and the appropriate treatment prescribed; finally, Action must be taken to minimize the likelihooci of his driving a car after he has been drinking. This "IDA" program is expected to have a significimt impact in controlling the drinking-driver behavior of problem drinkers, and, indirectly, of other heavy drinkers who become part of the highway death and injury problem. 


\section{B. IDENTIFICAII ON}

In developing and carrying out measures to identify the problem drinker who drives, two factors must be considered; the methods proposed must ensure that a significant number of problem drinkers are not overlooked and, on the other hand, that individuals are not identified as problem drinkers when, in fact, they are not. Three basic means are available for identifying problem drinkers: through apprehension on the highways, through court records, and through health and social agency records.

On the Roads

How can identifiration on the roads be improved? Special enforcement at the times and at places where drinking is done could greatly increase the number of problem drinkers who are apprehended driving while intoxicated.

Greater use of alcohol screening procedures to the extent permitted by the Fourth and Fifth Amendments to the Constitution, should be encouraged to facilitate the identification of the problem drinker. One State, New York, has adopted a procedure which permits a police officer to require a roadside chemical test of arivers involved in an accident or suspected of violating a provision of the vehicle and traffic law. This is in contrast to most chemical test laws now in effect which are applicable only after a driver has been arrested for a drinkingdriving violation.

Another possibility for tightening enforcement procedures would be to make the presence of .15 percent blood-alcohol illegal per se rather than merely presumptive evidence of illegality. This would greatly aid in the conviction of individuals who, by chemical tests, have been found to be driving with this excessive blood alcohol level.

\section{From Court Records}

The Court records systems can be improved through greater automation and through other means to assure that previous DWI and other alcoholrelated convictions are made known to the judge before sentencing and that there is an effective system for transferring information from court records to the licensing agency. In practically all States, records of non-traffic alcohol-related offenses are not available to the licensing agency. As a result the licensing activity is not able to take such information into consideration.

In Health and Social Agency Records and Driver Improvement Courses

Improvement in the identification of problem drinkers can be achieved by obtaining the cooperation of health and social agencies in providing information to the driver licensing Bureau. Nany individuals with drinking problems who do not come through the courts as a result of a DWI prosecution are being treated for drinking problems by social 
and health agencies. Provisions should be made for providing the names of individuals who are receiving treatment for alcoholism, or for problems clearly related to excessive drinking even where that specific diagnosis of "alcoholism" is not used. Physicians should be encouraged to report identified problem drinkers by telephone to driver licensing authorities, preferably to a member of the medical review board, with clear understanding that the confidentiality of the physicians' identity will be safeguarded. In many juxisdictions, drunk driving charges are frequently reduced to offenses such as reckless driving which involve lesser penalties. In States which have a penalty point system, these "reckless" driver:s may be required to attend ariver improvement courses. Through interviews and screening tests it may be possible to identify the problem drinkers attending such programs and get them into special treatment and retraining activities.

\section{DECISION}

The information identifying problem drinkers can be further evaluated by the courts and licensing agencies, with the assistance of medical advisory boards, to establish the extent of the individual's drinking problem and the degree to which it has made him unfit to drive a car.

The action most appropriate to each specific case can then be determined and procedures initiated to assure that the correct measures of driving instruction, treatment or assistance are applied.

Who should make these decisions? For those problem drinkers who are processed through the courts, the court must make the decision based on data gathered by its probation department. For those individuals who are not offenders against the law, but who have a drinking problem, licensing agencie: must be able to make administrative decisions regarding the is suance and/or limitation of driving licences.

\section{Decision Making by the Courts}

Once a conviction for drinking-driving has been made, sentencing should be postponed to permit a pre-sentencing investigation by the probation department. Thi:; investigation would include: (1) a careful check of both the licensing agency and court records, tc gether with cross checks with social and health agency records; (2) a medical examination including a psychological evaluation; and (3) a probation department inquiry with family, employer, and associates to determine whether the individual gives evidence of having a drinking problem. 
The findings of the probation separtment study should be provided to the judge prior to sentencing. If there is evidence that the individual has a drinking problem, the judge can place the convicted driver on probation and provide for driving restriction, driver assistance, and referral for effective treatment with regular reports to the court.

\section{Decision Making by the Licensing Agency}

The primary mechanism employed by the licensing agency in making its decision would be a Medical Review Board. This Board would review the information received by the licensing activity from social and health agencies, from courts and other government agencies. The Medical Review Board would be empowered to examine the information forwarded to the licensing agency; review the record of any driver involved; require a medical examination when the Review Board cieemed appropriate; and provide a hearing for the license holder or applicant. Based on these data, the Medical Review Board would recommend to the license administrator the denial or restriction of a license, if there is clear evidence. that the individual has a drinking problem. The Board would also provide for periodic jeview of their recormmendations as new evidence of progress in therajy may be forthcoming.

\section{ACTION}

Three approaches are possible to individuals who have been determined to be problem drinkers who drive. First, their driving privilege can be suspended. Second, an effort can be made to control their drinking. Finally, and most difficult, an attempt can be rnade to neither deny drinking nor driving entirely, but to assure that the two never take place together.

The "No-driving" Isimitation

The "no-driving" remedy has been the standarc. penalty for DWI used in the past. However, as noted, action normally involves only the license revocation, with little or no effort to enforce this revocation. Properly used, license revrcation can be a means by which the court motivates the individual to seek therapy and to profit by $\mathrm{i}$.

Effective enforcement will involve surveillance of the individual; possibly the is suance of sfecial coded maxkings for his car to facilitate identification by the police; provision for impounding the vehicle of individuals found to be driving with revoked licenses; and finally, exploring the 
possibility of insurance penalties against those involved in accidents when driving with revoked licenses. NHSB is now exploring the extent to which these devices are permitted by law.

To encourage and assist the penalized driver to live within the limitations of his license revocation, a driver assistance program should be considered which could assist him in finding alternative means of getting to and from work through car pools, mass transit, etc.

The "No-drinking" Limitation

Moving to the no.drinking alternative, one approach which is presently finding some success is the court motivated use of a protective drug such as Antabuse. When this drug is taken regularly, it makes drinking so unpleasant that the individual is forced to refrain from use of alcohol. The drug cannot be used on all individuals since it does involve some physiological side effects. Where it can be used safely, it provides a means for ensuring that the individual does not dxink, thereby making it possible to permit him to continue ciriving. This enforced sobriety may also open the way for effective therapy.

To provide a means for permanent reduction in the drinking problem, courts should implement procedures for refering problem drinkers to health agencies for therapy. Such facilities can include both hospitals and private agencies such as Alcoholics Anonymous.

\section{E. SUMMARY}

The concept of the NHSB comprehensive countermeasures program then is to initiate action in a number of areas designed to: (I) increase the percentage of problem drinkers who are identified either to the courts or licensing agency; (2) assure that decisions are made regarding the most appropriate procedures to reduce their drinking problem and to assure that they do not $\mathrm{drink}$ and drive; and (3) assure a follow-up action program to carry out these decisions. While the activities of any given commurity or State under each of the elements of the Identification, Decision, Action Program may vary, it is only by coordinated activities in all three areas that an effective program can be developed. The thrust of the NHSB program will be to persuade both States and communities to look broadly at their drinking-driving problem; to focus on the problem drinker who drives, while making provisions for the occasional social Arinker who will be caught up in the enforcement system; and to imolement, on a priority basis, a broadly defined couniermeasures prograri. 
SECTION IV

COMPREHENSIVE ALCOHOL SAFETY ACTION PROGRAMS (ASAP)

\section{A. OBJECTIVES}

The purpose of ASAP is to catalyze and stimulate comprehensive action to reduce the role of alcohol as a casual factor in highway fatalities and injuries.

Specific Objectives:

- Demonstrate program feasibility and methodology,

- Generate major impact and visibility across the nation to generate public support and pressure for action in all jurisidctions,

- Stimulate States and communities to extend comprehensive alcohol safety programs more widely in the areas of responsibility,

- Save lives and reduce injuries in communities involred,

- Study the impact of intensive multifaceted countermeasures programs at the comnunity level on the ultimate criterion -- crash reduction,

- Evaluate cost effectiveness of specific countermeasures and countermeasures combinations in order to establish a valid basis for follow-on effort,

- Document the legal, administrative and political problams associated with countermeasures implementation.

\section{B. OVERVIEW}

ASAP projects will be conducted primarily at the local level, in cities, metropolitan areas, and counties, focusing on law enforcement, traffic courts, special driver counseling and assistance efforts, and public information. 
:SSUE: Funding of ASAP Projects.

$\therefore \therefore$.

ATERNATIVES:

$\cdots$

1. Encourage State and communities to undertake Alcohol Safety Action Programs with their own resources, with Federal role restricted to technical assistance.

2. Fund ASAP projects jointly by a matching ratio such as 50-50 or 75-25.

3. Fund ASAP projects with 100\% Federal Section 403 funds.

\section{UISCUSSION:}

States and communities will be encouraged to intensify their alcohol countermeasure programs, and many programs ranging from piecemeal to partial are underway in scattered locations about the country. However, none attempts a truly comprehensive program of the broad scope desired. It has become increasingly evident that states and communities require greater motivation and resources in this area, and that these will not be forthcoming without direct Federal funding. Even the relatively inexpensive measure of Implied Consent legislation and implenentation of the national standard level of $0.10 \%$ BAL has been difficult of accomplishment and remains only partially implemented. Tough programs directed at alcohol counter-. measures are not necessarily politically attractive, particularly in competition with other demands upon local officials. While alternative l will be pursued, it promises at best limited success until the national progran gains momentum.

Present Section 402 grant-in-aid $50 \%-50 \%$ funding of alcohol countermeasures is leading to progress, but because of limitations of apportionment and other needs in supportive standards areas, these funds cannot support full-scope ASAP projects. Grant-in-aid funds additional to Section 402 and directed specifically to alcohol countermeasures would be more attractive, particular at the higher ranges of Federal fundirg, such as $75 \%$. There are disadvantages to alternative 2, however. As has been evidenced with Section 402 programs, fund-sharing leads to incomplete programs and to adulteration of the degree of Federal control necessary to assure comprehensiveness of the programs. A major factor in the choice of ASAP locations will be the capability and willingness of the locale to expand its efforts and to utilize increased local resources to zomplement Federal funds. However, State and local authorities have been remarkably consistent in their candid appraisals that adequate local support and responsiveness can be achieved only with the spur of Federally funded projects, even though the community will be required to extend its own funded efforts.

Alternative 3 is preferred. Federal fundins of projects under Section 403 offers the foll owing advantages:

- Greater Federal control to assure the desired level of comprehensiveness of programs. 
- Provisions for more effectively monitoring constructive evaluation of projects; and

- Assurance of greater program reception of communities.

While this alternative provides for Federal funding of the costs of the increased efforts required to conduct ASAP projects, stringent requirements will be placed upon the local areas involved and a substantial portion of overall alcohol safety program costs will be borne by them. Local resources will be utilized for the development of a comprehensive project proposal and for financing ongoing alcohol safety efforts. Also, the willingness of a community to utilize its own resources in support of ASAP project activities will be a consideration in project site selection. Projects now underway include use of community resources to support such activities as special police enforcement actions, extensive presentencing investigations and expansion of medical facilities.

Evexy effort will be made to require the community to utilize its. own resources to develop the proposal, with technical assistance of the Bureau, and to hold Federal funding until the planning phase which encompasses derivation of specific plans, the development of a data base, and the staffing of the project at the local level with competent professional management. Each ASAP project requires successful completion of the planning phase prior to commitment of Federal funds for the operational phase. In any case, no activities will be Federally funded until there is reasonable assurance that a community will actually undertake a project. A major task in the ASAP effort, however, is to spur the community into enthusiastic support and to bring into being an organization to coordinate the various agencies and interests involved. Such coordination is mandatory. Once the organization is established and the necessary climate has been created, failure to follow through would have exiremely deleterious effects and renders it difficult to impossible again to rekindle the community support. Therefore, in some cases, development grants amounting to no more than $\$ 10,000$ will be provided to support the writing of the detailed proposal which leads to the contract and the initiation of the planning phase.

Prime contractors for projects will be governmental agencies. Subcontractors will be authorized for work outside the functional area of the prime contractor. Contracting procedures will not differ substantially from those which currently apply to demonstration projects under Section 403 of the Act. Cost reimbursement type contracts will be let based upon an evaluation of proposals submit:ed by applicant communities.

Since alcohol highway safety programs require involvement of various State, local and pr vate agencies, it is considered essential that each initia: project in a State incompass a wide range of countermeasures which demonstrate the impact of coord nated efforts. While it is not anticipated that any single: project will encomp:iss a total countermeasure program, each project will emplo: several major countırmeasures.

Community emphasis on improved law enforcement, traffic court procedures, public information, and special driver counseling and assistance efforts must be complemented by itate level improvements in driver licensing, motor vehicle registration, traffic records and more effective legislation. Thus the impact 
of a comprehensive approach can be evaluated and, insofar as possible, the results of individual cconents delineated.

After the establishment of a comprehensive project in each. State, and as experience is gained regarding the relative effectiveness of countermeasure combinations, establishment of more specialized projects will be considered.

Nine ASAP projects are now underway, and twenty additional ones will be initiated during FY 1971. Thirty new projects will be started in FY 1972 and twenty-seven new ones in FY 1973. Figure 4-1 shows the development plan for the total 86 projects. As illustrated project costs will range from approximately $\$ 500$ thousand per year for standard sized projects to about $\$ 3$ million per year for projectsin selected large metropolitan areas. Project duration will be 3-4 years.

Estimated annual costs of standard sized projects are demonstrated by the cost analysis of some typical ASAP projects underway as illustrated by Figure 4-2.

By end FY 1972 each State will have an ongoing project in a selected city or area. (It is possible, however, that one or a very few states will. still lack the legislative base, viable records capability, or adequate interest and capability), and an additional $6-7$ projects will have been initiated with primary emphasis on second projects in key States, e.g. California, with $11 \%$ of the nation's drivers.

Because certain aspects, such as 1 icensing, registration measures, State legislation, State highway patrol, etc., are State rather than local in nature, the initial thrust will be to institute an ASAP project in each State to tie together the State machinery with the special activities being undertaken in the community. Thus, the project in each state will develop the necessary coordination within that State, establish the basis for State-wide action, and provide the machinery for wider application.

In FY 1973, twenty-seven projects will be initiated. Emphasis will be on: fewer programs, in larger metropolitan areas and multi-jurisdictional areas, each requiring the recources of multimproject units; and on projects which undertake only certain countermeasure sets, omitting those less productive, in order ts hold down program costs. Before these projects are initiated, early exserience data will have begun to become available from the earlier, smaller projects with which to sharpen countermeasure usage.

In FY 1974, all 86 projects will be in operation and fund requirements will peak, although no further programs are initiated. In FY 1975, the fund requirements drop off sharply, and the program phases out end FY 1976. (See Figure 9-1).

As indicated or page 1-6, the general funding support as each section 403 ASAP project phases out will be to Section 402 matching grant-in-aid assistance: to continue the effort, with eventual transfer to full state local funding. This process is alraady in effect with respect to the CARE-SOM EMS project in Mississippi, which vill complete the 403 phase and be continued with 402 funding. 
Factors which ensure phaseout of Federal support are: (1) the contractual nature of the ASAP projects under Section 403 funding; (2) NHSB emphasis during contract negotiation on the phaseout process and encouraging continuation of effective countermeasures by States and communities; (3) the development of complementary capabilities in the conduct of alcohol safety programs at the community level during the operational period of projects; and (4) the generation of wide public support and pressure in the States to pursue programs, even with local resources.

The locations will be selected by NHSB, with assistance from the Governor's Representative and the Bureau Regional Directors, from those local areas having strong interest and capability. The Regional Directors will approach the Governor's Representatives to initiate selection actions.

Most of the FY 1970 projects were undertaken in States and communities by officials and agencies familiar with the alcohol safety problem. In some cases the projects involve outstanding authorities in the field. As the program is extended into additional locations in FY 1971, certain communities will participate in the program which have not hed extensive experience in formulating and carrying out the kind of comprehensive program envisaged in the NHSB program. Consequently, the Bureau plans to assist the selected communities by the following efforts:

1. By preparing an instruction manual for communities on how to plan an alcohol safety program and how to prepare a proposal for NHSB funding. Also, assistance will be provided to the selected communities to help them develop their proposals and prugians.

2. By designing a manpower development program in alcohol and preparing course curricula to train project managers and other local government officials in tect.niques for administering a community oriented alcohol ccuntermeasure program. This effort was initiated with available FY 1970 funds so that courses can be conducted in FY 1971 for those localities selected to participate in the program.

3. By developing evaluation methodology to be incorporated in a "Comprehansive Alcohol Safety Action Frogram Evaluation Manual" for use by communities undertaking ASAP projects. FY 1970 funds are being used to accomplish this in advance of the initiation of the FY 1971 program. Evaluation of program effectiveness is an essential requirement which must be built into the project design at its inception. The Bureau will provide consulting assistance in adapting this generalized evaluation design to the specific needs of each community.

4. By funding development grants of not more than $\$ 10,000$ to assist communities in the effort required to adequately prepare a project proposal.

These grants would cover a 4 to 6 months period prior to contract signing and the initiation of the 6 months planning phase.

These steps will be taken in order to assure that every program is efficiently managed. In every case full-time specialists, professionally 
trained in the area of alcorol safety, will be appointed to manage the community programs. The proi...t management manuals and project evaluation manuals to be prepared by th:.: Bureau will ensure that the managers have a detailed blueprint to follow in supervising the program. Evaluation reports required under this plan will assure the Bureau of early indication of project effectiveness。

Different communities may want to undertake differing mixes of countermeasures. Some will want to give special emphasis to enhanced law enforcement, others to improving court procedures or to rehabilitation of problem drinkers who drive. Some communities may find that local attitudes are conducive to initiating the more innovative features of the program involving identification of problem drinkers through the assistance of the medical profession, public health facilitices and social velfare agencies. The NHSB program will encourage such diversty, seeking only to assure that the proposed demonstration project is (a) comprehensive and multifaceted in its approach to the problem; (b) focuses on the problem drinker who drives; and (c) includes an intensive evaluation of project cost and effectiveness.

\section{DEVELOPMENT OF COMPREHENSIVE ALCOHOL SAFETY ACTION PROGRAMS}

The development of a comprehensive program in alcohol safety involves. four steps:

1. As a first step, the Bureau Regional Director and the respective Governor's Representative should determine the interest of a number of communities in carrying out an alcohol safety program, specitically the interest of local and state agencies involved in highway safety programs and in the treatment of problem drinkers and alcoholics. A selection process will tren be initiated.

2. Once an applicant community is tentatively selected to conduct an ASAP project, the community is ready to move on to the organization of a local action group in alcohol safety. The group can then act as a policy guidance and steering committee.

3. After such a program group has been formed, a survey of current highway safety statistics and community capabilities must be undertaken to determine the potential effectiveness of a highway safety program and the facility and organizational requirements for the community to implement such a program.

4. The final step in the development pirocess for those locations selected is the writing of a froject proposal for submission to the National Highway Safety Bureau. The steps in the developmental process are described in more detail in the paragraphs below.

Selection of Applicants 
The initial selection of applicants will be the primary responsibility of the Regional Directors working in close cooperation with tne States in their respective Regions. Each Region will be encouraged to select not more than ten (10) applicants and to include at least one from each State for the FY 1971-1972 projects. The selected applicants will then be assisted in the preparation of preliminary applications by NHSB. These applications will contain only the essential information needed for the purpose of selecting sites for subsequent proposal development. The use of a preliminary application process will eliminate much costly, time-consuming work for the applicants not selected. Applicants will be clearly advised that being selected to submit an application in no way inlies a commitment for funding since the FY 1971 program includes plans for the initiation of no more than twenty (20) new projects. The applications will be reviewed and evaluated by the National Highway Safety Bureau, and tentative locations will be selected to proceed to the development of full formal proposals. In evaluating the preliminary applications, the following criteria will be considered:

Evidence of Community Support -- Tris will include an evaluation of whether the major enforcement agencies, courts, treatment centers, and other groups which will be involved in the program actively support the proposal.

Demonstration of Community Capability - This will be judged on the basis of the facilities available, and programs currently underway in the community, including additional facilities which the community plans to provide from its own resources. Also involved will be a determination as to whether there have been sufficient highway fatalities and serious injuries within the area of the proposed program to permit a demonstration of the effectiveness of the effort and to make the project cost effective relative to input -Federal funds -- and output -- reductior of crashes, death and injury.

Willingness of the Community to Make Some Efforts on on 1 ts Own -- While the NHSB will provice financial support to cover costs of the increased effort required to conduct an intensive program, its decision will be based, in part, on the extent to which the community is ready and able to use some of its own resources in supporting the alcohol safety program.

Willingness to Undertake a Broad Multifaceted Program -The NHSB balieves that single courtemeasures cannot have a major effect on highway fatalities. It is interested, therefore, in communities developing a broad multifaceted action program capable of making a significant impact on the traffic fatalities related to alcohol. 
Evidence of Effective Organizational Plan -- Since a large number of commun ty organizations will be involved in a project, an effecti... organizational flan for conducting the program will be a prime requirement. Evidence will be evaluated that the organization has been carefully considered, and that it is located within an appropriate framework in the local or State government, and that it has the support of local, and where appropriate, State government agencies.

Adequate Provision for Program Evaluation -- There is inadequate objective evidence to demonstrate the effectiveness of countermeasures in the area of alcohol safety. It will be essential therefore to evaluate at least the total program impact of the comprehensive action project. Evaluation will permit both an assessment of the total program impact and specific countermeasure effectiveness which can lead to program modifications to increase overall cost-effectiveness.

Establishment of a Community Alcohol Safety Organization -It is clear that development of a broad countermeasure program involves the activities of many different community groups and government agencies. Increased detection and apprehension of problem drinkers who drive will require special activities by local health and social agencies. Ensuring that convicted drivers who are problem drinkers receive treatment will depend upon local courts initiating procedures toward prosecution, conviction, diagnosis, and referral to treatment agencies. Ensuring that probiem drinkers are not fermitied to drink and drive will require stringent enforcenent of driver license revocations, together with provision for restoring the driving privilege on evidence of progress in rehabilitation. Public support for more rigid enforcement can te achieved only through an intensive program of public education using mass media, facilities. Programs directed at the prevention of problem drinking and at groups with special susceptibility to drinking-driving accidents, such as yourg drivers, must be integrated into the educational system. Thus, the implementation of a broad countermeasure program $\mathrm{w}^{\mathrm{i}} \mathrm{ll}$. require the cooperation of many local and State agencies.

To develop this integrated attack on the problem of alcohol and highway safety will require substantial organizational efforts within the community. This community-wide organization must include individuals representing citizer groups, private organizations and government organizations -- local, State and Federal. A starting point for such an organization is the local council on alcoholism. Such councils usually have representatives from State and local government, private hosfitals, courts, police forces and other groups concerned with the problem of alcoholism. In some cases it may be desirable to exfand such an established group to take the lead in establishing an alcohol safety program. In other cases a new citizens' group will need to be formed. While all communities participating in this type of program will 
require a corrunity citizens' organization, the program can generally be :anajed best by a local government agency such as the mayor'suffice. In any case, it is important that representatives of all those facilities in the local area which will become involved in the model program are brought together so that each can be represented and work in the planning activity.

In developing a community organization an attempt should be made to bring together the kinds of organizations listed in Figure 4-3. To the nucleus provided by existing citizens' groups on alcoholism should be added representatives from: (a) national State and local social and health agencies (private and goveriment) which deal with problem drinkers; (b) representatives from local courts which bandle cases involving alcohol (both traffic and criminal); (c) representatisis of local government; (d) representatives from local enforcement agencies; (e) representatives from the local university medical school or life sciences departments (if local universities are not available, representatives from technical consulting organizations should be utilized); (f) representatives from State or local departments of education; (g) representatives from local radio, TV and newspapers. Along with these community resources, assistance from the Governor's Representative for Highway Safety, and representatives from the department of motor vehicles, the State highway patrol, the State mental health agency and the State department of education may also be helpful when available. This organization can then determine whether support for an intensive alcohol safety program exists within the community. It can also supervise a survey of community capabilities.

Kequirements for a Survey of Highway Accident txperience and Agency Requirements for the Proposed Program Area

To support the need for and the potential effectiveness of a comprehensive alcohol safety project, a survey should be conducted of the current levels of vehicle accidents and fatalities experienced in the local area. As a part of this survey, an evaluation of the capabilities of local enforcement and treatment agencies should be made. These data will provide the community with an indication of the extent to which an alcohol safety urogram is required and the potential effertiveness of such a program. They will also provide a basis for estimating the additional personnel and facilities which will be required by participating ayencies. This in turn will indicate the cost and the probable schedule for implementation of the program. Each candidate community will need to design a survey which is appropriate to its own needs; however, at least the following eight areas will be included in such surveys:

For the geographical area to be covered in the proposed ASAP project, statistics should he developed on the number of vehicles using the roadways and the number of niles driven.

Accident statistics can then be related to this baseline. Accident statistics should nclude the number of fatalities from multi-vehicle, single vehicle and pedest $i$ an accidents for a period of the last three years. Blood alcohol levels in atally injured drivers and adult pedestrians should be sur-

1 veyed. Arrests and convictions for driving while intoxicated and other alcohclrelated offenses should be listed. These data may be supplemented by local social agencies' e;timates of per capita liquor consumption. From these data 
it should be possible for the community to estimate the numbers of fatal and serious injury accidents which have occurred during the last three years and their relationship to the consumption of alcohol. Where a significant number of fatal and serious injury accidents have occurred and there is evidence that these are related to alcohol consumption, the community has a basis for believing that an effective alcohol safety progran would reduce these fatalities. If the number of such accidents is not significant, an alcohol safety program is not justified.

A survey should be made of current laws pertaining to alcohol-related offenses and highway safety. Are there provisions for chemical tests? Are the presumptive levels specified? What are the penalties provided for by these laws? Is mandatory license revocation required? For what period? What are the penalties for driving while license is suspended or revoked? What are the laws governing non-traffic alcohol-related offenses?

The current status of State driver record systems and 1 icensing requirements should be ascertained. Do current licensing provisions facilitate physicians and/or health agencies reporting alcoholics to the licensing agency? Do licensing laws permit the Director of Motor Vehicles to deny licenses to problem drinkers and alcoholics? Is there a provision for medical review boards to determine the qualifications of problen drinkers to drive? Are medical examinations provided for? Is the current driver record system capable of prow viding timely information to courts and enforcement agencies on the driving record of individuals apprehended for drinking-driving offenses? Is there a provision for reporting non-driving alcohol-related convictions to the licensing record system? Is this done effectively?

A survey of current driver education facilities should be conducted. Is driver education provided through the schools or by other means to all youths of licensing age? What provision is made in these courses for instruction on alcohol safety? Is any instruction on alcohol safety provided in elementary and high school courses outside of driver education? Do the courts provide for offenders' schnols? What is the content of the curriculum? What is the availability in the local area of mass media facilities, TV, radio, newspapers?

Court facilities and practices should be surveyed. This should include a list of all courts involved in alcohol enforcement, both traffic and nontraffic. What is their case load? What are the present practices in sentencing alcohol offenders? What are the capabilities of the probation department? Have any provisions been made for medical examinations and/or treatment of alcohol offenders? What flexibility do the courts have in sentencing traffic and nontraffic alcohol offenders?

A survey shou'd be made of all enforcement agencies in the proposed demonstration area. The list should include the responsible agencies and their personnel, with information on what kinds of special equipment and facilities they have for alcuinui safety enforcement, and the level of trainins in the use of chemical tests and in alcohol safety enforcement practices of the personnel of these agencies? An analysis of the technical assistance available to the community
should be undertakt:n. What kinds of technical assistance are available to 
the communities involved in the demonstration project? Are there nearby universities with alcohol research activities and treatment capability? Are there consulting firms with capability in highway safety, in survey techniques or data processing procedures?

A survey must also be made of the available alcoholism treatment facilities. What is the capability of these facilities for treatment of problem drinkers? What is their present case load? To what extent can this be expanded? What kinds of costs are involved in receiving treatment? What support is available through social agencies and private groups?

By developing this information the candidate community will be in possession of adequate data to develop a comprehensive action program proposal.

\section{Preparing a Project Proposal}

Based on the survey of highway statistics and agency capabilities the local alcohol safety group should be able to develop an alcohol safety action program. The specific countermeasures listed in figure 4-4 should be reviewed in light of the survey to determine which are applicable to the particular conditions of the area to be covered by the project. Some of the proposed countermeasures will be inapplicable because the basic State legislation does not exist. In other cases the capability of State or local enforcement agencies will not permit the application of a given procedure. In some cases modificam. tions of the proposals in Figure $4-4$ will suggest themselves. Some communities may al ready be applying countermeasures similar to those suggested. These can be incorporated in the overall project. In this way, a program tailored to the needs of the coimunity can be developed from the various countermeasurt:s available to it.

\section{ASSISTANCE TO BE PROVIDED BY THE NATIONAL HIGHWAY SAFETY BUREAU TO COMMUNITIES WISHING TO DEVELOP ALCOHOL SAFETY PROGRAMS}

The National Highway Safety Bureau will provide assistance to States and communities selected to develop comprehensive alcohol safety community action programs. This support will include both technical assistance in the develop. ment of program plans, and following the approvel of an ASAP project proposal, financial assistance in carrying out the community action program.

\section{Assistance Prior to Proposal Submission}

The Bureau will provide public education materials such as movies, speech outlines, slides, etc., for individuals interested in developing community interest in a demonstration program. The Bureau will also provide a detailed manual on how to develop a community program and how to apply for financial assistance under Section 403 of the Highway Safety Act. Once a comi. munity has initiated a local alcohol safety organization, the Bureau will arrange for the vijit of a team of safety specialists to discuss the various aspects of the comprehensive alcohol safety action program. The Bureau will also assist the losal communities in developing a program by arranging for visits by consultants to provide technical assistance. Finally, the NHSB wil assist local communities in contacting other government departments, such as the Department of Health, Education, and Welfare, for information and assistance 
related to alcohol safety programs. Prior to the submission of a formal project proposal, the NHSB will provide an informal review of the draft and assist communities in finalizing their proposal. On a limited basis in cases of special need, the NHSB will provide development grants not to exceed $\$ 10,000$ to cover costs incurred in proposai development.

\section{Contracts for Comprehensive Programs}

The amount of the contracts for action projects will, of course, vary depending on the needs of the community. The funds requested can cover the following areas:

1. Costs associated with project initiation: these include planning activities, training of personnel, procurement of equipment, conducting surveys to determine the areas for most effective enforcement activity. ( $1 t$ is desirable to issue separate planning contracts and procede to a contract for an action project only if the planning grant is fully successful.)

2. Costs associated with each of the countermeasures proposed for inclusion in the alcohol safety program where these are clearly above the normal state safety program requirements.

3. Costs associated with diagnosis and reeducation (not treatment) activities for problem drinkers required by the courts. These payments may be made to health and social agencies if these activities take place under their supervision. The NHSB will not support general treatment expenses and medication of alcoholics. These treatment expenses will be borie by the local agencies with the assistance of tre state department of mental health or from Federal sources such as the Department of Health, Education and Welfare as described below. Among' the expenses which the NHSB will consider fun.'ing in connection with the treatment and rehabilitation of alcoholics and problem drinkers are the following:

Acute detoxification of individuals apprehended for traffic offenses,

Physizal examinations ordered by the courts to deterinine whether individuals convicted of drinking and driving are alcoholics,

Expenses associated with record keeping by social or health agencies required to provide reports to courts or licensing agencies,

Driver education and driver assistence activities carriad out in health and social agencies,

Treatinent with prophylactic drugs such as Antab ise when provided under court direction as a provision of probation.

4. Costs assoziated with program evaluation, including both data gathering and data analysis will be funded by the NHSB. 


\section{E. ASSISTANCE FROM OTHER GOVERNMENT ACENCICS}

Excessive use of alcohol has been a problem in the United States for many years. Most people are aware of the problem the alcoholic presents to society, to his government, and to his family. This awareness has led to such major social experiments as Prohibition. Since Prohibition, attempts to eliminate excessive drinking in the United States have given way to programs to rehabilitate problem drinkers. Whi le considerable development has occurred in methods of treating alcoholics, much remains to be done. The alcoholics contribution to highway fatalities, serious as it is, is only one aspect of his cost to society. Cost to his family and to industry in lost work hours may be even greater than the losses he causes on the highway. Any comprehensive program must include efforts to deal with all aspects of the problem of alcoholism. The NHSB will support only those activities that relate to highway safety. The Department of Health, Education and Welfare has prime responsibility in assisting states and communities in improving their treatment and rehabilitation facilities. Communities requiring assistance in this area may be able to take advantage of their eligibility for com munity mental health assistance. The NHSB will assist those communities planning highway safety programs in contacting appropriate HEW organizations.

In addition to the funds available under the programs of the Department of Health, Education and Welfare, assistance may also be available through the programs administered by the Department of Housing and Urban Development and the Justice Department.

\section{F. COMMUNITY ACTION PROGRAM}

While the deficiencies in current alcohol safety efforts cannot be easily overcome, a number of improvements in enforcement procedures are available to state and communities who desire to strengthen their alcohol safety programs. Unfortunately, while the relationship of alcohol to highway crashes is well documented, little research has been done on potential countermeasures for this problem. Many proposals for action have been made which appear to have merit, but few have been completely validated. To delay action until fully validated countermessures are available, however, would mean acceptance of the present toll of nearly 500 a week fatalities related to alcohol from now until such time as neasures are validated. Action must begin, always with the provision that any program must have built into it a method of evaluation so that its impact can be measured and the program modified as necessary to ensure effectiveness. Since no group of proven countermeasures is available, the NHSB has develoyed, with the advice of the knowledgeable experts in the alcohol safety fielt, a list of countermeasures for consideration by States and communities desiring to improve their alcohol safety programs. This list ( $f$ igure $4-4$ ) is not exhaustive; additional possitilities exist. Moreover modifications of those listed may be more appropriate in a number of communities.

These proposals are presented for guidance to states and local communities only. Each community, in developing its program, may select from those listed, develop its own modifications or variations of these proposals, or propose entirely new method; of attacking the alcohol safety problem. It is probable, however, that programs embodying a single countermeasure or even two or three, will be unlikely to have a major impact upon the highway deaths and injuries 
due to alcohol. Therefore, the National Highway Safety Bureau is looking for cominities wiliing to implement a broad program rather than programs invilusis only one or two countermeasures. As can be seen by reference to Fi......4. 4.2 , some of the proposed countermeasures require action at the Srate level; others can be instituted by local communities. Some require nilislation at the community or State level; others can be implemented under current laws. Each community interested in developing an alcohol safety program will have to select from the countermeasure possibilities available to it; i.e., those that can be supported by present legislation or for which new legislation can be enacted rapidly.

\section{G. CURRENT PROGRAM STATUS}

During FY 1970 a number of communities were contacted to determine their interests in developing intensive alcohol safety programs and responded favorably. Of these, nine developed and submitted proposals to the National Highway Safety Bureau, and were selected to undertake ASAP projects. The actual countermeasures that are contemplated embody a wide range, as can be seen from Figure 4-5.

Additional countermeasures may be added during the life of the project. In some cases, communities which begin with a limited set of countermeasures will add to the list as other organizations and government agencies can be brought into the program.

In general the communities 1 isted in Figure $4-5$ have the benefit of near-by technical organizations which have assisted them in developing their

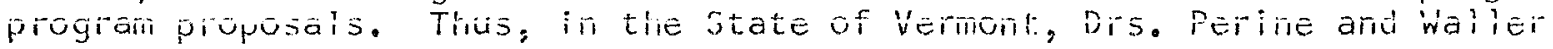
at the University of Vermont have taken the lead in writing the proposal and in organizing the program. The University project has been supported for the last three years by the Highway Safety Bureau Research Program.

The community organization necessary to prepare the groundwork for a community program and the technical skill required to develop and write a proposal is often beyond that available to local agencies and government. Thus it will be necessary to provide technical support to those communities which lack it, if comprehensive programs are to be initiated. For this purpose the Bureau is developing a detailed manual on procedures for implement$\because$ these programs and evaluation techniques.

ASAP programs will not generally come into full operation for six months in order to provide time for planning and training of personnel. This planning period appears to be a critical need in most communities since a number of the countermeasures proposed are new activities which require a good deal of organization, coordination and trairing prior to their implementation. Expenditures will generally be lower during the planning period than when a program is in full operation. Figure: 4-6 provides a budget estimate for ASAP projects for FY $1971-F Y 1976$.

As can be seen from this table, the cost of the programs initiated during FY 1970 will increase gradually up to just under $\$ 4,500,000$ a year in FY 1972 and FY 1973. During the current Fiscail Year twenty additional

1 projects will be initiated and another forty during FY 1972. BY FY 1973 
86 projects will be underway. This will provide a broad-based demonstration of the comprehensive community program concept. The wide distribution of these programs should stimulate the States to start other intensive programs on their own. From the experience gained during the current year, staffing requirements have been formulated. An appreciable increase is required in the field assisting communities in developing and implementing their demonstration progiams.

\section{H. AN EXAMPLE OF A COMPREHENSIVE COMMUNITY PROJECT IN THE STATE OF VERMONT}

The State of Vermont has submitted a proposal for analcohol countermeasure demonstration project which has been reviewed by NHSB and will be funded shortly. It is one of several similar projects which will be started in FY 1970. The Vermont project has the following objectives:

1. Document the nature and extent of the alcohol problem in the state and the countermeasures currently employed.

2. Demonstrate the effectiveness of specific countermeasures.

3. Evaluate countermeasure cost effectiveness.

Project Plan

Phase I -- Establish baseline data against which to evaluate subsequent changes.

-- Develop detailed countermeasure program.

-- Document methods currently in use.

Phase II -- Implement specific countermeasures applying different mixes in different parts of the State to determine relative degrees of effectiveness.

\section{Countermeasure Description}

The following five categories of countermeasures will be carried out:

1. Developmert of predictive psychological-.biographical profile of drivers from licensing examination.

2. Intensified enforcement on the highway and other measures of identifying problem drinkers.

3. Transportation assistance to drivers who have had licenses suspended or revoked.

4. Efforts tc modify drinking/driving behavior.

1 5. Public education, including driver education. 
These countermeasures are further described as follows:

Driver Profile

Development of a driver profile questionnaire for use in driver licensing examinations to identify high-risk drivers for referral to special counseling. The questionnaire will draw on considerable research already completed. Mobile Automated Examination Vans will be used to administer the questionnaire, will contain modern electronic instruments and programmed procedures, and will provide a means of educating the applicant in the process of testing him.

Intensified Enforcement on Highways and Other Identification

Measures

Intensified enforcement will involve primarily a heavier saturation of police patrols in each of the State's five police districts successively for a period of from two to six months. This will enable a key evaluation to be made: how long the effect of the increased enforcenent continues after enforcement is returned to previous levels. Expected increases in DWI apprehensions will place a greater burden on the courts and the project budget provides for meeting this workload. In addition, the Governor will seek new legislation to permit the use of checks using breathalyzers to determine blood alcohol level of drivers.

Problem drivers would also be identified from social welfare and public health public records and through pre-scitence evaluation of convicted driving-while-intoxicated drivers. Once identified, decisions of the action to be taken would fall within the jurisdiction of the district courts and the Motor Vehicle Department. The courts are empowered to use probation, suspended jail sentences and referral for treatment. The Motor Vehicle Commissioner has discretionary power for actual reinstatement of suspended drivers' licenses.

\section{Transportation Assistance}

For drivers whose licenses have been susperded or revoked because of drunken driving, a program of transportation assistance will be introduced in selected areas of the state. Transportation will be provided only to and from place of employment during which time an educational program for the DWI driver will be undertaken.

Modification of Drinking Driving Behavior

This part of the demonstration project interfaces with a projected National Institute of Mental Health grant for community mental health resources. Individuals who have been identified as highrisk, problem drivers will have ready access to available treatment programs involving behavioral therapy, re-€ducative and group 
therapy approaches under the NIMH share of the program.

An important DOT contribution to behavior modification involves evaluation of convicted driving-while-intoxicated drivers under pre-sentencing procedures to determine which one of the various programs they should be referred to. The range and effectiveness of therapeutic and rehabilative programs currently in operation will be ascertiained.

\section{Public Education}

This involves the following three elements:

Provide information for the general public about the risks of crashes in which alcohol is a factor and about methods by which they can reduce this risk through modification of their own behavior.

Disseminate information on problem drinking characteristics.

Promote legislative and program support.

\section{State Agency Support}

A key element in any alcohol demonstration project is the willingness of state and local officials to modify existing programs to dovetail with the countermeasures project. The Vermont project is supported by ihe foliowing officiais:

\section{Governor}

Attorney lienera!

Commissioner of Mental Health

Commissiorer of Motor Vehicles

Commissiorier of Public Safety

Chief District Judge

Chief Medical Examiner

Chairman Alcoholic Rehabilitation Board

Director, Division of Chronic Diseases, Department of Health

Support is also expected from the Greater Burlington Traffic Safety Committee, Vermont State's Attorney Association, the mass media and driver education programs in Vermont's high schools.

\section{Evaluation of Legal Aspects}

Arrangements have been made to initiate a cuoperative study of lawrelated aspecis of the project with the Council on Law-Related Studies, a non-profit foundation housed togather with the Harvard Law School.

Projects Cost: and Administration

The project is; estimated to cost about $\$ 2$ million and will take 
about four years. It will be administered by the Vermont Department of Mental Health and supported by internationally known experts on the alcohol problem from the University of Vermont. 


\section{FI GURE $4-1$}

NARRATIVE OF ASAP PROGRAM DEVELOPMENT PLAN

States with

$\frac{\text { One }}{\text { Project }} \quad$ Two

FY 1970

9 Standard Sized $(\$ 500 \mathrm{~K} /$ year $)$ projects initiated 9

FY 1971

20 Standard Sized projects initiated in 20

20

new States

FY 1972

5 medium sized ( $\$ 1$ M/year) projects in cities

with over $500 \mathrm{~K}$ population in 5 new States

16 standard sized projects in 16 new States

16

1 project in a large metropolitan area

(\$3 million/year) example Chicago

8 standard sized projects at sites with special

$2 *$ problems or osportunities

\section{FY 1973}

6 projects in large metropolitan areas

21 standard sized projects at sites with special problems or osportunities

* Puerto Rico and Washington, D.C. 


\section{FIGURE 4-1 (cont'd.) \\ NARRATIVE OF ASAP PROGRAM DEVELOPHENT PLAN}

SPECIAL PROBLEM OR OPPORTUNITY AREAS

1. Communities with special laws - i.e. Baton Rouge with British Roadside testing system.

2. Certain interjurisdictional areas, e.g., Washington, D. C., St. Louis, Minneapolis-st. Paul.

3. Border areas: San Diego, El Paso and Nogales

4. Special Environment: High Alcohol Consumption Areas (Las Vegas, Miami, Tampa, etc.).

5. I solated units permitting complete control of traffic -- Hawaii, Puerto Rico.

6. Young driver problens: College towns and military bases. 


\section{FIGURE $4-2$}

ANNUAL COST ANALYSIS OF TYPICAL ALCOHOL SAFETY ACTION PROJECTS UNDERWAY (Based on Estimated Costs for FY 1971 Operation)

Project Element

Administration

Enforcement and Prosecution

Driver Re-Education

Public Information and Education*

Evaluation

TOTAL ANNUAL COSTS .......

\section{Seattle}

$\$ 153,577$

129,500

138,780

37,500

144,767

$\$ 604,124$

$1,119,300$
Port land

$\$ 130,759$

145,604

147,063

67,327

110,000

$\$ 600,753$

$\$ 536,790$

Population
$(2+2$ 


\section{FIGURE $4-3$}

\section{AGENCIES AND OTHER ORGANIZATIONS WHICH}

\section{SHOULD PARTICIPATE IN PROGRAM DEVELOPMENT}

1. Local Citizens Groups on Alcoholism

2. Courts concerned with handling drinking offenders .. both highway and non-highway related offenses

3. Enforcement agencies concerned with drinking offenders

4. Local government

5. Social agencies, both public and private, dealing with probiem darinkers

6. Health facilities, National, State and local, both public and private, which treat problem drinkers and alcoholics

7. The local Department of Education

8. Local communications media including $T V$, radio and newspapers

9. Universities or other sources of expert consultants

10. State agency representatives including the State Motor Vehicle Department, the State Highway Patrol, the State Department of Education and the State Mental Health Department 


\section{FIGURE $4-4$}

\section{Identification}

Include Alcohol Safety Questions in License Examination and Driver Handbook

Provide for Certification by the License Applicant Regarding Previous Arrests and Treatment for Alcoholism

Record in Driver's Record Alcohol Relate 1 Traffic Convictions from Court Records

Record in Driver's Record Non-Traffic Alcohol Related Convictions

Record in Driver's Record from Agency Records Contacts with Social and Health Facilities for alcoholism or problems deriving therefrom

Provide for Flagging Vehicle Record for Cars Owned by Problem Drinkers

Provide fur Inciucing Chemical Tesi Date on Accident Report Furm

Provide for Chemical Tests and Specify Concentrations

Provide for Implied Consent for Chemical Tests

Require License Revocation if Test is Refised

Set Specifications and Procedures for Che:nical Tests

Establish Qualifications for Alcohol Safety Personnel

Provide for ispecial Enforcement of Drinking-Driving Laws

Provide for ispecial. Training on Breat-Testing Equipment

Determine Locations and Times of Day of Accidents Involving Drinking Pecestrians 


\section{$\frac{\text { FIGURE } 4-4}{\text { Continued }}$}

\section{Decision}

Require Pre-Sentence Investigation of Convicted Drinking Drivers

Provide for Referral of Problem Drinkers for Treatment

Provide for Use of Disulfiram where appropriate

Establish Medical Advisory Boards (MAB's) for Licensing Agency

Provide for Review of Convicted DWI Drivers by MAB Prior to Reinstating Licenses, as permitted by Law

Empower MAB to Require Physical Examinations of Drivers whose Records they Review

\section{Follow -up Action}

Provide for Vehicle Impounding for Driving while Revoked or for Second DWI Conviction within Three Years

Provide for Special Surveillance of Drivers with Revoked Licenses

Develop Special Pedestrian Safety Programs in Areas of High Accident Risk or Drinking, i. e., (1) better lighting, (?) reduced speed limits, (3) special cautjon signs, etc.

Provide Special Patrols for Intoxicated Pedestrians

Arrange for Deloxification and Treatment As.sistance for Pedestrians

Provide for Suspension or Revocation of License Plates of Vehicles Owned by Perscns Convicted of Driving while Driver's License is Suspended or Revoked for DWI or DWUI

Provide for Special Tags or Registration Certificates for Vehicles Owned by Convicted Drinking Drivers who ar : convicted for Driving with Suspended or Revoked Drivers License 


\section{$\frac{\text { FIGUTRE } \cdot 4-4}{\text { Continued }}$}

Prohibit the Transfer of Vehicles with Special Registration Certificates

Develop Mass Media Public Education Campaign on Alcohol Safety

Develop Speakers Bureau Program on Alcohol Safety

Augment Alcoho: Safety Sections of High School Driver Education Programs

Add Sections on Alcohol to Primary Safety Courses and to Appropriate Secondary Courses (Family Life Courses, etc.)

Develop Special Offenders' School Driver Improvement Programs

Implement a Driver Assistance Program in Cooperation with Social and Health Agencies 
Fizure $4-5$

\section{Alcohol Safety Action Program}

PROPOSED FY 70 ALCOHOL. DEHONSTRATION PROGRAM

\begin{tabular}{|c|c|c|c|c|c|c|c|c|c|c|c|c|c|c|c|c|c|c|c|c|c|c|c|c|c|c|}
\hline & \multicolumn{9}{|c|}{ ionitiritontion } & \multicolumn{6}{|c|}{ LEÊiSiüii } & \multicolumn{11}{|c|}{ AETION } \\
\hline & \multicolumn{3}{|c|}{$\begin{array}{c}\text { APPREHENSION } \\
\text { ON ROADS } \\
\end{array}$} & \multicolumn{3}{|c|}{$\begin{array}{c}\text { DRIVERS } \\
\text { LICEMSING }\end{array}$} & \multicolumn{3}{|c|}{ DTHER } & \multicolumn{4}{|c|}{ COIRTS } & \multicolumn{2}{|c|}{$\begin{array}{l}\text { DRIYER } \\
\text { LLCENSTHS }\end{array}$} & \multicolumn{2}{|c|}{ COHTROL } & \multicolumn{3}{|c|}{ REYAEILITATION } & \multicolumn{2}{|c|}{$\begin{array}{c}\text { ASSIST } \\
\text { AMCEE }\end{array}$} & \multicolumn{4}{|c|}{ PUBLIC EDUCATION } \\
\hline LOCATIOHS & 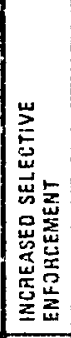 & 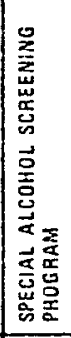 & 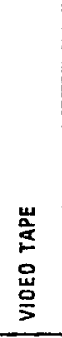 & 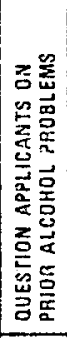 & 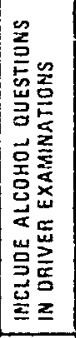 & 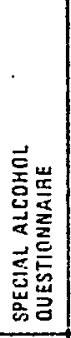 & 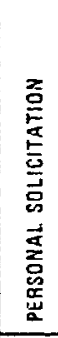 & 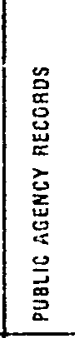 & 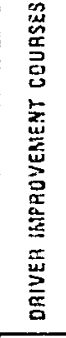 & 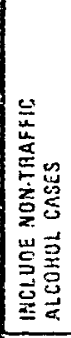 & 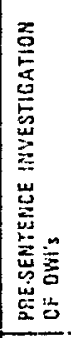 & 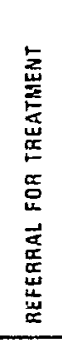 & 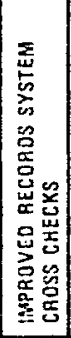 & 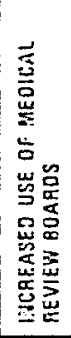 & 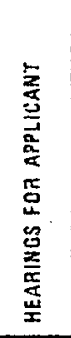 & 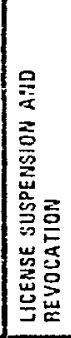 & 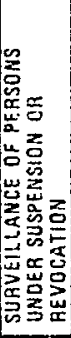 & 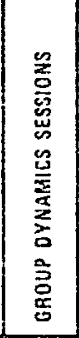 & $\begin{array}{l}\text { 岁 } \\
\text { 嬡 } \\
\end{array}$ & 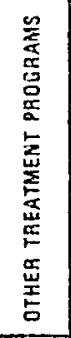 & 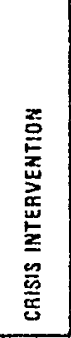 & 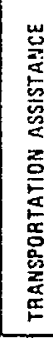 & 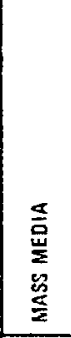 & 喜 & 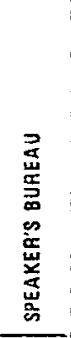 & 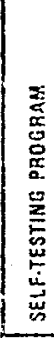 \\
\hline ALzUQUERRQUE & $\Delta$ & & $\Delta$ & $\Delta$ & & & & & & & $A$ & $\Delta$ & & & & $\Delta$ & & $\Delta$ & $\Delta$ & $\Delta$ & & $\Delta$ & A & $\Delta$ & $\Delta$ & $\Delta$ \\
\hline AKM ARBOR & $\Delta$ & & $\Delta$ & & & & & & & $\Delta$ & $A$ & $\Delta$ & A & & & A & $A$ & $\Delta$ & $\Delta$ & $\Delta$ & & & $A$ & $\Delta$ & $A$ & \\
\hline CHARLOTTE & $\Delta$ & & $\Delta$ & 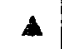 & & $\Delta$ & & $\Delta$ & a & & A & 4 & A & & $\Delta$ & $A$ & $A$ & $A$ & & $\Delta$ & & & 4 & A & $\Delta$ & $\Delta$ \\
\hline OEHYER & 4 & & $\Delta$ & $\Delta$ & ش & & & A & & & $A$ & $\Delta$ & & A & & 4 & A & 4 & $\Delta$ & A & & $\Delta$ & $\Delta$ & A & & $\Delta$ \\
\hline HADISON & $\Delta$ & & $a$ & $\Delta$ & & $\Delta$ & & $A$ & & & A & $\Delta$ & 4 & $\Delta$ & $\Delta$ & A & $\Delta$ & $\Delta$ & & $\Delta$ & & & $A$ & $\Delta$ & $\Delta$ & \\
\hline MASSAU COUNTY & $\Delta$ & $\Delta$ & & $\Delta$ & & & 4 & $\Delta$ & & & $\Delta$ & $\Delta$ & & & & $\Delta$ & & $\Delta$ & $\Delta$ & & $\Delta$ & 4 & $\triangle$ & $\triangle$ & $\Delta$ & $\Delta$ \\
\hline PORTLAMD & $\Delta$ & & & & $\Delta$ & & & $\Delta$ & & $\Delta$ & 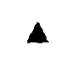 & $\Delta$ & & $\Delta$ & $\Delta$ & $\Delta$ & $\Delta$ & $\mathbf{\Delta}$ & $\Delta$ & $\Delta$ & $\Delta$ & & a & $\Delta$ & $\Delta$ & \\
\hline SEATTLE & $\Delta$ & & & & & & & $\Delta$ & & A & $\mathbf{A}$ & $\Delta$ & & & $\Delta$ & 4 & $\Delta$ & $\Delta$ & $\Delta$ & $\Delta$ & & & $\Delta$ & $\Delta$ & & \\
\hline VERMONT & $\Delta$ & & & & & $\Delta$ & $\Delta$ & $\Delta$ & & A & $\AA$ & $\Delta$ & & & $\Delta$ & $\Delta$ & & A & & 4 & & $\Delta$ & $\Delta$ & & $\Delta$ & \\
\hline
\end{tabular}


FIGUF.E $4-6$

ALCOHOL SAFETY ACTION PROGRAM

ASAP PROJECT DEVELOPMENT PLAN AND ESTIMATED BUDGET

FY 1970-1976 (Millions of Dollars)

\begin{tabular}{|c|c|c|c|c|c|c|c|c|}
\hline ZIVITIAL YEARA & I: 1370 & $\mathrm{Fi} 1971$ & Fi 1972 & FY i973 & FY 1974 & FY $\quad 1975$ & FY 1976 & TOTAL \\
\hline 70 & $\begin{array}{l}9 \\
(\$ .9)\end{array}$ & $\begin{array}{c}9 \\
(\$ 3.5)\end{array}$ & $\begin{array}{c}9 \\
(\$ 7.0)\end{array}$ & $\stackrel{9}{(\$ 6.6)}$ & - & & & $\$ 18.0$ \\
\hline 71 & & $\begin{array}{l}20 \\
(\$ 2.0)\end{array}$ & $\begin{array}{c}20 \\
(\$ 14.0)\end{array}$ & $\begin{array}{c}20 \\
(\$ 14.0)\end{array}$ & $\begin{array}{c}20 \\
(\$ 14.0)\end{array}$ & $\because$ & & $\$ 44.0$ \\
\hline 72 & & & $\begin{array}{c}30 \\
(\$ 9.0)\end{array}$ & $\begin{array}{c}30 \\
(\$ 25.0)\end{array}$ & $\begin{array}{c}30 \\
(\$ 25.0)\end{array}$ & $\begin{array}{c}30 \\
(\$ 22.0)\end{array}$ & & $\$ 81.0$ \\
\hline 73 & & & & $\begin{array}{c}27 \\
(\$ 14.4)\end{array}$ & $\begin{array}{c}27 \\
(\$ 33.0)\end{array}$ & $\begin{array}{c}27 \\
(\$ 33.0)\end{array}$ & $\begin{array}{c}27 \\
(\$ 25.0)\end{array}$ & $\$ 105.4$ \\
\hline $\begin{array}{l}\text { TOTAL PROJECTS } \\
\text { IN FORCE } \ldots . . \ldots . .\end{array}$ & .. 9 & 29 & 59 & 86 & 77 & 57 & 27 & \\
\hline TOTAL FUNDS ASAP.. & .. $\$ .9$ & $\$ 5.5$ & $\$ 30.0$ & $\$ 60.0$ & $\$ 72.0$ & $\$ 55.0$ & $\$ 25.0$ & $\$ 248.4$ \\
\hline
\end{tabular}




\section{SECTION V}

\section{STATE AND COMMUNITY PROGRAMS ON MATCHING FUND BASIS}

\section{A. OVERVIEW}

State and community matching grants under Section 402 of the Highway Safety Act provide a very effective complement to the Section 403 funds required for the alcohol safety program. Uncierlying the alcohol safety program are, of course, vitally essential research and safety manpower development needs, as well as the obvious and over-riding requirement for building public understanding and support. Based on the se activities the Bureau is initiating a two phased action program:

1. Comprehensive Community Alcohol Salety Action Programs (described in the previous section) which, as results are evaluated and countermeasure effectiveness established, will be phased over to State funding, and

2. Matching 402 grants to States and communities for coordinated programs in developing the facilities and supporting activities which wi.i pave the way for extending ihe comprenensive community programs on a State-wide basis.

At present State and Community grants under Section 402 of the Highway Safety Act are being made to support the alcolol standard, one of sixteen highway safety standards promulgated by the Secretary. Grants include such elements as:

- Procurement of breathalyzers

- Training of police personnel in theij use

- Procurement of video-recorders

In addition, expenditures under othe $r$ standards, such as Traffic Courts, impact on the alcohol problem and may reduce this source of highway crashes. However, as yet these expenditures do not represent a comprehensive approach nor are they susceptible to cost effectiveness measurements. 
NHSB has moved in the direction of comprehensive program planning with adoption of the Annual Highway Safety Work Program concept. Alcohol countermeasures will be included in the Annual Work Program of each State. There are a number of State-wide activities which are integral parts of any cohesive, coordinatec alcohol safety program. Such activities at the State level exist in areas of driver licensing, vehicle registration, traffic records, and others, such as State coordinated requirements and standards for driver education and training. Therefore, immediate and substantial requirements exist for Section 402 funds to be applied both specifically in support of alcohol countermeasures and in areas where benefits to the alcohol safety program are important collateral effects.

Matching grants to States and Communities under Section 402 is a logical follow-on to the comprehensive community action program. The sequence being followed by NHSB involves a progression which can be shown as follows:

- Research

- Comprehensive Alcohol Safety Action Programs at the cominiuntity leved

- State and Community grants

- Sustaining programs fully funded by the States

As the community action programs in alcohol begin to produce tangible evidence of effectiveness, the States will be better able to develop comprehensive alcohol programs under Section 402 incorporating the experience acquired in the se community comprehensive projects. Eventually, Section 402 alcohol grant program; would be replaced by sustaining programs funded primarily by the Sates.

NHSB intends to encourage the States to begin planning for comprehensive Section 41$) 2$ alcohol programs as soon as possible without waiting for the completion of the community action projects. The Annual Highway Safety Work Program, which requires comprehensive program planning by the States, provides the opportunity to do so. States should Give very high priority to alcohol countermeasures in their safety work plans. The Bureau will assure priority treatment of alcohol progra:ns in the annual work plans and in the programs of States in process of translating to annual work plans. Annual work 
plan formats now being explained to the States will include an example of the kind of comprehensive planning for an alcohol program envisaged by the Bureau.

A summary of alcchol countermeasures will be sent to all States and those that are considered key ones will be so identified. Implementation of such key countermeasures is considered essential for Annual Work Programs. Figure $5-1$ is a summary of countermeasures suitable for State programs.

While these important 402 steps are esseritial to the alcohol safety coordinated program thrust, it is not possible to carry out the comprehensive community ASAP programs with Section 402 funds. The comprehensive programs at the community level are essential to bring to bear the full gamut of countermeasures and to achieve a "critical mass" effect in producing tangible results in lives saved, as well as to provide testing of the countermeasures and their relative effectiveness in a real-world setting.

The Bureau intends to push rapidly for comprehensive Section 4n). alcohol programe in State wide activitics.

\section{B. STATE SAFETY PROGRAMS}

In this section a number of countermeasures -. some traditional, some new - are listed under eight headings These headings correspond to eight of the sixteen Highway Safety Program Standards. As a group they comprise a broad, integrated and intensive program which if applied nationally would produce a sizeable reduction in highway deaths and injuries due to excessive use of alcohol. This program embocying these countermeasures will be used by the Bureau for two purposes:

1. To provide guidance to the States in developing comprehensive alcohol safety programs for inclusior in their Annual Work Plan Requests, and

2. For review by the States and the National Highway Safety Advisory Committee with a view to dpgrading the current Highway Safety Program Standards. 
The countermeasures are summarized in figure 5..1. As can be seen from this figure some of the countermeasures involve actions to be taken at: (a) the State level, (b) primarily at local or community level, or (c) at both levels. Figure 5-1 indicates only the primary focus of the various countermeasures. Supporting activitics will frequently be nccessary at the State level for programs prirnarily conducted in the community and at the community level for those programs which are the primary responsibility of the State. Thus, if the state licensing agency is to maintain a record of all individuals being treated for alcoholism, communities must support this effort by ensuring that their local health and social agencies report such individuals to the licensing agency. Cn the other hand if local courts which bear the prime responsibility for diagnosis of problem drinkers and assisting them into treatment are to function effectively, they must receive the support of the State licensing agency in providing, in a timely fashion, the driving record of the convicted drinking driver. Thus, most of the proposed countermeasures involve some action at both community and State levels. Figure 5-1 indicates only the primary action area.

Overall these countermeasures are directed at four major goals:

The development of public support for aicchol safety programs through an intensive public education program, including formal ciassroom education in such areas as driver education and primary school safety courses.

- The identification of problem drinkers throagh: (i) more intensive enforcement of drinking driving laws so that more. problem drinkers will be apprehended and brought before the courts where they can be placed into treatment as a condition of their frobation; and (b) through voluntary programs implemented by health and social agencits which provide driver improvement courses and driving assistance to problem drinkers.

- An increase in the number of problem drinkers receiving treatment for their drinizing problem through use of authority and power of courts to motivate the individual to take ireatment in lieu of jail, fine and othe: standard court penalties.

- More rigorou:i standards with regard to licensing individuals with drinking problems, and with regard to suspending or revoking licenses of inclividuals found to have drinkirg problems. This must be combined with stricter enforcement of license restrictions for those individuls convicted of drinking and driving. Such enforcement to be co:mbined with assistance to the driver to ensure that 
during these perious when he is not peimitted to drive, he will still be able to get to and from his job.

The countermeasures will play a significant role in both the State Annual Work Program and in Standards Development.

1. Through the Annual Highway Safcty Work Programs States will be encouraged to implement as many of the proposals presented in this section as possible. At a minimum they will be expected to undertake at least one item appropriate to each of the four major goals listed in the previous paragraph. Programs which do not include activities in each of these arcas are not likely to have an early, significant impact upon highway falalities. Even an effective program of treatment through the courts, for example, could not have an early impact since too few problem drinkers presently come through the courts in relationship to the total number who drink and drive. Continuing revocation or suspension of licenses is of limited use until provisions are made for increased enforcement and for alternative methods of transportation for those affected. Increased intensity in efforts to apprehend individuals who are drinking and driving will be effective only when such individuals are broughtis into coint and convicted. Tüblic culucation alone will. not have a major impact unless it results in real programs to identify problem drinkers, prevent them from driving while drunk, and provide increased treatment facilities. Thus, only a miltifaceted effort can really make a significant early impact upon highway fatalities. It is this type of effort which the National Highway Safety Bureau desires the States to undertake.

Annual Work Programs will be developed under a standard format developed by the Bureau for this purpose. These formats are . illustrated in figures 5-2 and 5-3. Figure 5-2 summarizes the relationship between the program elements of the Annual Work Program:s and the National Highway Safety Standards. The work planned firr each element under each Standard will be described on the subelement plan shown in figure 5-3. The example shown in figure $5-3$ is for the work that has been traditionally accomplished with Section 402 funds: the procurement of breath-measuring equipment and the training of enforcement persomel in its use. As proposed in this document, however, the State alcohol safety activities resulting from the annual work plans would be much broader, hopefully encompassing many of the countermeasures listed in :igure 5-1. The program elements relevant to the Comprehensive Alcohol Program envisaged by the Bureau are underlined in figure 5-2. It will be the mission of the Office of 
Alcohol Safety working with the Office of State and Community Comprehensive Programs to insure that, as rapidly as possible, State annual work plans contain an entry for each of the underlined program elements.

2. The alcohol safety countermeasures have real and substantial implications in the majoris of the Highway Safety Standards - - for example, Police Traffic Services, Traffic Records, Codes and Laws, etc. As the countermeasures are successfully tested in the community comprehensive ASAP programs, and found to be effective, practicable, and valid in actual use in a real world setting -. a city or area as it exists and functions now -- the measures will be incorporated into the Highway Safety Manual which provides guidance for implementing the Highway Safety Standards. Changes to the standards themselves will then be effected as appropriate.

\section{ALCOHOL SAFETY COUNTERMEASURES}

Vehicle Registration

The purpose of vehicle registration is to provide information identifying the owner, type, weight, size and carrying capacity of every vehicle licensed to operate with a Statc, to ensure certain requirements are met, to raise revenue or provide a base for raising revenue, and to make registration data available for enforcement and other operational uses. Specific countermeasures are necessary for supervising the driving of those individuals who had their licenses revoked or suspended as a result of drinking driving conviction. While very little attention has been given this general problem, what research data are available indicate that large proportions of those drivers who had been prohibited from driving through revocation or suspension continue to drive anyway. A recent study in California, for exarnple, indicated that two-thirds of those drivers whose licenses were revoled were apprehended for trafic offenses during the period when they we re not authorized to drive. f number of such drivers had multiple offesnes. Unless methods are developed which permit easier identification of drirers who should not be permitted to use the roadways because of convicticns for drinking driving the most frequently invoked penalty of license revocation is of limited use at sest. 
The provisions within this Section on vehicle registration provide for special registration certificates or plates for vehicles owned by drivers who have been convicted of driving while their licenses have been suspended or revoked because of drinking-driving offenses. The presence of these tags on the vehicle will permit local enforcement authorities to recognize that the vehicle is owned by an individual who has been convicted of drinking and driving, and to check that it is not being driven by the revoked driver. One such system has been provided for in Minnesota. This check could be further facilitated by having the license provide a rough description of the individual who is prohibited from using the vehicle. This approach involves using the numbers on the license plates to describe the age and sex of the individual prohibited from driving.

\section{Proposed Countermeasures}

The State should ensure that motor vehicle registration laws provide for the is suance of limitalions on registration and operation of motor vehicles which may include but not be limited to:

- Vehicle registration laws providing for the suspension or revocation of the license plates of any vehicle owned by an indivdual convicted of a drinking-driving effense whe drives during the period during which his driving privilege is limited or suspended.

- Laws, if within the limits of the Constitution, providing for the is suance of special registration certificates so that the vehicles may be used by other family members and by the convicted individual himself if his driving privilege is restricied rather than suspended. These certificates should aid in identifying the owner who has been convicted of driving under the influence of alcohol, and whose privilege to operate the vehicle on the public roads is restricted.

- Laws providing that while the vehicle has this special registration designation, the vehicle may not be transferred except with special approval of the Department of Motor Vehicles. 
- Laws providing for the certification by an applicant for vehicle license plates as to whether he or any nember of his immediate family has been treated for alcoholism within the last five years.

Education: Public Support

A prerequisite to the effective implementation of all the countermeasures embodied in the Community Action Program will be a strong base of public support. The public must come to recognize the extent of the hazard presented by the problem drinker both to himself and to innocent road-users. Further, the public must come to recognize that the problem is not drinking per se, nor is the program aimed at abstinence or prohibition, but at a deviant group -problem drinkers with emotional problems involving an excessive use of alcohol, who must be identified and rehabilitated. The public must also come to accept the concept that the treatment of these problem drinkers is not hopeless and that the tragic highway toll due to problem drinkers is not an unmodifiable fact of life. The information presented should also indicate where individuals may go for help with problems arising out of excessive drinking. (see page 6-2)

\section{Proposed Countermeasures}

- A mass media campaign to educate the public on the relationship of the misuse of alcohol to highway fatalities with emphasis on the role piayed by the problem drinker.

The development of a Speakers Bureau Activity to support the Public Education Campaign.

\section{Education: Driver Improvement}

Since a large portion of all driver fatalities jnvolve individuals who are problem drinkers, an essential part of any alcohol safety program is reaching those individuals who are under treatment in public, social and health facilities. A program designed to minimize the dangers that these persons will drink and drive needs to be an adjunct to other assistance provided to problem drinkers and their families, and a component of any rehabilitation program. The assistance to the problem drinker should include, but not necessarily be limited to the following three items:

- A review o: the individuals driving record and a driver counseling session with the problem drinker to determine the extent to which he has had problems in driving, how and when he uses hi.: car, and what methods are available to him to avoid driving at times when he will be drinking.

An alcohol safety training program to acquaint the problem drinker, and members of his family, with the danger of drinking and driving; and to help make the problen drinker aware of the extent to which his driving is impaixed by his drinking. 
- A community support program which will help bring aid to the problem drinker to permit him to receive assistance to avoid drinking and driving. Among the features of this community support program should be:

A hot line phone number which he may call when he needs transportation to avoid driving while drinking. To support the hot line it may be useful to consider: providing a special fleet of cars on a volunteer or paid basis during evening hours to answer hot line calls and take drivers home.

Provision for transportation by family members, friends, neighbors when needed to avoid drinking and driving.

A program of monitoring by family members and friends to help ensure that the problem drinker does not drink and drive. In this connection, it may be useful to provide the family with a set of inexpensive breath testers such as the Alcotest, so that the problem drinker can be made aware he is not fit to drive.

Education: Driver Education

Each state or local comming should undertake a comprehensive program of education on alcohol and drugs in relation to highray safety in their primary and secondary schools. These programs should include at least the following countermeasures:

The augmentation of the alcohol safety sections of high school and conmercial school driver education programs.

- The addition of material on alcoholism to the curricula of primary and secondary school safety programs, and/or health programs. 


\section{Driver Licensing}

The effort to keep the problem drinker off the road must begin with the driver licensing activity. Too frequently, individuals with serious drinking problems receive licenses because there is no adequate provision for collecting and recording information from courts, hospitals, social agencies and other organizations dealing with problem drinkers. With 100 million drivers on the road, licensing record systems are overburdened, and licenses are frequently granted to individuals who are under suspension or revocation in a nother locality or to individuals with repeated histories of drinking and driving. The problem is manifest in the reverse direction also. A current study sponsored by the Bureau in California has indicated that frcquently individuals arrested for drinking and driving have been sentenced by the court as first time offenders when it was actually their third or fourth offense, because the records from the state licensing department failed to reach the court by the time the trial was conducted.

To be really effective, a comprehensive program for the reporting of problem drinkers to State licensing agencies must be developed. The studies reviewed in the Alcohol and Highway Safcty Report indicated that drinking drivers involved in fatal crashes viere several times more likely to have been treated for alcoholis m than normal drivers and many were known to social agencies for years prior to their fatal accident. If we are to reduce these fatalities, thosc social agencies must report individuals under their treatrnent to the driver licensing activity so that steps can be taken to ensure that they do not drink and drive.

The State of Michigan has taken an important lead ir this connection by requiring that State mental hospitals report the admission and discharge of individuals treated for alcoholism. In addition, the director of the institution must make a recommendation regarding the readines of the patient to resume driving. Other States must $\mathrm{b} \geq$ encouraged to take similar action. The Veterans Administration a.sd the Department of Health, Education and Welfare can be influentia:. in this process by setting up procedures for their hospitals to provide the same type of information to locél licensing agencies.

Of critical importance in this connection will be the cooperation and suppoxt of the medical profession. We have traditionally provided for the protection of suciety through the reporting by the physician to appropriate government agencies of certain dangerou; communicable diseases and gunshot wounds. Alcoholic drivers will kill two to three times more 
Americans than guns. It is time that alcoholism is added to this small list of dangerous diseases, which it is a physicians's responsibility to report to the appropriate government agency.

It is important that each State make sure that the medical information which is received is interpreted by competent medical specialists. Currently, 32 of the 50 States have provision for a Board of Medical Advisors tor the Motor Vehicle Department. Such boards should be given the responsibility for review of information coming from medical sources, and for advising the director of the motor vehicle department whether to grart license applications.

Proposed Counterneasures

To ensure that to the extent possible all problem drinkers and alcoholics are known to the licensing agency and that as a result, appropriate action is taken on their driver licenses, the State should as a minimun, require that:

- The license application includes a certification by the applicant indicating:

Whethor he has ever been corvicted of a drinking-driving offense

Whether he has ever previously had action taken against his license for a drinking-driving offense

Whether he has ever been convicted of any other offense in which intoxication was a major factor (drunk and disorderly, etc.)

Whether he has ever bcen admitted to a medical facility or social institution for treatment as an alcoholic.

- The records of the licensing agency include information on problem drinking collected from the following sources:

The Certifications by applicants in regard to their drinking prohlems described above.

Court records of convictions for drinking-driving offenses. 
Court records of all non-traffic convictions related to the consumption of alcohol (i.e. public drunkenness, drunk and disorderly, etc.)

The records of State and local government medical and social agencies covering the admittance and discharge of individuals treated for alcoholism and alcohol related medical conditions as permitted by law.

Reports from licensed physicians through a provision for alcoholism to be added to the list of diseases which physicians should report to the State licensing agency.

- Based on the records described in 2 above, the driver licensing agency will:

Provide each local enforcement agency with a list of individuals within its jurisdiction who have convictions or reports indicative of problem drinking.

Ensure that all individuals convicted of driving under the juffuence or while inioxicated ate ieportod to the National Driver Register.

Develop proper safeguards for handling this information to ensure the protection of the individuals involved (see section on Traffic Records, Standard 10).

- A Medical Acivisory Board(s) is (are) estatllished to:

Devlop c:: iteria by which the driver licensing agency may determine whether licenses should be issued to applicants with drinking records and under what limitations the driving privilege should be permit ted;

To revie' the application of individuals who have a drinking record, is indicated by information provided to the licensing agency by the applicant himself ax from the sources described ahove and make recommendaticns to the State licensing agency as to whether these individuals should reccive a license and under what limitations; 
To review the record of any licensed driver convicted of a drinking otfense or from whom othcr information indicating a history of problem drinking has been recorded, and make a recommendation to the State licensing agency regarding whether the individual should be permitted to retain his li:cense and under what limitations;

To review the records of drivers whose licenses have been subject to action for drinking offenses, prior to reissuance of licenses to these individuals. The Medical Advisory Board will submit recommendations to the State driver licensing agency as to whether the driving privilege should be restored and under what limitations, if any.

The Nedical Advisory Board should be empowered to require a medical examination by a physician approved by the Medical Advisory Board for any individual whose license or application for license comes before it for review.

- The State Drivers Handbook and the driver licensing examination should inclucie questions on alcohol in relation to highway safety, including but not limited to the following kinds of information:

The relationship of alcohol (particularly alcoholics and problem drinkers) tc accident statistics.

The arnount of alcohol consumption which will impair a person's ability to operate a motor vehicle in safcty.

Traftic Recordis

To ensure the identification to the Motor Vehicle Department of all alcoholics and problem drinkers, a system of reporting of these individuals to the licensing agency has been described under the section on Driving Licensing. To ensure that the se data are available to the courts and enforcement agencies, and that they are properly handled, the Traffic Record System must permit the addition of information relating to problem drinking to the current record system.

To ensure that the program is being effective, and to make modifications and reorientation of the activity as necessary, it will be essential to have an effective system of evaluating the impact of the program ondrinkingdriving accidents. Several different types of data are available for 
evaluating the impact of the program. The ultimate criterion is, of course, a reduction in the number of fatal and serious accidents involving drivers who have significant alcohol blood levels. Arrangements should be made within the State and community to ensure that all fatally injured drivers and, if possible, all drivers involved in serious injury and fatal accidents receive a blood alcohol test. Another method of measuring the program inpact which will be more immediately responsive and sensitive to changes produced by the safety program will be measures made on drivers using the road but not involved in accidents. By stopping drivers at times and at places of fatal or serious injury accidents and requesting their cooperation in taking a breath test anonymously, a measure of the number of drivers exposed to drinking-driving accidents can be made. A decrease in this percentage of intoxicated would give an immediate indication of the impact of the program.

\section{Proposed Countermeasures}

The State should take action to add to the current traffic records systems the following:

- The Driving Recori. Fiovision sicuid be made for storage of the following kinds of data:

Information on driving and non-driving convictions involving alcohol,

Information resulting from reports from social and health agencies, the applicant himself and physicians as provided for in the section on Licensing,

Actions of Medical Review Board,

Such data will be maintained frermanently and will not be erased from the driving record,

Provision will be made for providing a special listing of individuals with this type o: information to the law enforcement agencies of local political subdivisions,

Jrovision will be ma de for protecting the confidentiality of the individuals involved. 
- Vehicle Record. In addition to the information contained on the vehicle record, a provision will be made for a special indication in the section containing the name of the current owner, if the owner or a member of his family residing with the owner has been reported by a physician or a qualified public agency to the licensing agency as having a drinking problem, has been convicted of a drinking offense or is currently under revocation or suspension as a result of a drinking offense.

- Accident Record. In addition to information currently collected, the accident record will include a record of whether chemical tests were made on all fatally injured drivers and adult pedestrians, and surviving drivers of accidents fatal to others, and if the tests were made the blood alcohol levels will be recorded.

- Proride for periodical evaluation of the State and community alcohol safety program. The NHSB will be provided with a summary of the State evaluation.

Poústirián Saféty

A significant portion of traffic fatalities (18 to 20 percent) involve pedestrians. In some cases these result from accidents in which the driver had been drinking, the pedestrian not under the influence of alcohol. This type of accident will be reduced by the countermeasures directed at the driver. About $1 / 4$ to $1 / 3$ of pedestrian fatalities involve children under sixteen where use of alcohol is not a factor. Studies of adult pedestrian fatalities have shown that from 50 to 60 percent have been drinking. Where pedestrian intozication results in an accident, countermeasures are difficult to devise. Intensive programs to locate and put problem drinkers and alcoholics under treatment will help. In contrast to the case of the vehicle operator, it is not possible to restrict the pedestrian from the use of the public roids. Other methods for combating this problem must be found.

Proposed Countermeasures

In order to reduce the number of fatahy injured peciesirians who have been drinking, local communities and, where appropriate, the State should undertake intensive programs to :educe this source of pedestrian injury and death. The following types of actions should be considered: 
- Determination of the locations and times of day of accidents involving adult pedestrians under the jnfluence of alcohol.

- Development of special pedestrian safety programs for areas where accidents involving drinking pedestrians are found to be highest or in areas surrounding drinking establishments. Arnong the possibilities considered should be the following:

Improving street lighting near drinking establishments or in high accident locations.

Reducing speed limits in arcas of drinking establishments,

Using special caution signs in high accident locations, Providing special police patrols

Locit courts arranging for detoxification centers and treatment assistance for pedestrians arrested for public drunkenness or similar offenses.

\section{Police Traffic Service}

The number of drivers who have been drinking varies markedly with time and place. In the evening hours, near to drinking establishments up to 20 percent or more may have measurable blood alcohol levels and up to 4 percent may be legally intoxicated. If the hazard presented by the intoxicated driver is to be reduced, special alcohol safety enforcement efforts must be undertaken. A considerable increase in apprehensions for DWI could be realized in most communiti es by special enforcement at. times and places of 'he greatest drinking and driving. This section calls for the implementation of such programs and for procurement of the specialized equipme.nt, training and manpower such programs will require.

In addition to increased enforcement of drinking driving laws, the police must monitor the druvers in their locality who have had their licenses suspended or revoked for drinking and driving. "'nless such revocations can be enforced, this penalty will become meaningless. Since most problem drinkers can not control their drinking, spezial efforts will be required to control their driving. 


\section{Proposed Countermeasures}

As part of a State and local police traffic services program, there should be a special alcohol safety enforcement capability which shall be given emphasis and priority over other aspects of the traffic safety enforcement system. This capability shall include:

- Assignment of personnel and operating procedures to insure the apprehension of drivers suspocted of alcohol-related offenses specified above; these procedures should include as a minimum:

Use of breath screening tests, as permitted by the Constitution

Special enforcement efforts at times and places where the greatest number of accidents and alcohol-related offenses occur and at frequent intervals in areas surrounding alcoholic beverage establishments, as permitted by the Constitution.

Operating procedures to insure apprehension and surveillance of persons whose driving privileges have becn revoked or restricted as a result of an alcohol-related disability or unfitness to drive.

- Operating procedures to train police officers in the use of breath testing equipment and in other alcohol safety enforcement measures.

Traffic Courts.

Aside from the large number of drinking-driving offenders who come before the courts a sizable portion of crimial offenses also involve drinking. At the present time, most of the problem drinkers among this group will receive fines and short jail sentences and then be released to continue their drinicing pattern and far too frequently return again to the court. It is essential that this revolving pattern be broken and that the recidivism among the drizking offense group be reduce 1 .

The first problem in handling these offende: $\mathrm{s}$ is to distinguish between the "problem ininker" and the individual who is a normal "social drinker" but has, as sccial drinkers do from time to time, gone beyond the bounds of reasonable consumption and been apprehinded and charged with a 
drinking related offense. "Social drinkers" can probably be effectively deterred from repeating the offense by a fine, temporary license revocation and other normal court penalties.

A larger portion of convicted drinking offenders, if not the majority, are "problem drinker $s^{\prime \prime}$ These individuals cen be identified by a presentence investigation and medical examination. Their personal histories frequently include previcus alcohol related offenses, contacts with social and health facilities, medical abnormalitics related to or known to be associated with heavy drinking and other signs. These signs are summarized in Figure 2-6. Once identified, the problem drinker should be referred to a local health facility for treatment for his drinking problem. Participation in the treatment program should be made a condition of his probation. For those with drinking-driving offenses the drivers license should be revoked pending successful treatment of their drinking problem. These individuals should be referred to the driver assistance program described in the section on driver education.

Proposed Colintermeasures

In ordcr to assiat traffic courts and othei judicial budies cuncerned with the adjudication of drinking-driving offenses, local government should ensure that:

- All individuals convicted of driving vihile intoxicated, under the influence of alcohol or other non-traffic alcohol related offenses are required to take a physical examination (including psychological examination) by a court appointed physician and are subject to a pre-sentencing investigation by a court probation officer to determine whetter they are alcoholics or problem drinkers. They are also tc be provided with an opportunity for medical counsel regarding their drinking problem.

- Where facilities are available, provision is made for individuals judged to be alcoholics or problem drinkers to receive treatment in lieu of jail, or fine. To provide maximum opportunity for the drinking driver to over come his problem and to maximize the probability that he wil! not drink and drive, courts may provide for the administration (under medical supervision) of a protective drug such as Antabuse or of a simila. medication. In such cases, provision must be made for supervision of the individual to ensure that he continues to use this medication regularly as a condition of his probation. 
Alcohol In Relation to Highway Safety

Highway Safety Program Standard 8 facilitates the apprehension of these drivers by providing for a chemical test which is more reliable than other methods of detecting intoxication and for "implied consent" statutes which require that individuals charged with driving while intoxicated submit to a chemical test or lose their license. Unfortunatcly, these limited steps have yet to be adopted by the fifty States. Only forty-seven States have chemical test laws and only twenty-six of these provide for definition of intoxication at the 0.10 percent blood alcohol level recommended by the Bureau. Only forty-six States have some form of implied consent law. Compliance by the States with this highway safety program standard must be increased if we are to improve the probability that individuals who are driving while intoxicated will be apprehended. Furthermore, the States will have to increase the funding of their alcohol safety program if they are to ensure that there are sufficient numbers of enforcement officers trained to use chemical tests and that adequate amounts of chemical tests equipment are available to all local enforcement agencies.

The present implied consent legislation is only a parial solution to the problem of detecting the drinking driver, since the individual must fir.st be charged with driving while intoxicated before the implied consent rule goes into effect. The British experiment meritioned earlier is making use of inexpensive breath testers (such as the Alcotest unit as a screening device) for the drinking driver. The Ajcotest unit and a similar device the Mobat Sober Metcr are about the size of a fountain pen and can easily be carried by law enforcement officers. Under the British system, if the driver is suspected by the policeman ox being intoxicated he can take, on the spot, a breath test using this device. If a positive test results he can be taken to the police station for a standard breath or blood test. This system can significantly increase the probability that drivers who are intoxicated will be detected and successfilly prosecuted. The State of New York has recently enacted a law whicis will take effect in September of this year, permitting a similar screeling procedure, based on. pobable cause. It is recommended that Stat a and tocal governments consider legislation similar to that of New Y ork State to provide for chemical screening, tests.

In addition to strengthening the chemical test laws, deterrents to DWI and driving while revoked need to be developed which do not depend upon action through the court system. Fines and license suspension may have some influence on social drinkers. However, beciuse of the present low probability of conviction in the courts, deterrents; to drinking and driving which 
have impact outside of the court system might be useful in reducing the proportion of the fatalities in which this group is involved. The Swedish Alcohol Safety Program cited earlier, provides for cancellation of insurance protection for the driver guilty of driving while intoxicated. This provision is thought to be a significant factor in obtaining compliance with the drinking driving statutes. Thirty percent of the Swedish arrests follow on information provided by the public, many times by wives who apparently feared the financial penalties of their husbands being involved in a crash while intoxicated. States should give consideration to whether automobile policies should be written to exclude protection of the driver guilty of driving while intoxicated, while still protecting the innocent victim of an accident. This type of penalty for LWI might exert a powerful effect on the heavy social drinker, and ensure cooperation of the family in supervising the problem drinker.

\section{Proposed Countermeasures}

In orcer to assist the law enforcement agencies and the courts in the apprehension of drinking drivers and the prosecution and adjudication of drinking-driving offenders, the State and where appropriate local jurisdictions should ensure that:

There is a specification of the following with respect to alcohol-related offenses:

Chemical test procedures for determining blood-alcohol concentrations.

Blood-alcohol concentrations, rot higher than .10 percent by weight, which define the terms "intoxicated," "under the influence," or "while ability to drive is impaired," and

A provision making it unlawful if the blood-alcohol concentration of a driver equals or exceeds .15 percent by weight.

- There is a speficatiun with regard to chemical tests for bloodalcohol ?evel that:

Any person operating a motor veh: cle upon a public highway is dcemed to have given his consent to a chemical test of his blood, breath, or urine for tha purpose of determining 
the alcohol content of his blood, if placed under arrest for driving while intoxicated, while under the influence of alcohol, or while his ability to drive is impaired by the consumption of alcohol.

In addition, any person operating a motor vehicle upon a public highway, who has committed a moving traffic violation or been involved in an accident, and the officer requesting the test has reasonable grounds to believe that such person has consumed alcohol to the extent that his driving ability may have been affected, is cleemed to have given his consent to a "screening" test of his breath to determine the presance of alcohol, and to a subsequent test of his blood, breath, or urine if such prelimina ry breath test indicates the presence of alcohol.

Appropriate action is taken ag inst the driver's license of any person who refuses to submit to any of the tests provided for in $a$. and b. above.

There is a specification by the State that blood-alcohol determinations shall be made on the bodies of all drivers and adult pedestrains who die within four hours of a traffic accident and on all surviving drivers in accidents fatal to others. More thorough autopsics are highly desirable.

- Uniform procedures are established for blood-alcohol determinations by:

Specifying methods and related details of specimen selection, collecticn, handling and analysis of blood, breath and urine collected for blood-alcohol determinations.

Setting procedures for collection of these specimens that shall ensure that they can be rapidly collected in as close continuity as possible to the time and place of apprehension. Options orovided to the suspected drinking-driver shall be limited to ensure that the test is not unduly delayed or avoided.

Sctting standards for the reporting and tabulation of the results of chemical tests and other data related to enforcement of highway s.afety programs. 
- Appropriate qualifications are established for personnel utilized in key activities in alcohol safety programs, specifically:

Personnel who administer chemical tests used to measure alcohol concentration in the blood, breath and urine.

The physicians to serve on Medical Review Boards.

The medical technicians who administrator Antabuse or other drugs as part of traffic court treatment pro. grams.

When an individual whose license has been subject to action as a result of an alcohol related offense is convicted for driving while revoked or suspended, the vehicle which he was driving at the time of his apprehension will be impoinded until his sull driving privilege is restosed. That a similar impound provision exists for an individual arrested for a second alcohol related offense within a three year period.

A progran of public information is designed and implemented to acquaint the driving public with the dangers of drinking and driving, and, in particular, with the hazard presented by proble:n drinkers and alcoholics. This program should provide information on the alcoholism consumption associated with blood alcohol levels. It should provide information on the court procedures and penalties for drinking and driving.

- A driver education and assistance program is devised and - implemented for individuals under treatment by State and local sociill and health facilities for alcoholism or other medical conditions for which excessive use of alcohol is an important part of the syndrome: 
Appropriate qualifications are established for personnel utilizea in key activities in alcohol safety programs, specifically:

Personnel who administer chemical tests used to measure alcohol concentration in the blood, breath and urine.

The physicians to serve on Medical Review Boards.

The medical techricians who administer Antabuse or other drugs as part of traffic court treatment programs.

When an individual whose license has been subject to action as a result of an alcohol related offense is convicted for driving while revoked or suspended, the vehicle which he was driving at the time of his apprehension will be impounded, when permitted by law or The Constitution, until his full driving privilege is restored. That a similar impound provision exists for an individual arrested for a second alcohol related offense within a three year period.

A program of public information is lesigned and implemented to acquaint the driving public with the dangers of drinking and driving, and, in particular, with the hazard presented by problem drinkers and alcoholics. Thi a program should provide information on the alcoholism consumution associated with blood alcohol levels. It should provide information on the court procedures and pestalties for drinking and driving.

A driver education and assistance program is devised and implernented for individuals under treatment by State and local social and health facilities for alcoholism or other medicil conditions for which excessive use of alcohol is an imporiant part of the syndrome. 


\section{FIGURE 5-1}

LIST OF POTENTIAL COUNTERMEASURES TO BE CONSIDERED

BY STATES AND COMMUNITIES PLANNING INTENSIVE ALCOHOL AND HIGHW AY SAFETY CAMPAIGNS

NHSB SAFETY

PROGRAM AREAS

MOTOR VEHICLE

REGISTRATION

\section{ACTIONS AT STATE LEV:EL}

a) Provide for suspension or revocation of license plates of vericles owned by persons who drive while their licenses have been suspended or zevoked for drinking-driving offenses

b) Provide for special tags or registration certificates for vehicles owred by convicted drinking driver who is convicted for driving while their license is suspended or revoked

c) Prohibit the trangfer of vehicles with special registration certificates

d) Provide for certification by the applicant regarding previous arrests and treatment for alcoholism

DRIVER EDUCATION a) Develop mass media public education campaign on alcohol safety

\section{ACTIONS AT COMMUNITY LEVEL}


c) Augment alcohol safety sections of high school driver education programs

d) Add sections on alcohol to primary safety courses and to appropriate secondary courses (family life: courses, etc.)

e) Develop special offenders school driver improvement programs

f) Implement a driver assistance program in cooperation with social and health agencies

ALCOHOL IN RELATION TO HIGHWAY SAFETY

b) Provide for implied consent for chemical tests and screening tests

c) Require license revocation if test is refused

d) Set specifications and procedures for chemical tests

e) Establish qualifications for alcohol safety personnel c) Augment alcohol safety sections of high school driver education programs

d) Add sections on alcohol to primary safety courses and to appropriate secondary courses (family life courses, etc.)

e) Develop special offenders school driver improvement programs

f) Implement a driver assistance program in cooperation with social and health agencies

a) Provide for local ordinance requiring chemical tests and specifying concentrations 


\section{Figure 5-1 (Continued)}

f) Provide for vehicle impounding for driving while revoked or for second DWI conviction within 3 years

g) Provide for cancellation of collision insurance if insured driver has BAL above .10 percent

TRAFFIC RECORDS a) Provide for addition of info: mation on problem drinkers to driver record:

1. Additional information; 2. Permanent storage; 3 . Provision:s of lists to local enforcement agencies: 4. Provision for confidentiality

b) Provide for flagging vehicie record for cars owned by problem drirkers

a) Drorida for inclüina gh chritial test data in accident record

d) Provide for program evaluation
Page 3 of 5

f) Provide for local ordinance permitting vehicle impounding for driving while revoked or for second DWI conviction within 3 years 
a) Provide for surrender of any additional driver's licenses

b) Provide for certification by the applicant regarding previous arrests and treatment for alcoholism

c) Record alcohol-related traffic and other convictions from court records

d) Record contacts with social and health facilities from agency reccrds

e) Provide for reporting of alcoholics by physicians to licensing agency

f) Delay issue of permanent license until record checked

g) Establish Medical Advisory Boards (MAB's) for licensing agency

h) Provide for review of problem drinking drivers by $M A B$

i) Provide for review of convicted DWI drivers by MAB prior to reinstating licenses

j) Empower MAB to require physical exams of drivers whose records they review

k) Include alcohol safety questions in license examination and driver hardbook 
TRAFFIC COURTS

PEDESTRIAN SAFETY

POLICE TRAFFIC SER VICES a) Provide for special enforcement of drinking-driving laws

b) Provide for special training on breath testing equipment a) Require physical examination and pre-sentence investigation of convicted drinking drivers

b) Provide for referral of problem drinkers for treatment

a) Determine locations and times of day of accidents involving drinking pedestrians

b) Develop special pedestrian safety programs in areas of high accident risk or drinking, i.e., (1) better lighting, (2) reduce speed limits, (3) special caution signs, etc.

c) Provide special patrols for intoxicated pedestrians

d) Arrange for detoxification and treatment assistance for pedestrians

a) Provide for special enforcement of drinking-driving laws

b) Provide for special training on breath testing equipment

c) Provide for special surveillance of drivers with revoked permits 
FIgUre 5-2; RELATIONSHIP OF PROGRAM ELEMENTS TO NATIONAL STANDARDS

\begin{tabular}{|c|c|c|c|c|c|c|c|c|c|c|c|c|c|c|c|c|}
\hline & & & & & & & & masitgut: & TESOAROAS & & & & & & & \\
\hline Peverten elements & 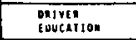 & 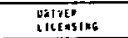 & 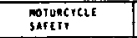 & 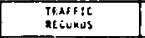 & $\operatorname{sen} \cos a$ & 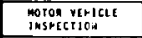 & 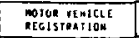 & 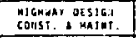 & 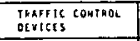 & 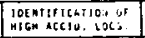 & couts ano lads & 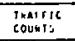 & 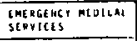 & pestitan & 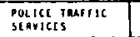 & 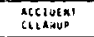 \\
\hline 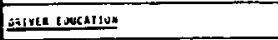 & 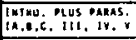 & & & & & & & & & & & & & & & \\
\hline 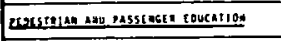 & & & & & & & & & & & & & & ons 10. & & \\
\hline 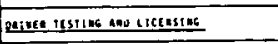 & & 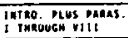 & 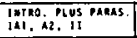 & 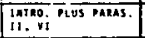 & & & & & & & & & am IIt & man. $y$ & & \\
\hline insentenct morcat stevicet & & & & & mana. 111 & & & & & & & & $\mathrm{su}$ & nees. $11 ., \mathrm{F}$ & Pasm. II & pasa. in \\
\hline 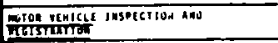 & & & 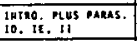 & 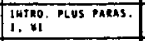 & & \begin{tabular}{|l|} 
Intropo pus panas. \\
1.11
\end{tabular} & 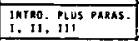 & & & & & & & & & \\
\hline 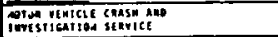 & & & & & & & & & & & & & & & & man. $1 \mathrm{ML}$ \\
\hline 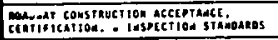 & & & & & & & & $\begin{array}{l}\text { lathe pus papas. } \\
\text { ti i1 }\end{array}$ & 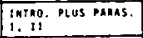 & & & & & 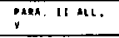 & & \\
\hline Suronctiment & & & 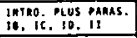 & & 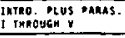 & & & FhaA. If. . A & $\sin \cdot 10$ & & & & & nans. .... & 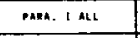 & pana. in \\
\hline 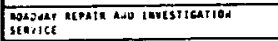 & & & & 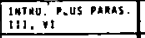 & & & & mese. 18. . & & & & & & & & \\
\hline 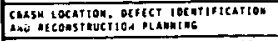 & & & & & & & & Pese 1E. C.1 & mean in & 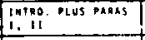 & & & & mase. & m.n. n., & \\
\hline 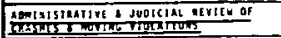 & & max. y & & & mase a & & & & & & & 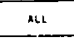 & & & & \\
\hline 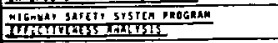 & mats. & Paras. VI. MII & $\operatorname{man.} \|$ & pasa. an & menses. Ire. V & 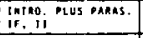 & 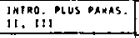 & 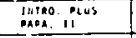 & Basen. It. 11 & PARA 11 & & & $\operatorname{sane} 111$ & $\operatorname{sens}, v 3$ & Pans. 19.0.6. & maen. II \\
\hline 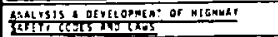 & & & & & & & & & & & ati & & & ....... & & \\
\hline 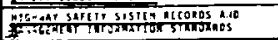 & & & & 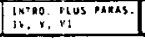 & & 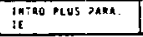 & 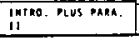 & & piatat is & & & $\because \because 8 \mathrm{x}$ & & sane - & B.tat 10. L. . & \\
\hline
\end{tabular}


Figur:e 5 - 3

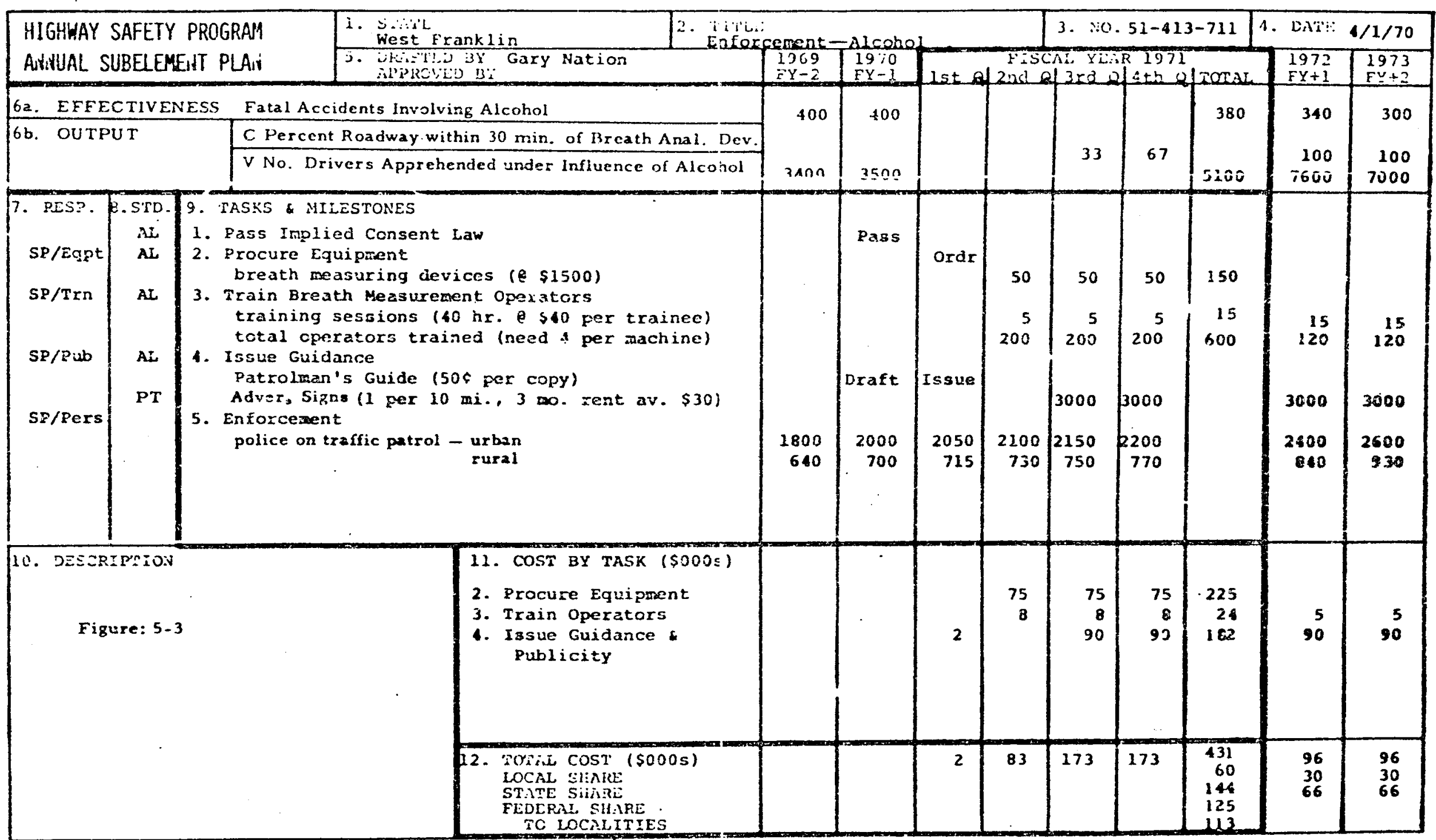




\title{
SECTION VI
}

\author{
PLAN FOR PUBLIC EDUCATION \\ AND MANPOWER DEVELOPMENT PROGRAM
}

\section{A. OVER VIEW}

The Department of Transportation's National Highway Safety Bureau is preparing to launch an entirely new and comprehensive attack on the problem of alcohol as it relates to highway safety.

The new approach is based on these facts: 1) approximately 30,000 auto crash fatalities involve the use of alcohol and 2) a relatively small number of drivers, those who habitually consume large quantities of alcohol, the problem drinkers, are responsible for the majority of these alcohol-related fatalities. These are facts derived from extensive research.

The foremost oljective of the National Highway Safety Bureau's alcohol safety program is to keep the problem drinker off the road. To accomplish this, methods must be found to:

1. identify and locate the problem drinker who drives

2. formulate appropriate measures, medical, social, and judicial, to deal with him.

A secondary program objective is to deter other types of occasional abusive drinking, drivers, especially in the under twenty-five age group, who also pose a highway risk. Whether the National Highway Safety Bureau's object:ves can be met is largely dependent upon the ability to obtain widespread public support. With the backing of the public, support can be cibtained from professional pex sonnel working in law enforcement, the judiciary, motor vehicle departments, education and other technical areas related to highway safei.y.

The required public education campaign must be in sharp contrast to past efforts in order to point out the dimensicns of the alcohol/highway safety problem and to distinguish between the social drinkers, who comprise approximately three-fourths of our driving population, and the problem drinkers, who we now know are major contributors to highway crash injuries and fatalities. 
The very essence of the program, and any hope of achieving results, is grounded on the success of a public education campaign. The public must understand the scope of the problem, and accept the target at which the program is aimed. Only then can there be hope of obtaining the support necessary to pass the necessary legislation, Fedcral, State, and local, and to obtain the tough law enforcement which will ensure the program's success.

This section describes the three major elements of this national education campaign: public education, community support, and manpower training and development.

\section{B. NATIONAL PUBLIC EDUCATION PROGRAM}

The National Public Education Program must be based on the facts described in Section II of this document, and must be designed to support the program concept described in Section III. To obtain this understanding and support, the public education program must accomplish four goals:

Develcp an Understanding by the Public of Theis Own Liquor Consumption levels in Relation to Blood Alcohol Measurements

Approximately three-quarters of the American prablic drink alcoholic beverages to some extent. The majority of these also drive. While any amount of alcohol reduces human performance capabilities, the probability of being involved in an accident does not increase significantly until approximately the .05 percent blood alcohol level. (See figure 6-1) Above .05 percent the probability of reing involved in an accident begins to increase and rises sharply after the .10 percent level. The NHSB has defined this level in its Highway Safety Standard 8 ("Alcohol in Relavion to Highway Safety") as being indicative of intoxication. Individuals who drive with blood alcohol levels above. 15 percent represent an especially high risk group. A: shown in figure 6-1, this requires such a heavy consumption of alcohcl that it is highly probable that the indiv dual has a drinking problem. A first requirement of the NHSB Alcohcl Countcrmeasures program will be to have the public come to understand figure 6-1 and its significance for them as drinkers and as drivers.

Until the recent advent of quantitative methods o: measuring blood alcohol level, the rzethods of determining the ex:ent of intoxication were inadequate and unreliable. Studies have shown that even trained 
professional, such as physicians, vary greatly in their judgments as to whether an individual is intoxicated. The public in general equated intoxication with certain standard behavioral signs such as staggering gait, slurred speech and euphoric behavior. It is well known, however, that many individuals can drink heavily without showing any of these signs to a marked extent. For the individual himself, detection of the level of intoxicction is generally even more difficult. Symptoms such as dizziness and slurred speech may be noticed by the driniker himself, but since one of the major effects of alcohol is to increase the individual's feeling of confidence in his own capabilitics and general feeling of well-being, the drinker often underestimates the extent of his inebriation. In any case, the symptoms sensible to the individual, or observable by others, are not necessarily completely corrclated with either the level of blood alcohol or decrement in the critical skills or attitudes that may be related to highway accidents. Finally, the specific behavioral patterns of the individuals may vary, some becoming sleepy and actually passing out under alcohol, while others reverse the normal pattern of increased happiness and elation and become sad, "unhappy" drunks.

The inadequacy of these behavioral signs for judging levels of intoxication is further complicated by social pressures. On the one hand, use of alcohol in condoned as a method for enlivening a party. Behavioral signs of drinkirg such as gaiety and hilarity are sanctioned by society. On the other hand, drunkenness is seen as a symptom of weakness and lack of manliness as in the "inability to hold one's liquor." Thus, while there is pressure at social gatherings for the individual to drink at least to the point where many inhibitions are lost, there is a need for the drinker himself to deny intoxication or erren impairment lest it appear that he cannot "hold his liquor."

The emphasis upon determining intoxication through bchavioral signs tends to be self-defeating, not only because the signs themselves are too unreliable to provide an adequate measure of level of intoxication but because the social pressures surrounding drinking require that many of these signs be denied by the drinker. Social practice also requires that his friends and the party host ceny those signs since it is not considered good form to imply that someone is "drunk." Potentially the use of chemical tests of blood alcohol provide a method of avoiding this problem, since they permit substitution of an objective, quantitative test for subjective behavioral signs. The anount of alcohol in the blood is a relatively direct function of the amount of alcohol ingested. This measure is not affected by the experience of the drinker. Rather it is a function of his weight and whether he has eaten. If legal and social sanctions are based on this objective measure, rather than on a 
subjective cvaluation of behavior, jt may be possible to reduce the social pressures bcth on crevconsumption of alcohos, and derial of intoxication.

Thus, for example the drinker need not achmit to any of the behavioral conscruences of intoxication. He need not admit that he is "drunk" in order to agrec to sumcone "lse driving the vehicli iome or in urder to turn down a final drink. 'The individual who "lolls his liquor well" can maintain this position even though agreeing that his blood alcuhol Ievel may be high. If cin deny the unacceptable social brhavior of being "drunk, "while adritting 10 the physiological status of having too high c. blood alcohol level. "The party host need not give the imupession that nis guest is exhibitng the maicsirable social behavior of being "drunk" if he suggests that they switch to coflee to avoid the physiological state of too high a BAI. The drinker can decide to let his wife drive home, because in doing so he need not admit to the undesirable social state of being "drunk," but only to the more neutral state of having a high BAL which would make him subject to arrest if he drivis.

Develop an Understanding by the Jublic that Problom Drinkers Account for the Major iortion of Highway Fatalicics Iue to Alcohol

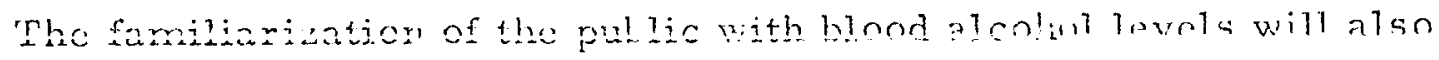
assist in making ihe public aware that the indivichals who a re currently involved in fatal accidents and convicted of drinking and driving offenses have been drinking amounts of alcohol which are gencrally wril beyond those normally cossumed by the average social drinker in the United States. Many of the drinking adults in this country resist stricter drinking-driving laus because they. assume that the individuals who are bcing arrested and charged with the drinking-driving offunse have bcen drinking to the sarre extent that they do at parties. Thus the individual who feels slightly "high" after two or three drinks reaches a blood alcohol level of $.0 E$ percent to .07 percent and assumes that the individuals charged with drinking-driving offenses have consumed a similar amount of alcohol. To him, these drinking drivess are just unlucky. "There but for the grace of God go I," the average social drinker says to himself. As is vell clocumented by rescarch studics, BAL's of fatally injurcd drivers and convicted drinking drivers are well above this level. (A recent study of convicted DWI Drivers in Oregon indicated an average BAJ, of . 21 percent) If the public can be made aware of the blood alcohol lo vels that they obtain during ticir normal social drinking, they will come to understand that the rnajor portion of the highway fatality pr sblem involves individuals who have a drinking problem. 
Develop an Understanding by the Public of the NHSB Alcohol Safety Progran

Once the public understands the meaning of blood alcohol measurements and the fact that most highway fatalities due to alcohol are produced by problem drinkers, they will be ready to support the need for an action program. At this point the alcohol safety program developed by the National Highway Safety Bureau (Section III) will need to be presented to the public together with a specific understanding of the ways in which they can support the program. The public should be made aware that all too frequently in the past efforts to reduce fatalities due to drinking and driving have been impeded by lack of pullic support. The public will need to be informed on where and how its interest can be most effectively expressed. Overall, the purpose of this third area of the public information program must be to mobilize the public in support of the NHSB National Alcohol and Highway Safety Program.

Develop an Understanding, by Young Drivers, of How to Avoid Problem Drinking and Driving

The public should come to recognize the eariy signs that drinking is taking an abnormal, excessive character and when this excessive drink-

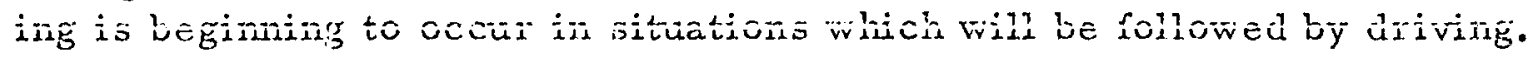
Improving the public's understanding of the symptoms of problem drinking will probably not produce a behavioral change in confirmed problem drinkers. It may be possible, however, to influence those who surround the problem drinker to take action to get him into treatment and to keep him off the road. It is important that the influence of family and associates be brought to bear during the early stages of the development of the disease, since the possibility of arrestirg a drinking problem is greatest during, this time. A key symptom cf problem drinking is denial. Since alcoholism is a socially condemned disease (as compared to heart disease or cancer), the individual himself ald frequently his friends and family go to some length to hide the fact that he has a drinking problem. While it may not be possible to overcome the individual's own denial, it should be poss:ble to convince family and friends that protecting the incipient problem drinker will only allow hirn to continue to get worse. Instead the farrily should use its influence tc begin to get the problem drinker into triatment and, importantly fror. the point of view of highway safety, the:y may help ensure that the problem drinker is not driving during times when he is drinking. 
While it appears unlikely that the problem driver can be stopped from drinking by a mass media compaign, there is somc rcason to hope that young drinking drivers can be given information which will alert them to the early signs that they are developing a drinking problem. At this stage in the development of a drinking problem it may well be possible for the individual to alter his course and to avoid developing the habit. To achieve this will require changing the all too prevalent attitude that heavy drinking is a "manly," desirable attribute. Rather, excessive drinking must be seen by the young driver as "sick" behavior indicating that the individual has some sort of "hang up." The one successful countermeasure piogram within the United States by Barmack and Payne at Lackland Air Force Base in San Antonio, Texas, was modeled on this concept. Excessive drinking was labeled as "sick behavior, "and individuals apprehended drinking and driving were given medical and psychiatric examinations. The effect of the campaign was to significantly reduce the number of highway accidents involving base personnel. An equally effective program may not be possiblc within a civilian environment since the coercive effect of military disciplinc is not available in the civilian domain. Nevertheless, the public education portion of this Air Force campaign suggests an effective formula for use with young people.

\section{COMMUNITY SUPPORT PROGRAM}

The National Public Education Program described in the preceding section will 1 ay the basis for action at the community level. As the public comes to understand better the role of the problem drinker in highway fatalities they will be prepared to support local action programs. To initiate these programs a number of materials will need to be developed at the national level. The purpose of the NHSB community support program wlll be to ensure that the speaker kits, movies, pamphlets and other promotional and educational materials, wich local communities will require to get their action programs undervay, are available to them. This program will be divided into four niajor areas (figure 6-2).

Materials for use by Local Community Leaders in Developing Action Programs.

These materials will include speaker kits, mov..es, slide presentations, pamphlets and other education materials which speakers can use with local service grouos to develop interest at the community level in undertaking action programs. These materials will ke developed by the National Highway Siafety Bureau through contracts. They will be reproduced in sufficient numbers to be distributed to the NHSB regional offices 
and to the local and State Office of Alcohol Safety representatives. They will also be distributed to the public through supporting organizations and agencies.

\section{Public School Education Program}

The majority of young drivers receive driver education as part of their high school program. Since young drivers are the most rapidly growing segment of the driving population (and the most dangerous), there is an unusual opportunity to advance the alcohol safety program through these education programs. Unfortunately, current driver education programs have relatively little material dealing with alcohol safety and with the attitudes of young drivers toward drinking and driving. Materials will be developed by the National Highway Safety Bureau to augment and strengthen these driver education programs so that emphasis can be given to this critical problem.

High school dr:ver education however presents only one opportunity for reaching the young driver. An even more significant impact may be obtainable through primary school safety education programs. To date, very little safety education is provided in puimary schools. Writietis provided is not well integrated but is rather in scattered, unorganized segments. The National Highway Safety Bureau has been working together with the National Education Association and the U.S. Office of Education to plan anu develop an integrated primary and secondary school safety program which would deal with all areas of safety, with a major focus being on drinking and driving. In this program it may be possible to achieve some impact upon parental drinking through the children. In any case, it may be possible to condition attitudes about drinking and driving prior to the time that drinking and/or driving becomes a proklem at the high school level. The materials developed in these two areas would be distributed to public and private schools through the facilities of the Office of Education, the National Education Association, and the American Driver Training and Safety Education Association. If good, integrated and meaningful material can be developed, it should be possible to implement effective primary education programs in most communities in the United States.

Support Activities Through Voluntary Organizations.

National volunticy organizations such as the Pilots Club, the Boy Scouts, the Rotiry, Alcoholics Anonymous, and professional societies such as the Amirican Medical Association, the American Psychiatric 
Association, the American Psychological Association, the Mental Health Association and others can be a means of developing local support for action programs. These organizations and professional societies have local chapters which could effectively take the lead in developing local alcohol action programs and in distributing alcohol safety education materials. The NHSB will take action to bring these groups into its community support program and to actively enlist their help in disseminating information and in organizing local groups to support alcohol action programs.

Governmertal Agency Support

The Veterans Administration, the Public Health Service, the Department of Housing and Urban Development and others which have establishments in local communities can be helpful in disseminating alcohol safety information and in supporting local organizations in the development of alcohol safety programs. State agencies such as the Motor Vehicle departments, the State police, and State mental health agencies, can also play an important and significant role ir. supporting community programs. The NFSB already has an effective system of contact with these State agencics thrnigh the Governor's highway safety representative. Through these representatives and the State agencies, materials and support can be channeled to local communities to aid them in developing comprehensive alcohol safety programs.

\section{MANPOWER DGVELOPMENT PROGRAMS}

Once the public has been mobilized on a national and community basis, it will be necessary to provide those active in the safety program at the community level with the technical knowledge required to carry out the alcohol safety program envisaged by the National Highway Safety Bureau. A critical need will exist almost immediately for community program managers. They must have the necessi.ry understanding of the results of current research on alcohol and highway safety and the many ramifications of the countermeasures program.

Project managers are only the beginning, however. Overall, 41 types of manpower specialists have been identified. Initially, many of these will, of necessity, je trained on the jobs, developing their skills as the demonstration frogram proceeds. Unless th: community action programs are to be significantly delayed, however, the Bureau will be $r$ equired to take on an intensive manpower training program in order to as sure the availatidity, at the local level, of sufficient personnel to carry out the proposed cointermeasure programs. Since many of those in 
need of specialized training are individuals who already are heavily involved in safety activity at senior levels, such as judges and prosecutors, motor vehicle department administrators, driver educators, probation officers, and others, training will have to be provided on an after-hour basis. Further, to hold the jnterest of these high level personnel, the courses must be well designed. They must also be carefully documented to ensure their acceptance by the specialists for whom they are intended.

Analysis of available information has produced a preliminary forecast of the manpower development requirements associated with the alcohol safety program contemplated by the National Highway Safety Bureau. Twelve (12) manpower development products or functions which are pertinent to the development of alcohol safety manning and personnel performance, and forty-one (41) types of manfower have been identified.

The manpower development functions are identified by the specific product which will be required. These items are as follows:

1. Manuals and operational guidebooks

2. Instructor training materials

3. Personnel training materials

4. Instructor training

5. Instructor employment

6. Instructional $f$ acilities and equipment

7. Personnel training

8. Training evaluation guides

9. Communications and announcenents

10. Conferences

11. Research and training grants

12. Special education and training devices and technology, including team training 
The types of manpower which have been identified are listed below, classified under four general headings.

Staff of Model Alcohol Project

1. Project manager

2. Technical director

3. Mannower development and planner

4. Public information and public support specialist

5. Research specialist

6. Field representative

7. Project advisory group

8. Lo:al government officials

\section{Special Prograr.2 Participants}

9. Court probation officer

10. Law enforcement specialist

11. Alcohol treatment personnel

12. Health personnel and physicians

13. Ccunselors for problem drinkers

14. Alternate transportation personnel

15. Alcohol test technician

16. Alcohol test expert, lab technician

17. Alcohol expert, physician

18. Duiver trainers and educators for drinking drivers 


\section{Established Community Participants}

19. Juclges

20. Prosecutors

21. Driver License Examiners

22. Police

23. Rescue, Fire, EMS

24. Motor vehicle registration and administration officials

25. Purveyors of alcoholic beverages, representatives and a6sociations

26. Alcoholic beverages distribution control officials

27. Social services, social welfare agents

28. Driver educators and trainers

29. Correctional agencies personncl

30. Traffic court administrators

Responsible and Involved Groups and Interests

31. Parents, legal guardians, and custodians

32. Alcoholics Anonymous

33. Salvation Army

34. Er.zployers

35. Urions

36. In:surers 
37. WCTU

38. Church leaders

39. Lawyers

40. Other professions

41. Other voluntary organizations

\section{Funding Requirements}

The funding requirements for Public Education and Manpower Development are summarized in Figure 6-3. The Nationa1 Public iducation effort will be initiated during the current year and run as a major effort for a three year period. The funds indicated are to develop materials for use by the media in public service space or in paid ads donated by private groups such as the insurance industry. None of these funds will be used to purchase TV time or periodical space.

Both the Community Support and Manpower Development Programs will grow rapidly, slightly in advance of the ASAP programs in order: to provide support to local communities in these countemeasure efforts. Activity in these areas will dip as the ASAP projects phase out, and then build up slightly again as the states take on the main burden of alcohol countermeasures activity, thereby creating new manpower needs. 


\section{Figure 6-1 \\ DRINKING AND HIGHWAY SAFETY}

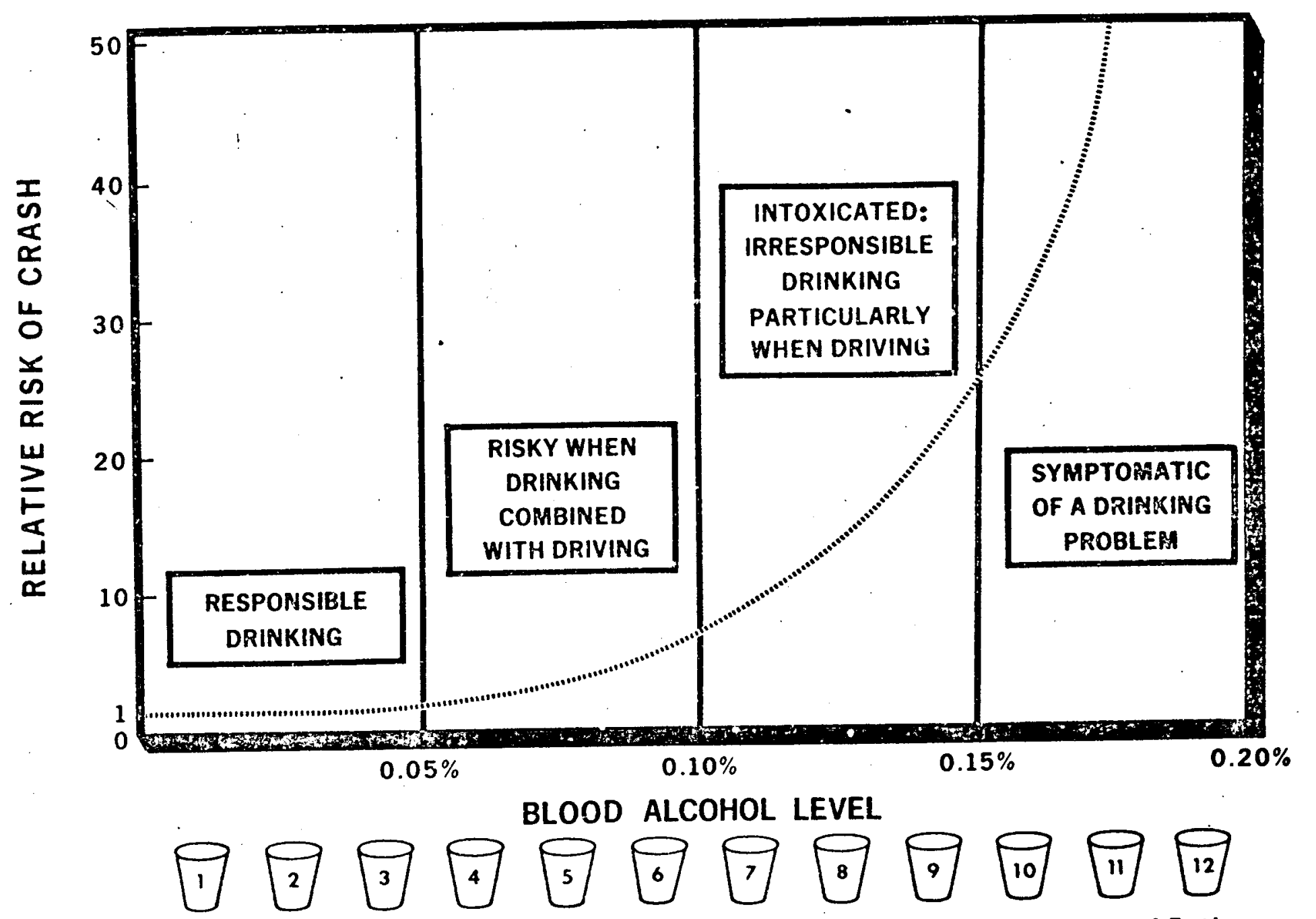

Number of $1 \mathrm{oz}$. Drinks of 86 Proof Whiskey For $160 \mathrm{lb}$. Man Within 2 Hours of Eating 
Figure 6-2

Community Support Program

1. Speaker Kits, Movies, Slides, Pamphlets

2. Public School Educational Programs

Driver Education

Primary and Secondary Schools

3. Work Th:ough National Offices of Voluntary Organizations to Local Communities

Pilots Clubs American Automobile Association

Boy Scouts American Fetroleum Institute

Alcoholics Anonymous Insurance Companies

AMA National Student Club Organizations (4-. DECA, VICA, etc.)

ADTSEA NEA

4. Governmental Agency Support

Licen:iing - Motor Vehicle Departments

HUD

Public Health Service

NIMH

Office of Education, HEW 


\section{Figure 6-3}

Public Education and Nanpower Development

Funding Requirements

(In Thousands)

FY 70 FY 71 FY 72 FY 73 FY 74 FY 75* FY 76*

\begin{tabular}{|c|c|c|c|c|c|c|c|}
\hline Program. & & 250 & 1500 & 1500 & 1500 & & \\
\hline Community Support Program & & 50 & 300 & 200 & 200 & 100 & 300 \\
\hline Manpower Development Program & 100 & 300 & 2000 & 1400 & 1400 & & 500 \\
\hline Total & 100 & 600 & 3800 & 3100 & 3100 & 100 & 800 \\
\hline
\end{tabular}

*Activities in support of ASAP programs will end with the exception of a small ongoing effort in community support by the end of FY 74. There will be a small new activity initiated in FY 76 in support of local activities as the states take over responsibility for these programs. 


\section{SECTION VII}

\section{A THREE YEAR PLAN FOR THE \\ RESEARCH AND DEVELOPMENT PROGRAM \\ IN ALCOHOL SAFETY}

\section{A. OVER VIEW}

The research and development program in alcohol and highway safety has the following major objectives:

- Programs designed to increase understanding of the nature of the relationship between misuse of alcohol/ drugs and highway safety. This new information will be used to formulate or modify countermeasure programs.

- Programs for manuals embodying the best available techniques in enforcement, court programs and retraining of problem drinkers for use by States and communities.

- Programis designed to produce improved systems for detecting; the presence of alcohol and drugs in the driver, improved protective drugs for drinking drivers, and new interlocli devices for preventing operation of vehicles by intoxicated drivers.

- Evaluation programs designed to devise improved methodology for determining the effectiveness of mass media and community alcohol s:afety programs.

The current state of the art in knowledge and techniques for application to safety programs is limited but growing rapidly. Research in the recent past has bien devoted primarily to establishing the relationship between alcohol and highway fatalities, with emphasis on the role of the problem drinker. During the current year (FI 1970), and at an accelerating pace in future years, research and development activities will focus on countermeasure procedures. The program presented in this document outlines the plan :o develop over the next three to four years a battery of weapons to be used by communities in coming :o grips with the alcohol and highway safety problem. While some applyed research remains to be done, particul arly in identifying and developing improved retraining 
techniques for problem drir: ers, the majority of the funding for $R \& D$ will be concentrated in advanced development and technology. The emphasis in these areas will be in producing packages of materials or mechanisms which are ready to be tried out in the field, either in demonstration projects or by the States in their safety programs. The major program areas under each of the $R \& D$ activities are summarized followirg this section.

\section{B. RESEARCH}

1. Introduction: Summary of Current Alcohol Research

Research sponsored by the NHSB in alcohol safety can be divided into three major areas: (a) determination of the relationship between alcohol and fatal and serious accidents; (b) characteristics of individuals who become involved in drinking-driving accidents, . i. e., of diagnosis of the problem drinker who drives; and (c) development of countermeasures directed at reducing drinkingdriving accidents. Each of these major ireas is reviewed below together with a brief summary of research currently underway.

2. The Relationship of Drinking to Fatal and Serious Injury Accidents

The large amount of data bearing on the relationship between use of alcohol and highway safety is well summarized in the October 1968 report of the Secretary of Iransportation to the Congress on "Alcohol in Relation to High'Nay Safety." This report indicates that upwar $s$ of 50 percent of all fatal accidents involved drivers who had been using alco.rol and that of these drivers whc had been drinking, a large portion had alcohol levels which could only have been obtained by such excessive drinking that they could be characterized as "problem drinkers." The report provided a good experimental basis for moving on to the next 1.wo steps in research on methods of reducing accidents involving alcohol. First, how can we recognize problem drinkers, and second, what countermeasures can we take to reduce their accident involvement? Most of the research since the formation of the Bureitu has dealt with these latter wo questions, since it was felt that research conducted prior to the formation of the Bureau established the basic facts regarding the involvement 
of the problem drinker in highway accidents. However, as a bi-product to the current research efforts, additional information, confirming the results of the DOT report, has been gathered. Studies at the University of Vermont, for example, have been consistent with those of Haddon and Brandis, and Neilson and others in showing over half of drivers responsible for fatal accidents had been drinking, and that 40 percent had BAL's over .10 percent as compared to only 2 percent of drivers using the road at times and places of fatal accidents.

3. Development of Diagnostic Procedures: Characteristics of Drivers in Fatal Accidents Involving Alcohol

Three major studies are currently in progress to determine the relationship between individual characteristics and the probability of envolvement in a serious or fatal accident involving alcohol. All three of these studies are utilizing similar methods, although they are studying different kinds of populations. Basically the method involves collecting data on drivers in fatal accidents. These data are compared with similar ineasurements on drivers who have not been in accidents to deternine which characteristics of the individuals are likely to he predictire of accident involrement. Those three studies, at the Uriversity of Southern California, the University of Michigan, and the University of Vermont, are briefly described below.

Universicy of Souther: $n$ California (FH-11-7099, \$450,000, 3 Years): USC is comparing drivers involved in fatal accidents who have and have not been drinking, with those in two other populations; individuals chosen at random from applicants for drivers licenses, and individuals who have been convicted of driving while intoxicatec (DWI). They are comparing these groups on such factors as age, sex, socio-economic status, previous offenses, etc. In order to deterrine how individuals with a high risk of envolvement in fatal accidents can be identified, they are also experimenting with varying methods of retraining convicted drinking drivers. 
University of Michigan (FH-11-7129, $\$ 100,000,1$ Year): HSRI is comparing drinking drivers involved in tatal accidents with DWI offenders, and with a group of alcoholics selected from a local public hospital. They are making similar comparisons to USC. In Addition they have undertaken the development of two specific diagnostic devices: the first of these is the "MAST" interview protocol developed by Dr. Seltzer. This device is intended for use by an interviewer to structure his questions in such a way that the probability that the individual being interviewed as a problem drinker can be assessed. A second device being developed at the University of Michigan is a psychological questionnaire with items not directly related to alcohol, but measuring personality characteristics which are correlated with problem drinking. This device is intended for use by physicians as one element of the medical examination directed at determining whether the individual referred by the court is a "social" or a "problem" drinker.

University of Vermont (FH-11-6899, $\$ 300,000,3$ Years): ABETS has been comparing drinking drivers who have been in fatal or serious accidents with individuals stopped at roadblocks at points where fatal accidents have occurred. The $y$ have also been comparing the se two groups with individuals convicted of DWI offenses. Like USC and HSRI they will compare their three groups on all of the background personality variables which they have recorded. In addition to biographical varicubles they have invited a portion of each of their groups in for laboratory tests which will provide additional data to help identify drivers likely to be involved in fatal accidents.

4. Countermeasures Research

Three progrems are underway specifically directed at devcloping procedures $f_{i} r$ handling problem drinkers and reducing the ir accident involvement and the amount of recidivism among DWI offenders:

University of Southern California (FH-11-"099, sec above): As a portion of the previously described study at USC, a program for treating convicted DWI drivers is bein! developed. This program involves several different treatments which will be compared in terms of their effectiveness in reducing recidivism and accident rates. The treatment involves referral to an 
alcoholism center or A.A., problem oriented and traditional group therapy, and an educational approach consisting of lectures and films. A for th group will receive no treatment and will act as a control for the effectiveness of the others.

Travelers Research Institute (FH-11-6923, \$138,000, 3 Years): The Travelers Research Institute has a program underway in Denver directed at evaluating various penalty and treatment procedures for DWI offenders. Their procedures include the following: (a) fines; (b) conventional probation; and (c) therapeutic treatment. The therapeutic treatment program is subdivided into four different activities: a course on alcohol problems run at a local or State college; out-patient treatment for alcoholism at the Denver General Hospital; in-patient treatment at the Fort Logan Mental Hospital; and finally an alcohol-treatment-release program through the Denver County Jail. Each of these procedures will be evaluated in terms of its effect on recidivism and accident reduction.

University of California, Los Angeles (FH-11-7305, \$100,000, 1 Year): At ITTE, a more basic research program is currently being conducted aimed at determining ihe differences in driving performance between drinking drivers who do and do not get involved in accidents. Based on a questionnaire two groups of heavy drinkers have been selected. One group includes individuals who have accidents and DWI offenses, the other includes drivers with clear records. The se two groups will be studied, drunk and sober, while driving the UCLA simulator and while taking a number of laboratory tests. These measures are designed to determine what factors differentiate between those whose drinking seems to interfere with their driving, and those who have clear driving records.

5. Future Research

Major activities in the near term applied research program will be directed to the development of new raethods for identifying and handling problem drinkers.

Identifying Problem Drinkers: The data given in the DOT report to the Congress on alcohol and highway safety, clearly indicated that a larke number of the drivers at fault in fatal accidents have high blood alcohol levels (.15 percent). This level appears to be 
well beyond that associated with normal social drinking. Can the se individuals therefore be classified as problem drinkers? There appears to be good basis for doing this since a number of the se drivers also show other evidence of problem drinking such as previous alcohol-related arrests. The evidence for this relationship needs to be extended, however, in order to determine whether "social drinkers" who give no evidence of "problem drinking" reach the levels as high as .15 percent with any frequency. Because blood alcohol level is an objective, quantifiable measurement in contrast to those subjective psychological symptoms normally used to diagnose problem drinking, it can become a valuable tool for law enforcement if we can establish its relationship to problem drinking with greater precision. During FY 1971, research programs will be initiated to relate blood alcohol levels more closely to traditional signs of problem drinking and alcoholism.

\section{DEVELOPMEN}

1. Training Programs for Problem Drinkers

In addition to better identification of problem arinkers through blood alcohol measures and other techniques, driver improvement courses are needed which will be effective with problem drinkers. Most States have driver improvement programs, but most of these focus on traffic law and on safe driving rather than on alcohol safety. Few have any extensive treatment of drinking problems or the relationship of alcohol to highway accidents. There is at present no driver improvement program known to be effective with problem drinkers. Programs initiated during the current year will atiempt to develop such training procedures. This training will have to focus, not only on driving skills, but on drinking habits and on the attitudes of the driver to both his driving and drinking. If effective programs can be developed then these zan be utilized not only with convicted drinking drivers, but with $d r$ :vers who enter the improverient program because of other traffic situations. Some of these individuals may also have drinking problems, but have not come to the attention of the courts through a crinking-driving arrest. 
2. Manuals and Informational Material

Programs to support the alcohol demonstration projects and community programs consist of the sollowing:

The development of manuals for use by enforcement and court personnel in comprehensive community action projects and for distribution through the facilities of the NHSB Traffic Safety Programs

The development of materials for mass media programs to familiarize the public with the role of alcohol in fatal accidents and to help them to better understand their own drinking behavior.

A number of special manuals and course materials will be developed for application in the field. In dealing with the public, two main objectives need to be met. Individuals need to learn what blood alcohol levels mean. And secondly, the public needs to come to understand the nature of ?roblem drinking, its relation to highway fatalities and the requirements for handling problem drinkers. Understanding aicobol and how to handle it should begin before the age at which drinking begins and needs to be part of a primary and secondary safety education program. A particularly significant need is for an effective program for dealing with young drivers who are generilly learning to drink as well as learning to drive. They represent a special hazard for this reason.

\section{TECHNOLGIGY}

A number of posisibilities exist for applying technology to the problem of apprehending drunk drivers and controlling the driving and/or drinking activity of known problem drinkers. These include:

The de'relopment of "sniffer devices": techniques developed by industry under contracts to the Defense Department for chemical and bacteriological warfare hold promise for the development of a set of remote sensirs which would detect the presence of substantial amounts of alcohol in the driver without his being required to provide a sample of blood or breath. This would probably avoid the Constitutional questions raised by the British Screening System and greatly increase the probab:lity of apprehending drinking drivers on the road. 
The development of devices to control ciriving by problem drinkers: the emphasis in the past has been upon rescinding the license of drinking-driving offenders without an adequate attempt to enforce this driving restriction. New technology may provide both the means for enforcing the license restriction and new means, via protective drugs and vehicle interlock devices, for controlling the drinking and driving of problem drinkers.

A longer range possibility, which is questionable at this time as a practical technological program area, is development of roadside detection devices to detect the erratic behavior of vehicles produced by drunken drivers from the roadside, thereby increasing the number of drinking drivers apprehended, and development of other electronic devices to detect the driver who is driving without a license. Pending further development and, if indicated, field testing, these devices are under deferred consideration.

\section{E. EVALUATION}

The plans for significant increases in funding for ASAP projects and 402 programs in alcohol safety will greatly increase the need for effective means of evaluating the impact of these programs in reducing highway crashes and injuries due to alcohol. The evaluetion procedures must not only be adequate to indicate the overall effectiveness of a given community's program, but also to provide information on the effectiveness of individual segments of the program. Information on specific components of the program is required by the program manzger so he can modify the elements of his project to maximize its overall effectiveness. New evaluation procedures will be developed and put together in the form of manuals which car be used by program dircctors in the ficld. In addition, there will be a recuirement for techniques and liejd test programs to evaluate the new devices developed in the technology program and to continuously evaluate and revise the education and mass media programs. 
FIGURE $7-1$

OVERALI OBJECTIVES OF THE RESEARCH AND DEVELOPMENT PROGRAM

IN ALCOHOL SAFETY

\section{- $\quad \underline{\text { Research }}$}

Identification of Characteristics of Problem Drinkers

Retraining Techniques for Problem Drinkers

Role of Drugs and Drugs in Combination with Alcohol in Accidents

- Program Material

Specialized Enforcement Techniques and Manuals

Court Techniques and Manuais for Handling DWI Cases

Safety Education Course Materials

Mass Media Materials

- $\quad$ New Devices

Alcohol and Drug Sensors

Protective Drugs

Vehicle Interlock Devices

- Evaluat:on

Procedures for Evaluating Community Programs

Evaluation of Overall NHSB Alcohol Safety Program

Evaluation of Mass Media Materials 


\section{ESTIMATED FUNDING}

RESEARCH AND DEVELOPMENT PROGRAM IN ALCOHOL SAFETY

\section{RESEARCH}

AREA

Identifying

Problem Drinkers

$B A L$ in Problem Drinkers

Retraining Techniques

Oriver Improvement

Techniques

Drugs \& Driving Performance $85 \mathrm{~K}$

Epidemiological Studies

TOTALS

$135 \mathrm{~K}$

$150 K$

\section{FY 1970}

FY 1971

$100 \%$

FY 1972

$100 \mathrm{~K}$

$200 \mathrm{~K}$

$200 \mathrm{~K}$

$100 K$

$100 \mathrm{~K}$

$100 \mathrm{~K}$

IOOK

$150 K$

$250 \mathrm{~K}$

$250 K$

$300 \mathrm{~K}$

$150 K$

i50K

$40 \mathrm{~K}$

$2.00 \mathrm{~K}$

$300 \mathrm{~K}$

$-$

E50K
$-$

$850 \mathrm{~K}$
$300 \mathrm{~K}$

$150 \mathrm{~K}$

$150 K$
-

$700 \mathrm{~K}$
$300 K$
FY 1976

$390 K$$$
\text { 8 }
$$ 
FIGURE $7-3$

ESTIMATED FUNDING

RESEARCH AND DEVELOPMENT PROGRAM IN ALCOHOL SAFETY

DEVELOPMENT

AREA

\section{FY 1970}

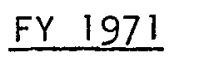

FY 1972

FY 1973

FY 1974

FY 1975

FY 1976

\section{Education Programs}

Primary \& Secondary Safety

$\begin{array}{rrrrr}100 \mathrm{~K} & 100 \mathrm{~K} & 100 \mathrm{~K} & 100 \mathrm{~K} & 100 \mathrm{~K} \\ 50 \mathrm{~K} & 200 \mathrm{~K} & 200 \mathrm{~K} & 100 \mathrm{~K} & 100 \mathrm{~K} \\ 200 \mathrm{~K} & 100 \mathrm{~K} & 100 \mathrm{~K} & & \\ 100 \mathrm{~K} & 100 \mathrm{~K} & 100 \mathrm{~K} & 100 \mathrm{~K} & 100 \mathrm{~K} \\ 100 \mathrm{~K} & 200 \mathrm{~K} & 300 \mathrm{~K} & 200 \mathrm{~K} & 200 \mathrm{~K} \\ 100 \mathrm{~K} & & & \end{array}$

Enforcement Programs

Apprehension of ürinking ürivers

Apprehension of

Revoked Drivers

\section{Court Programs}

Court Procedures

Codes \& Laws

Handling of Problem Drinkers

$150 K$

$\underline{225 K}$

$100 \mathrm{~K}$

$50 \mathrm{~K}$

$100 \mathrm{~K}$

$200 \mathrm{~K}$

$300 \mathrm{~K}$

$100 K$

100K

TOTALS

$150 \mathrm{~K}$

$275 K$

100K

IOOK

100K

$50 \mathrm{~K}$

$50 \mathrm{~K}$

$200 K$

$100 \mathrm{~K}$

$100 \mathrm{~K}$

$1200 \mathrm{~K}$

$1300 \mathrm{~K}$

$600 \mathrm{~K}$

$600 \mathrm{~K}$ 
ESTIMATED FUNDING

RESEARCH AND DEVELOPMENT PROGRAM IN ALCOHOL SAFETY

NEW DEVICES

AREA

FY 1971

FY 1972

FY 1973

FY 1974

FY 1975

FY 1976

Alcohol \& Drug Sensors

Public Education Materials

Sniffers

$45 \mathrm{~K}$

$200 K$

Quantitative Devices

Drinking History Measures

Diagnostic Blood Tests

for Alcoholics

$175 \mathrm{~K}$

$200 K$
$300 K$
$100 K$
$100 K$

$100 \mathrm{~K}$

$200 \mathrm{~K}$

$50 \mathrm{~K}$

$200 K$

$200 K$

$200 \mathrm{~K}$

Blood and Urine Tests

for Drugs

Electronic Detection Systems

Protective Drugs

Drinking Inhibitors

Blood Alcohol Reducers

Alcohol Counteractors

Vehicle Interlocks

$200 \mathrm{~K}$

$300 \mathrm{~K}$

$300 \mathrm{~K}$

$300 \mathrm{~K}$

$300 \mathrm{~K}$

$300 \mathrm{~K}$

200K. 200K

$300 \mathrm{~K}$

$300 \mathrm{~K}$

$300 \mathrm{~K}$

200K

$100 \mathrm{~K}$

$200 K$

TOTALS ...............

$610 \mathrm{~K}$

$200 \mathrm{~K}$

$150 \mathrm{~K}$

$150 \mathrm{~K}$

$200 \mathrm{~K}$

$200 \mathrm{~K}$

$200 K$

$200 \mathrm{~K}$

$200 \mathrm{~K}$

IOOK

$200 \mathrm{~K}$

$200 \mathrm{~K}$

$200 \mathrm{~K}$

$300 \mathrm{~K}$

$2100 \mathrm{~K}$

$1200 \mathrm{~K}$

$1200 \mathrm{~K}$ 
FIGURE 7-5

ESTIMATED FUNDING

RESEARCH AND DEVELOPMENT PROGRAM IN ALCOHOL SAFETY

EVALUATION

AREA

Mass Media Impact

Community Program Procedures

\section{National Program}

Evaluation

TOTALS

\section{FY 1970}

$40 \mathrm{~K}$

$40 K$

$100 \mathrm{~K}$

$180 \mathrm{~K}$

$180 \mathrm{~K}$
$75 \mathrm{~K}$

$100 K$

$75 \mathrm{~K}$

\section{FY 1971}

$75 \mathrm{~K}$

$100 \mathrm{~K}$

-

$225 K$
$100 \mathrm{~K}$

$300 \mathrm{~K}$

FY 197
$100 K$

OOK

$200 \mathrm{~K}$
FY $1974 \quad$ FY 1975

FY 1976
IOOK

$100 \mathrm{~K}$ 
FI GUF:E 7-6

ESTIMATED FUNDING

RESEARCH AND DEVELOPMENT PROGRAM IN ALCOHOL SAFETY

SPECIAL FACILITY REQUIREMENTS

AREA

Driving Simulator

Fatal Accident Record

Bibliographic Services

Research Grant Program

TOTALS
FY 1970

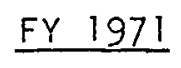

FY 1972

\section{FY 1973}

FY 1974

$275 K$

$300 K$

$300 \mathrm{~K}$

$300 K$

$250 \mathrm{~K}$

$200 \mathrm{~K}$

$25 K$

$25 K$

$75 \mathrm{~K}$

$200 \mathrm{~K}$

.

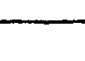

$700 \mathrm{~K}$
$200 \mathrm{~K}$

$30 \mathrm{~K}$

$270 K$

$\longrightarrow$

$800 \mathrm{~K}$
FY 1975

FY 1976

.




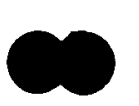

.

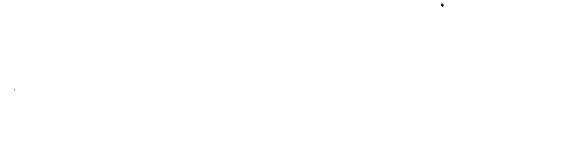

RESEARCH AND DEVELOPMENT PROGRAM IN ALCOHOL SAFETY

AREA

Research

Development

$150 \mathrm{~K}$

$275 K$

$1150 \mathrm{~K}$

$1300 K$

$1950 \mathrm{~K}$

$200 K$

Special Facility Requirements

$180 K$

$225 K$

$300 K$

$700 K$

$700 K$
$100 \mathrm{~K}$

$800 K$

$900 \mathrm{~K}$

$900 \mathrm{~K}$

FY 1975

FY 1976

$300 \mathrm{~K}$

$600 \mathrm{~K}$

$1200 \mathrm{~K}$

$5000 \mathrm{~K}$

$3000 \mathrm{~K}$

$3000 K$

TOTALS

700K

1500K

$-$

$5000 \mathrm{~K}$

$5000 \mathrm{~K}$ 
SECTION VIIT

PLAN FOR PROGRAM EVALUATION

\section{OVERVIEW}

While the significance of alcohol to bighway safety has been recognized for nearly three decades, it was only during the last decade that carefully controlled epidemiological research has brought into clear focus the full significance of the misuse of alcohol to highway fatalities. The studies of Haddon, Nielson and others in this country have provided the new techniques required to assess the blood alcohol in drinking drivers. As a result of their work in the data which was summarized in the Department of Transportation Report to the Congress on:Alcohol in Relation to Highway Safety in October 1968, a need has developed for the maintenance of records on the role of alcohol in highway safety. As a result a key portion of the NHSB Action Program on alcohol and highway safety involves the evaluation of the effectiveness of various alcohol countermeasures. The National Highway Safety Bureau's Highway Safety Standard on "Alcohol in Relation to Highway Safety" requires that blood alcohol measures be made on all fatally injured drivers and on all drivers in accidents fatal to others. Unfortunately most states do not conform to these requirements currently and there exists no methodolgy for collecting the data from the various States in order to provide a National picture of the status of alcohol as a highway hazard. As a result it is not possible to say whether the role of alcohol is increasing or decreasing on a national basis. Thus, there is a requirement for a national reporting system which will permit the evaluation of the overall effect of the National Highway Safety Bureau's program.

$\underline{\text { Requirements }}$

To provide adequate evaluation of the Bureau's alcohol safety program, two types of evaluation procedures are envisioned:

1. A system o: collecting nationwide data on fatal and serious injury accidents which provides data sufficiently descriptive to assess the role o:: alcohol, and

2. Individual evaluation programs for each of the ASAP projects

Evaluation of ASIP Projects

The need for evaluation programs for community programs has been discussed in sec:ion 4 of this paper. 


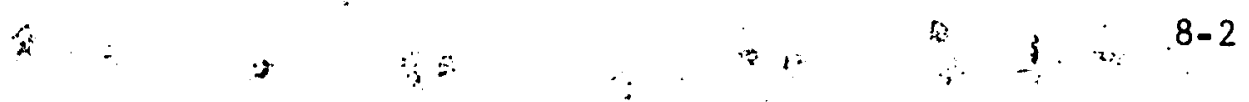

It is intended that a manual will be developed by the Bureau for use by project managers in setting up their evaluation program. . This manual will describe in detail proposed evaluation techniques for measuring for five data areas. These are: (1) Criterion data; deaths and serious injuries due to drivers with positive blood alcohol levels. (2) Intermediate measures: Measurements such as the blood alcohol levels of drivers using the roadways at time and places of fatal accidents. (3) Program element measures such as the amount of residual among convicted drinking drivers receiving special retraining under the alcohol safety program. (4) Program cost and personnel effort data and (5) Public and official reaction to the program, gathered through attitude measuring devices.

These data sources will-be designed to provide the contractor and the Bureau with an overall assessment of the effectiveness of the alcohol safety program in addition to providing a contractor "quick-look data" with information on the functioning of the various elements of the community program. These quick-look data reports will serve as a menagement information system for the project manager. which will permit: him to vary the effort in various areas of the program in order to achieve maximum results. The NHSB will receive these reports on each. denonstration project. Any given project will cover only a localized area and it will take some time to develop sufficient accident data to give a picture in the localized area of the impact of alcohol on highway safety and the extent to which this effect: is increasing or decreasing.

\section{National Data Recuirements}

To provide a means of comparing communities which have implemented intensive programs with those which were continuing conventional enforcement procedures, and to provide a source for reporting to the Nation current prcyress or lack of progress, the NHSB will require a National Alcohol Safety Record System. Among the alternatives which will be considered is the desirability of the NHSB establishing a fatal accident record data bank which would include all fata? accidents which occur within the 50 states. This alternative as compared to a procedure involving a more limited sample o: fatal accidents or a procedure involving collection of both fatil and serious injury accicients shall, be considered and evaluated. Among the possibilities to be considered would be a sample based on a few compact geographical areas which represent the driving populations and conditions of the United States, as compared to a geographically more widespread sampling. 
The final sample chosen should be sufficiently broad that it will be possible to compal: the impact on highway accidents due to alcohol in those are:" where there are community alcohol safety action programs with wose in which there is no special program activity. The advantages and disadvantages of each of the major alternatives will be discussed from the standpoint of: (1) information quality and accuracy and (2) the cost and practical problems of implenientation. Ideally, the program selected should provide information of the type 1 isted below. The items are in rough order of priority of importance. However, some of these items will be obtainable much more easily than others, and it is probable that the final plan will include some of the lower priority items while omiting sore of the more imoortant jtems.

1. The estimated number of accjent-involved drivers and pedestrians tabulated by: (1) blood aicohol concentra.. tions (or other appropriate measure); (2) accident severity class; (3) type of accident; and (4) time of day.

2. The estimated proportions or number of drivers at various blood alcohol concentrations among the nonaccident-involved drivers and pedestrians on the road by the time of day.

3. Sex and other social characteristics of accident-involved drivers and pedestrians, as a function of blood alcohol level.

4. For road type, vehicle type, model and body style, the distribution of blood alcohol level of drivers and pedestrians.

5. For drivers and pedestrians on the highway, trip destination and the place where alcohol. was consumed as a function of blood alcohol concentration.

6. For drivers and pedestrians on the highway, information on drinkiag habits, including anount, phase of drinking, frequency of dricking and driving, jegal, family, job or social probicns related to use of alcohol as a function of blood alcohol concentration.

7. Can un ssual behavior of alcoholic drivers be determined prior so accidents and in what fraction of cases is this possible?

8. The number of "inmocent" drivers, passengers and pedestrians killed and/or seriously injured by firivers known to have been drinking. 


\section{SECTION IX}

\section{RESOURCE REQUIREMENTS}

Resource requirements for the alcohol safety program are summarized in Figure 9-1. The heart of the program is the ASAP projects described in Section IV -- nine underway, twenty to be initiated during FY 1971, thirty planned for FY 1972 and twenty-seven planned for FY 1973. Figure 9-1 reflects the projected phaseout of Federal funding under Section 403 of the Act。

It is expected that by the fifth or sixth year after the initiation of this program, the major portion of the funding for state and community action will be borne by matching funds under Section 402. of the Highway Safety Act. The 402 funding requirements would in turn gradually phase down to reflect any increasing ability of the States to support the entire program on their own. Specific Section 402 increases are not requested for the alcohol program, since emphasis on alcohol will be achieved initially by increasing the priority given to this area in the State Annual Work Plans. After the States have presented their initial annual work proposals and have been able to create a plan for the development of comprehensive alcohol safety programs, it will be possible to reflect more precisely the follow-on costs of activities in the alcohol area.

Factors which ensura phaseout of Federal support are: (1) the contractual nature of the ASAP projects under Section 403 funding; (2) NHSB emphasis on tho phascout procoss during contract nogotiation and cricouiaging continua. tion of effective countermeasures by States and communities; (3) the development of complementary capabilities in the conduct of alcohol safety programs at the community level during the operational period of projects; and (4) the generation of wide piblic support and pressure in the States to pursue programs, even with local resources.

A second item summarized is the cost for the research and development program as described in Section VII. The current and planned NHSB research and development program is primarily devoted to the development of new countermeasures and support materials for use in community programs. Considerable work remains to be tone on the development of new alcohol sensors and new training materials. Further, most of the countermeasures proposed have not been fully validated by full-scale trials in actual community settings.

Costs for the publi: education and manpower development program described in Section VIáciso summarized in Figure 9-1. This program will be critical to providing suppor: to communities which are interested in initiating comprehensive start.up programs. Only as the climate of public opinion supports such intensive programs will it be possible to initiate them and to achieve the necessary legislative and enforcerent actions to make them effective. Public education and support is vital. Since most communities at this time lack m.anpower with the special training required to carry out the proposed counte -measure programs, it will also be necessary to initiate a manpower training program. This training program is an essential adjunct of the overall effo-t which will need personnel capable of carrying out the 
comprehensive community action projects.

The final item shown in Figure 9-1 is administrative costs. These administrative costs are associated with the staffing estimates provided in Section XI, together with the expected travel, printing and other costs of the Office of Alcohol Countermeasures, and of the enlarged field activities which will be needed to support the community comprehensive programs. Administrative costs under section 403 funding are based on an estimated 25,000 per position and increase and decrease with ASAP projects.

A more detailed description of funding requirements for each of the various cost ejements of the program is provided in Figures 9-2 through

7.59-5. The data presented here is a consolidation of resource information presented in separate sections of the study (i.e., ASAP, Public Education and Manpower Development, Research and Program Management).

In view of the recent deliberations by the House and Senate Public Works Committee regarding the authorizations for FY 1972 and 1973 (Fannin Bil1), there appears t.o be a possibility that the psogram will be limited to 52 projects, one in each state and one in the District of Columbia and Puerto Rico. In addition, Congress may impose a time limit on spending for ASAP projects of either June 30, 1974 or June 30, 1975. Both of these proposals would curtail the cotal program impact., particuiariy the proposal embodying a June 30, 1974 spend:ng deadline. This latter plan would not only reduce the total number of projects from 86 to 52; it would also, because of the time limitation, result in twenty-three of the fifty-two projects being limited to two yeais rather than three years of operation. Moreover, even to achiere two full years of operation would require accelerating the initiation of the twenty-three projects planned for initiation in 1972, with the result that the authorization appropriation for FY 1972 would need to be increased. The impact of these two propcsals is summarized in Eigures $9-6$ and 9-7. Note that there is no chenge in the total appropriation request for FY 1972 on the June 30,1575 deadlines. The savings in not conducting the final thirty-four prcgrams would begin to be realized in 1973 and beyond. In the case of the June 30, 1974 deadline, however, in order to get underway the last thenty-three projects and give them even a reduced two year period of operation increases in funding woujd be required in 1972, with total funding levels falling below the initial request from 1973 onward. 


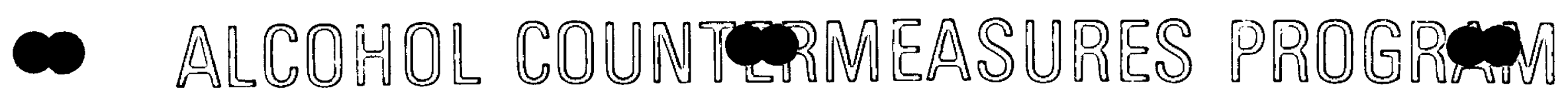

Figure 9-1

COST (MILLIONS OF \$)

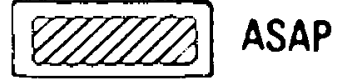

REREARCH

PUBLIC EDUCATION AND
MANPOWER DEVELOPMENT

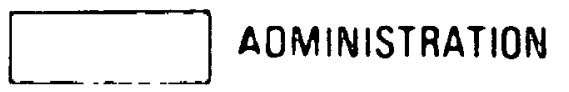

IN FY71

PUBLIC ED. $=\$ 3$

MANPOWER $=\$ .3$

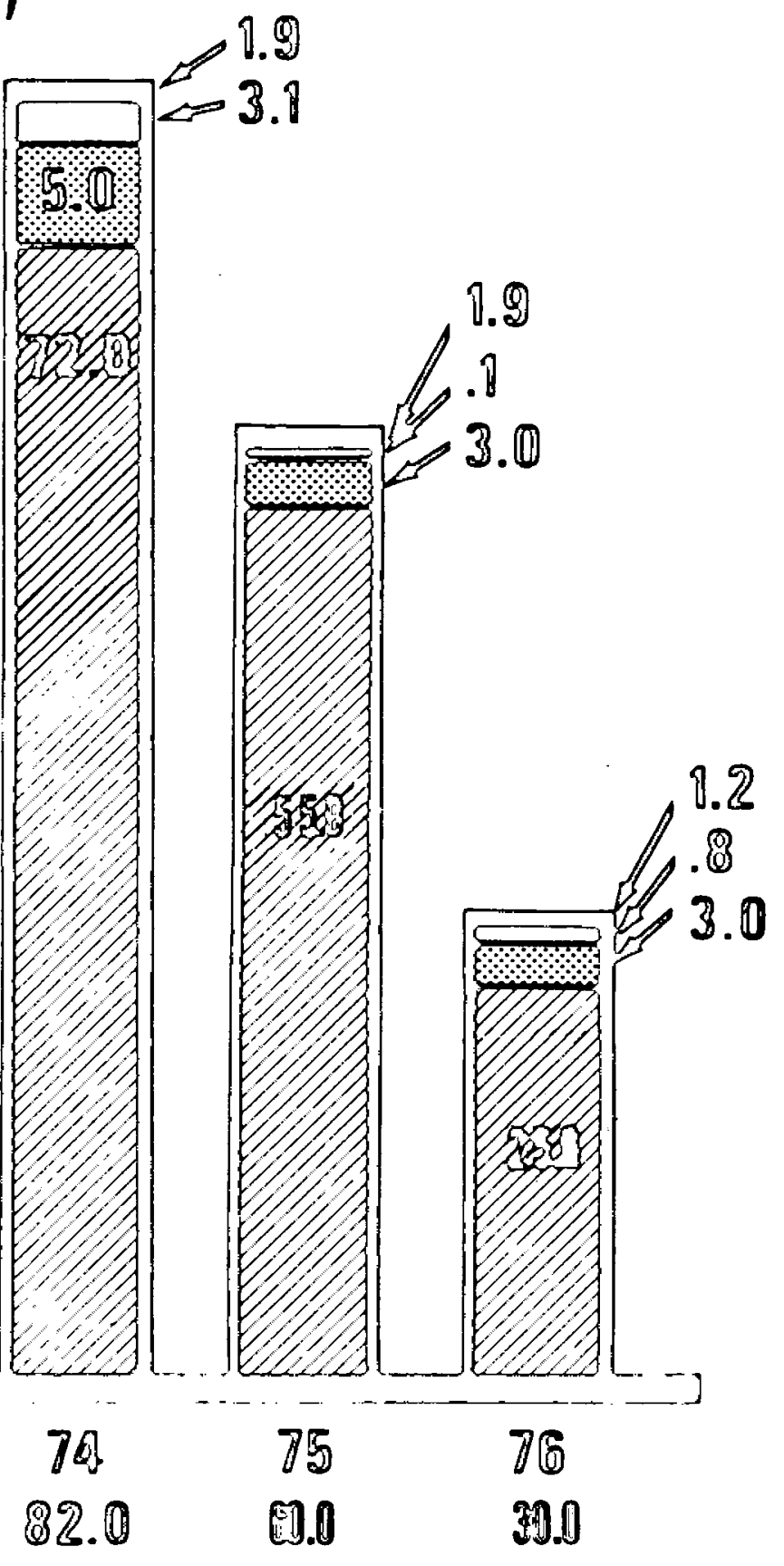


ALCOHOL SAFETY ACTION PROGRAM

ASAP PROJECT DEVELOPMENT PLAN AND ESTIMATED BUDGET

FY 1970-1976 (Millions of Dollars)

\begin{tabular}{|c|c|c|c|c|c|c|c|}
\hline 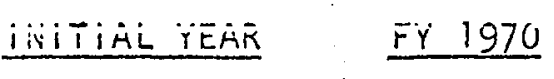 & FY 1971 & FY 1972 & FY 1973 & FY 1974 & FY 1975 & FY 1976 & TOTAL \\
\hline$\frac{9}{(\$ .9)}$ & $\begin{array}{c}9 \\
(\$ 3.5)\end{array}$ & $\begin{array}{l}9 \\
(\$ 7.0)\end{array}$ & $\stackrel{9}{(\$ 6.6)}$ & & & & $\$ 18.0$ \\
\hline 71 & $\begin{array}{l}20 \\
(\$ 2.0)\end{array}$ & $\begin{array}{c}20 \\
(\$ 14.0)\end{array}$ & $\begin{array}{c}20 \\
(\$ 14.0)\end{array}$ & $\begin{array}{l}20 \\
(\$ 14.0)\end{array}$ & & & $\$ 44.0$ \\
\hline .. & & & & & & & \\
\hline 72 & & $\begin{array}{l}30 \\
(\$ 9.0)\end{array}$ & $\begin{array}{c}30 \\
(\$ 25.0)\end{array}$ & $\cdot \begin{array}{c}30 \\
\$ 25.0\end{array}$ & $\begin{array}{c}30 \\
(\$ 22.0)\end{array}$ & & $\$ 81.0$ \\
\hline 73 & & & $\begin{array}{c}27 \\
(\$ 14.4)\end{array}$ & $(\$ 33.0)$ & $\begin{array}{c}27 \\
(\$ 33.0)\end{array}$ & $\begin{array}{c}27 \\
(\$ 25.0)\end{array}$ & $\$ 105.4$ \\
\hline $\begin{array}{l}\text { TOTAL PROJECTS } \\
\text { iN FORCE } \ldots \ldots \ldots .9 .9\end{array}$ & 29 & 59 & 86 & 77 & 57 & 27 & \\
\hline TOTAL FUNDS ASAP... $\$ .9$ & $\$ 5.5$ & $\$ 30.0$ & $\$ 60.0$ & $\$ 72.0$ & $\$ 55.0$ & $\$ 25.0$ & $\$ 248.4$ \\
\hline
\end{tabular}




\section{FIGIJRE 9-3}

Public Education and Manpower Development

\section{Funding :Requirements}

(In Tiousands)

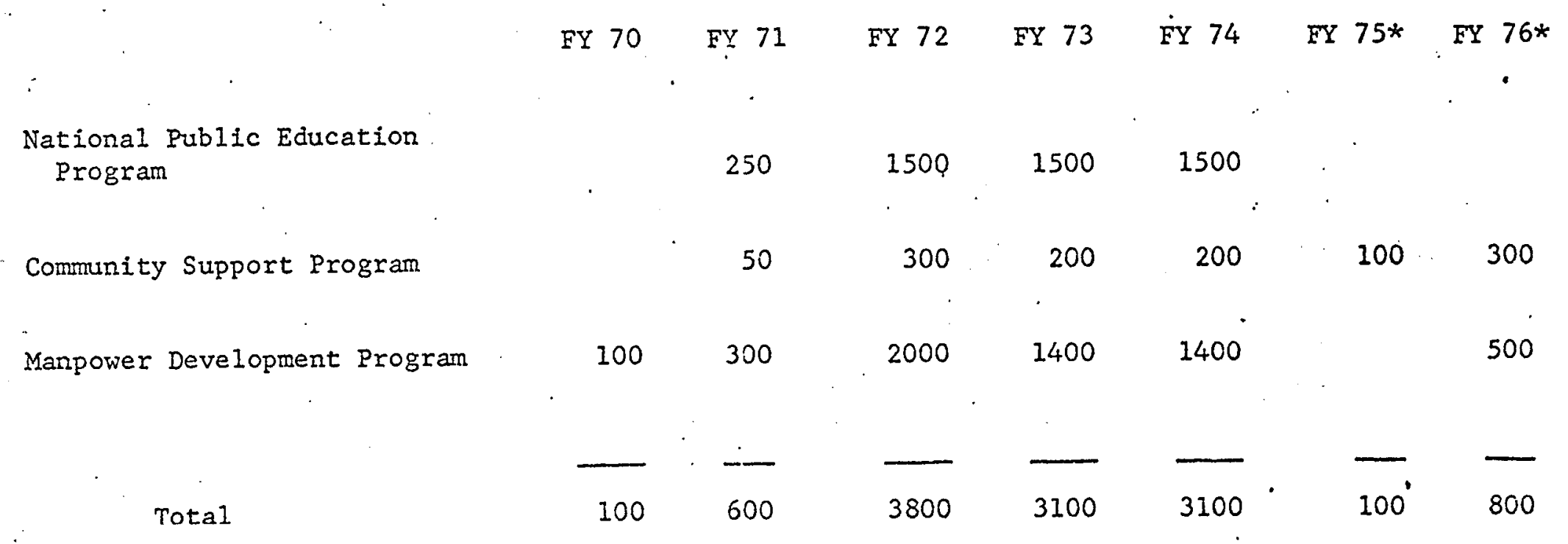

*Activities in support of ASAP programs will end with the exception of a small ongoing effort in commity support by the end of FY 74. There will be a small new activity initiated in FY 76 in support of local activities as the states take over responsibility for these programs. 


\section{FIGUR: 9-4}

ESTIMATED FUNDING

RESEARCH AND DEVELOPMENT PROGRAM IN ALCOHOL SAFETY

DEVELOPMENT

AREA

\section{FY 1970}

FY 1971.

FY 1972

FY 1973

FY 1974

FY 1975. FY 1976

\section{Education Programs}

Primary \& Secoridary Safety

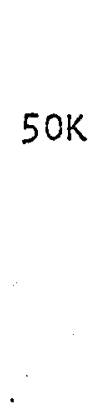

Drug Education Programs

\section{Enforcement Programs}

Apprehension of Drinking Drivers

- Apprehension of Revoked Drivers

\section{Court Programs}

\section{Court Procedures}

Codes \& Laws

$100 K$

$50 \mathrm{~K}$

Handling of Problem

Drinkers

I50K

$225 \mathrm{~K}$

$100 K$

$100 \mathrm{~K}$

$100 \mathrm{~K}$

$100 \mathrm{~K}$

100K

$100 \mathrm{~K}$

$.200 K$

$200 K$

$200 K$

$100 \mathrm{~K}$

100K

$100 \mathrm{~K}$

100K

$100 \mathrm{~K}$

look

$100 \mathrm{~K}$

look

looK

$100 \mathrm{~K}$

$100 \mathrm{~K}$

$200 K$

$300 K$

$200 \mathrm{~K}$

$200 \mathrm{~K}$

TOTALS

150K

$275 \mathrm{~K}$

100K

IOOK

$100 K$

$50 K$

$50 \mathrm{~K}$

$200 K$

$100 \mathrm{~K}$

$100 \mathrm{~K}$

1150K

$1200 K$

1300K

$600 \mathrm{~K}$

$600 \mathrm{~K}$ 


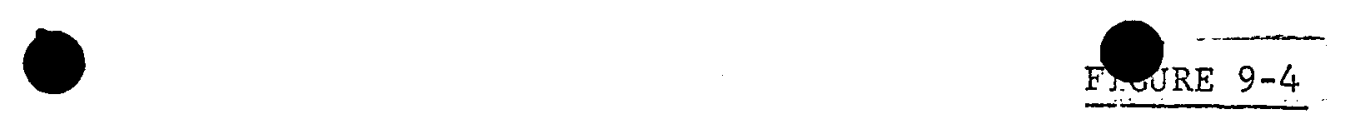

ESTIMATED FUNDING

RESEARCH AND DEVELOPMENT PROGRAM IN ALCOHOL SAFETY

NE:W DEVICES

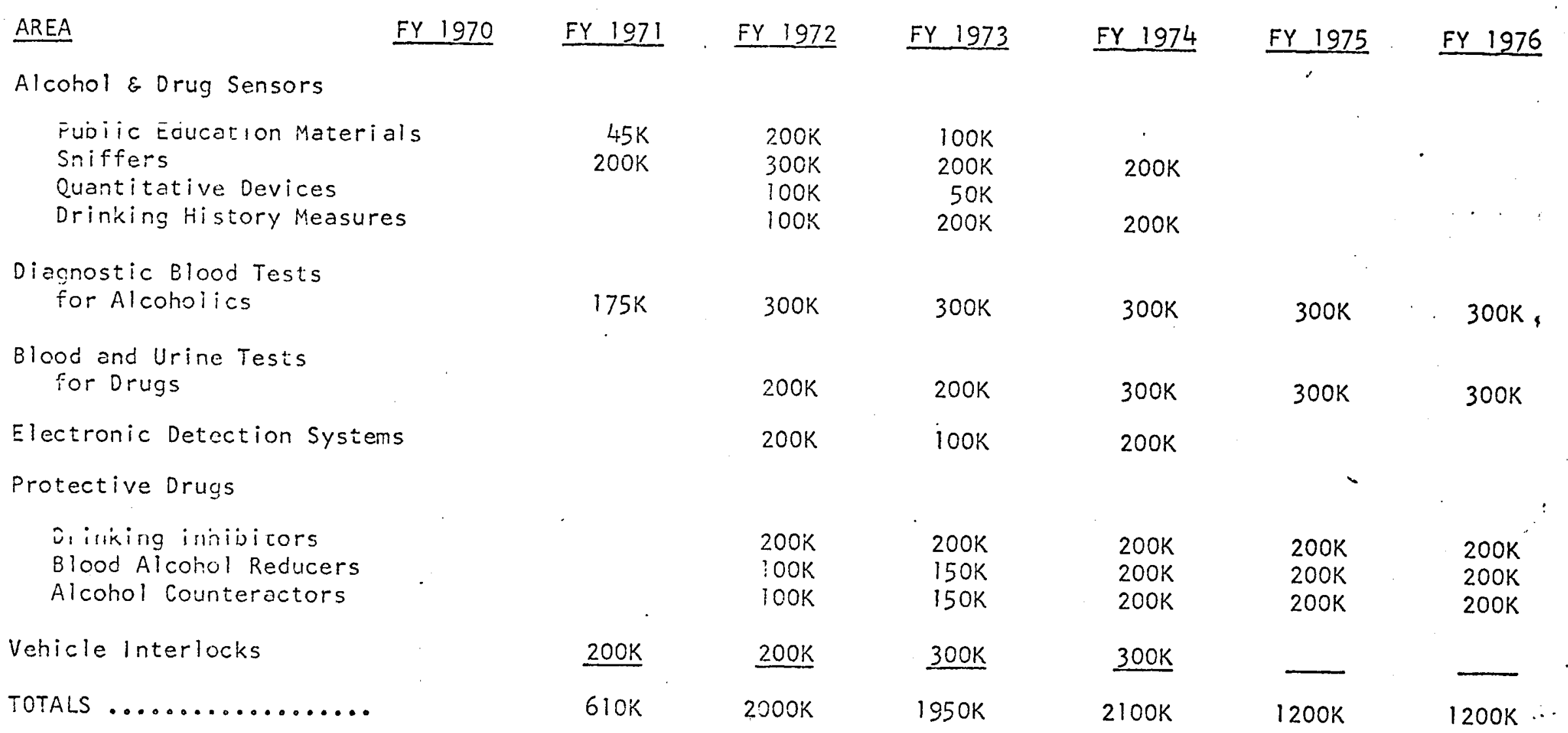




\section{-}

AREA

Mass Media Impact

Community Program Procedures

National Program Evaluation

TOTALS
FIGURE $9-4$

ESTIMATED FUNDING

RESEARCH AND DEVELOPMENT PROGRAM IN ALCOHOL SAFETY

ELALUATION

\section{FY 1970 FY 1971 FY 1972 FY $1973 \quad$ FY $1974 \quad$ FY $1975 \quad \underline{\text { FY } 1976}$}

$40 \mathrm{~K} \quad 100 \mathrm{~K} \quad 100 \mathrm{~K}$

$40 \mathrm{~K} \quad 75 \mathrm{~K} \quad 100 \mathrm{~K}$

\begin{tabular}{lllll}
$100 \mathrm{~K}$ & $75 \mathrm{~K}$ & $100 \mathrm{~K}$ & $100 \mathrm{~K}$ & $-100 \mathrm{~K}$ \\
\hline $180 \mathrm{~K}$ & - & - & $-200 \mathrm{~K}$ & $-100 \mathrm{~K}$
\end{tabular}


RESEARCH AND DEVELOPMENT PROGRAM IN ALCOHOL SAFETY

SPECIAL FACILITY REOUIREMENTS

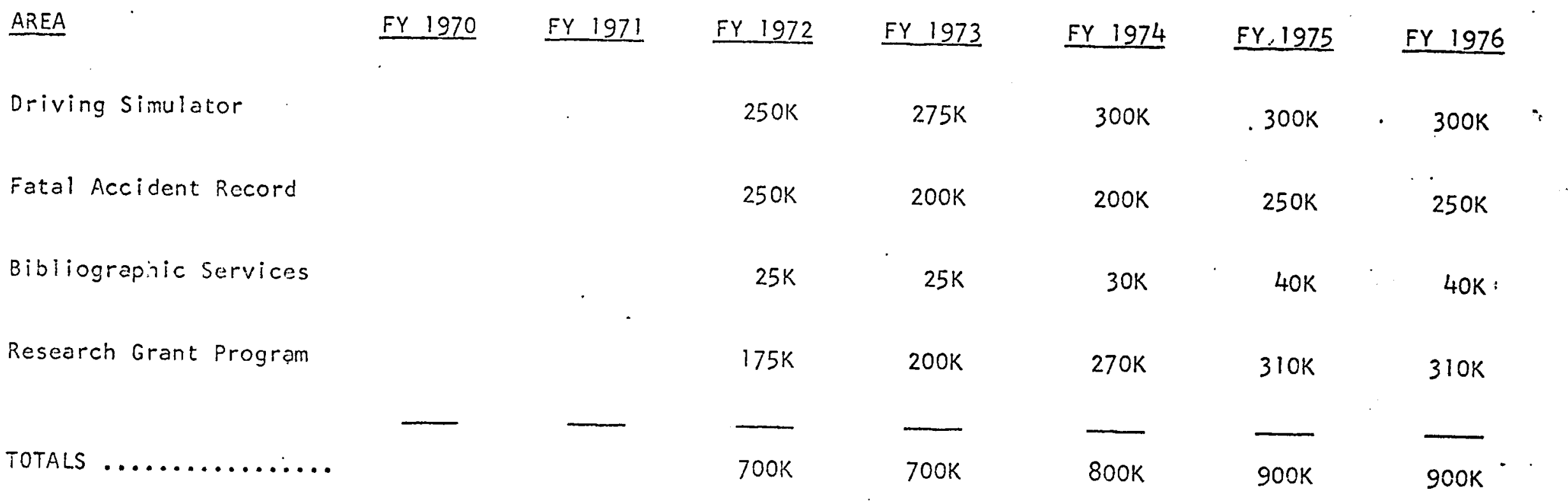




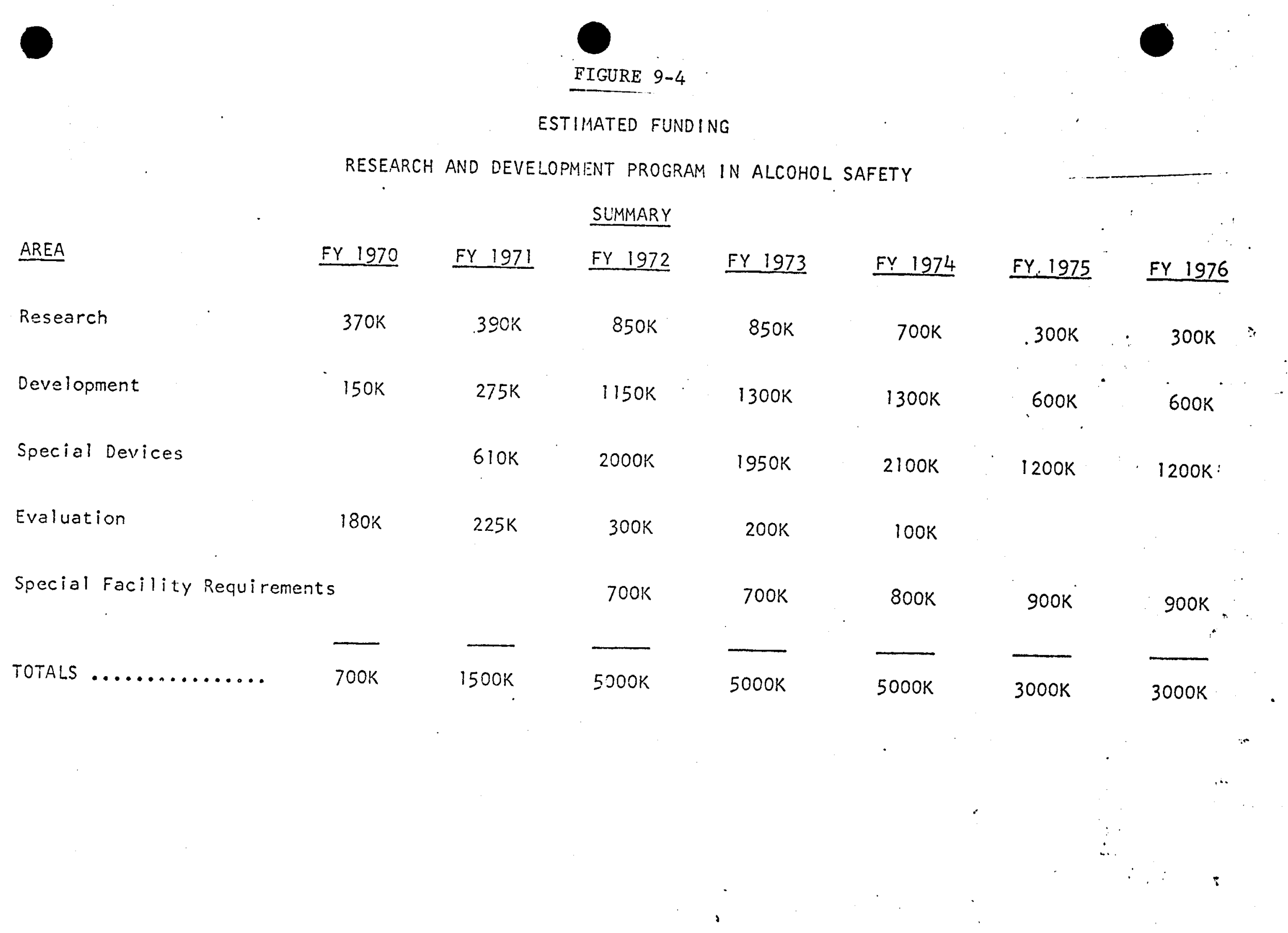


FIGURE 9-5

ESTIMATED FUNDING REQUIREMENTS

ADMINISTRATTON

(MILLIONS OF DOLLARS)

\section{FISCAL YEAR}

1971

1972

1973

1974

1975

1976

\author{
TOTAL \\ PROJECTED \\ STAFFING
}

22

65

100

100

100

65 $\underline{\text { FUNDING }}$

$\$ 1.2$

$\$ 1.9$

$\$ 1.9$

$\$ 1.9$

$\$ 1.2$

TOLAL $\ldots \ldots \ldots \ldots \ldots \ldots \ldots \ldots \ldots \ldots \ldots \ldots$ 
FIFTY-TWO PROJECT ALCOHOL PROGRAM

(FY 1974 LIMIT VERSION)

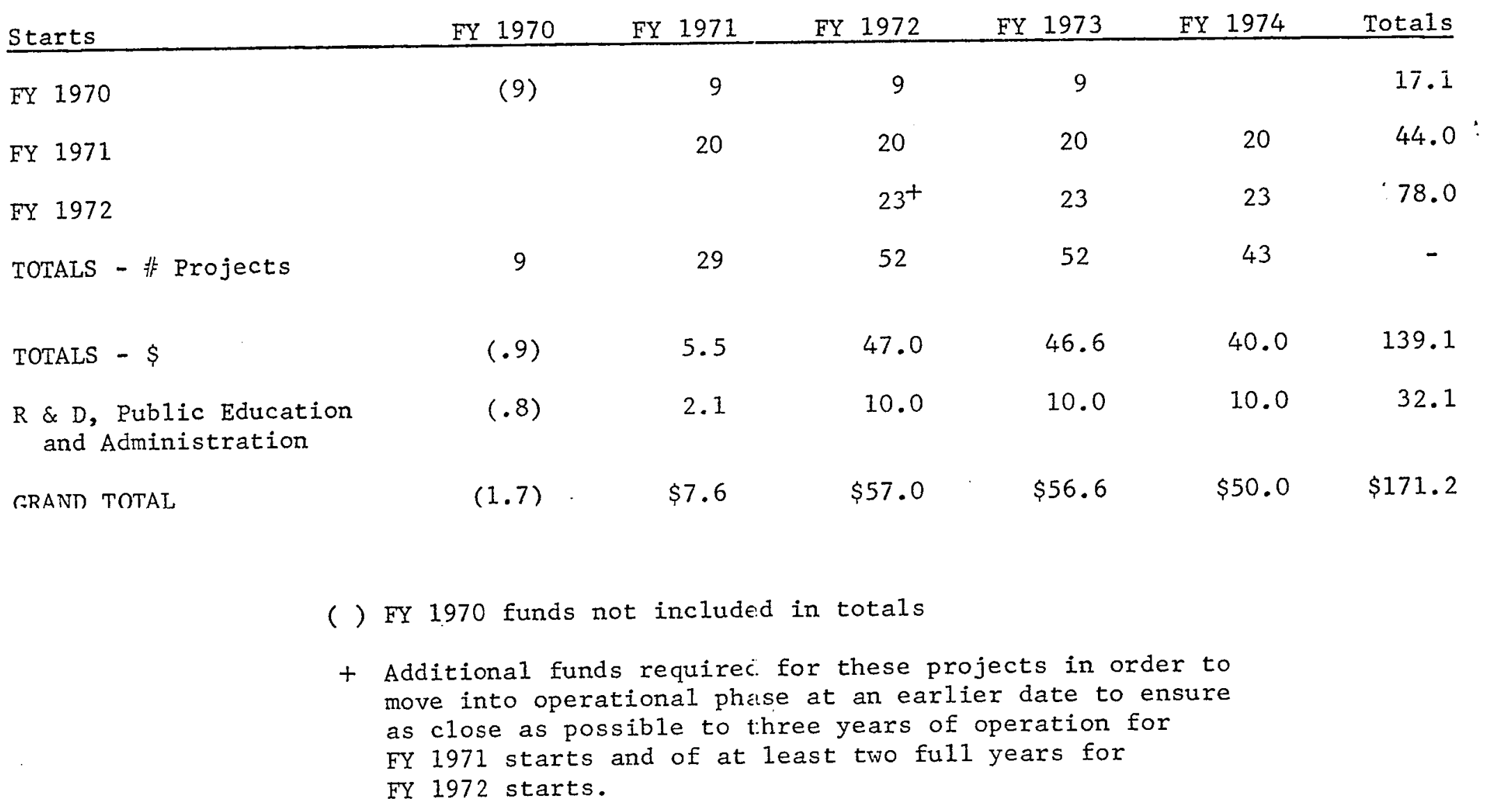


Figure $9-7$

FIFTY-TWO PROJEC: ALCOHOL PROGRAM

(FY 1975 LINET VERSION)

\begin{tabular}{|c|c|c|c|c|c|c|c|}
\hline Initial Year & FY 1970 & FY 1971 & $F \quad 1972$ & FY 1973 & FY 1974 & FY 1975 & Funds \\
\hline 70 & (9) & 9 & 9 & 9 & & & 17.1 \\
\hline 71 & & 20 & 20 & 20 & 20 & - & 44.0 \\
\hline 72 & & & 23 & 23 & 23 & 23 & 73.0 \\
\hline Total Projects & 9 & 29 & 52 & 52 & 43 & 23 & \\
\hline $\begin{array}{l}\text { Total Funds for } \\
\text { ASAP' }^{*}\end{array}$ & $(.9) *$ & 5.5 & 30.0 & 42.6 & 36.0 & 20.0 & 134.1 \\
\hline $\begin{array}{l}\text { Research and } \\
\text { Development, Public } \\
\text { Education and } \\
\text { Aaminiscration }\end{array}$ & $(.8)$ & 2.1 & 10.0 & 10.0 & 10.0 & 5.0 & 37.1 \\
\hline Total Funds & $(1.7)$ & 7.6 & 40.0 & 52.6 & 46.0 & 25.0 & 171.2 \\
\hline
\end{tabular}




\title{
SECTION $\mathrm{X}$
}

\author{
INTERAGENCY RELATIONSHIPS
}

OVERVIEW

The National Highway Safety Bureau will establish liaison with other organizations involved in alcohol problems so that the national alcohol highway safety program will mesh smoothly with related efforts of the other agencies and their's will similarly complement the NHSB program. This is true particularly in three areas: (1) coordination of the DOT program on problem drinker-drivers with the Department of Health, Education and Welfare efforts directed toward treatment and rehabilitation; (2) coordination and support in gaining public understanding; and (3) support on medical aspects of research and development activities. The major governmental and private agencies with which inter-relationships must be established are given in figure 11-1. NHSB will seek to establish small working groups with these agencies, chaired by NHSB technical personnel, to achieve inutual support, consistency of program directions, and a synergistic effect.

\section{Background}

Research data on the relationship of alcohol to highway safety have clearly indicated that the major portion of the alcohol and highway safcty proticm is produced by the probleii driakes who drives. The Bureau has focusid on these excessive drinkers in its countermeasure program. Thus, the program deals primarily with "sick" persons who become hazards when they use the highway. NHSB's concern is to reduce highway death ani injury caused by these problem drinkers. Treatment and rehabilitation as a public health or medical problem is the responsibility of other agencies. These facets interact so that it is necessary to devilop a close working relationship with groups dealing with problem drinkers as a health problem.

Alcoholism is a very old disease. It has been with man since the cave and has been the target of social action and of political movements for centuries. It remains a major problem in our modern society. The Manual on AlcohoLism of the American Medical Association estimates that there are from four to six million alcoholics. When their family members are considered $a \%$ least $20,000,000$ Americans have been directly affected by this disease. The Federal Bureau of Investigation reports indicate that more than 41) percent of all arrests are for drunkenness, the greater proportion presunably alcoholics. Major industrial firms have estimated that the alcoholic employee loses 22 more working days per year than the non-alcoholic em loyee, suffers twice the number of accidents, and has the 1ife expectancy some 12 years shorter. The Bureau will target in specifically on the highway safety aspect, to reduce highway fatalities and injuries. Wile the highway program does not assay to attack the overall problem if alcoholism, it can have an important impact on this 
problem when integrated with the efforts of other agencies and groups. In particular, by providing a "case finding" technique for pre-alcoholics, the Bureau program will aid in identifying and treating more problem drinkers during early manifestations of their disease when treatment is most likely to be effective.

\section{Three Areas of Required Interaction}

The NHSB will require the support of outside agencies and groups in the following three major areis:

1. Treatment and rehabilitation of alcoholics. A critical problem for the Bureau in developing community demonstration programs has been the problem of the hondling of problem drinkers who are convicted of drinkingdriving offenses. In soliciting the participation of the courts in intensive alcoholic enforcement programs, one of the first objections to be overcome is that there are no facilities available to the courts to which to refer problem drinkers for treatment. Throughout the country a number of judges have shown interest in referring problem drinkers for treatment rather than sentencing them to standiard penalties, but many have had to give up their plans since they wera not able to find any rehabilitation facility which would accept these individuals for treatment. Inless a system of support can be found to finance the additional facilities needed in communities which take on a demonstration program, this problem wilz continue to be a major block to the Bureau's program.

Funds for treatment are available through the NIMH community mental health program and through State mental health agencies. An interagency liaison system will seek, for communities which are attempting to establish alcohol and highray safety demonstration programs, priority in acquiring funds for treatmint as well.

2. Public educaicion and manpower training. A number of private organizations (insurance companies, the National Safety Council, the American Medical Association, et a1) are now sponsoring public information campaigns on driaking and driving. In addition, several groups are presently sponsoring nationwide public information campaigns on alcoholism.

The Bureau's alcohol safety program will require (as indicated in section 6) a national public education program on alcchol. It will be necessary to ensure that the current programs do not corflict with the Bureau's program and that as much cooperation as possitile is achieved between agencies working in this field. Participatior of the medical profession and social and health agencies is also essential to the Bureau's manpower training programs designed to acquaint court frobation officers and others with methods for handling problem drinkers. $\because t$ is important that these agencies and the Bureau proceed together rather than in variance. 
In seeking the requisite coordination, the Bureau must ensure that its program is not subordinated or confused with activities supporting other programs. At the same time it must assure that other major campaigns are not running counter to the Bureau's thrust. For example, past campaigns by the National Safety Council have emphasized the concept that "if you drink, don't drive." This approach is contrary to the proposed new approach of the Bureau. Agencies operating in this field must be solicited to support the Bureau's program, and to modify any features of their own programs which appear in conflict.

3. Research and development. In developing new technology for apprehending drinking drivers and for diagnosing problem drinkers, it will be necessary to support from medical specialists. NHSB has no specialists in this area, and makes use of informal advisory support from the National Institute of Health.

Inter-relationships Which Need to be Established

Inter-relationships need to be established with the following agencies for the purposes described:

1. Department of Health, Education and Welfare.

$a$ Natinnal. Tnstitutes of Health

(1) Funding support for treatment facilities in demonstration communities. An agreement should be established with HEW which will provide for priority consideration for funding support from the Community Mental Health Center. It is understood that "his center will have approximately 5 million dollars for FY 1971 earmarked for alcoholism programs. These funds could be a major factor: in achieving successful demonstration projects, if they can be channeled to those communities which will be undertaking these programs for the NHSB. NIH personnel should accompany NHSB personnel to the field to survey potential demonstration sites and to assist the local community personnel in developing proposals for submission to NIH.

(2) Public Information. The Nationa:. Institute of Health will be supporting a national campaign on alcoholism. To date their discussion with NIMH public education personnel (Mr. Sands) suggests that their approach to the problem drinker is very similar to that of the national campaign for alcohol and highway safety. To ensure their support of the NHSB program, and to get their technical inpul:s (in relationship to the diagnosis and treatment of problem drinkers) they will be invited to participate on the NHSB pubiic education work:ing group.

(3) Consultant Service and Research. The Bureau has already made request for the part-time services of one of the members of the NIMH Alcoholism Center - Dr. Nathan Rosenberg A similar request will 
also be made for the services of Dr. Philipson, a very knowledgeable British physician who has worked in alcoholism for many years. Through this kind of advisory service we can strengthen the Bureau's alcohol safety research program.

b. The Public Health Service

The Public Health Service operates a number of hospitals around the country which treat, or could potentially treat, alcoholics. Further, PHS has funds for research on alcoholism in relationship to accidents in general. The Pullic Health Service also receives reports of communication on alcoholics. A representative from the Public Health System will be invited to participate on a working group of the office of Alcohol Safety.

\section{c. Office of Education -}

The Office : of Education has been relatively inactive in the area of safety education. Recently, however, the NHSB has initiated discussions with the Office. : of Education regarding an integrated safety education program from primary through secondary schools. This activity would provide an important approach to the problem of misuse of alcohol in conjurction with driving, both through pressures that children might place on parents (as in the present anti-smoking campaign), and as a method of dealing with the young drinking driver who is a special hazard on the highway. NHSB will seek support from the Office of Education in the development of national safety programs. Their assistance is needed not only because of the potential financial support which they can provide, but also because of their influence in persuading school systems to accept the program once developed.

\section{d. Department of Defense}

The Armec Forces have highway safety programs of differing intensity. The most active appears to be the Air Force which has a fairly sizeable investment in driver education and in highway safety programs. The Army and Navy are less active. Nevertheless, for all three services vehicle crashes c.re the major source of death (battlefield casualties not excluded). Since the majority of the members of the Armed Forces are young and a large proportion single, drinking-driving accidents are a major source of lost time accidents. The mili:ary has, therefore, a major interest in this problem. Moreover, they have been the most successful group in reducing fatalities from private vehicle accidents. In part, of course, this is a result of their better control over their personnel. Their active participation in this national program will ve sought to save the lives of men in the services, to use the influence servicemen can exert on local ccmmunities, and to influence these young men who will be returning to civil 1 ife. 


\section{e. Department of Justice}

Because of the recent concern with "crime in the streets" the Department of Justice has received considerable funding support for intensive local law enforcement activities. The research data reviewed in the section on "The Problem" have demonstrated that many of the drivers involved in fatal accidents, and those arrested for drinkingdriving offenses, have previously committed criminal offenses involving alcohol. More intensive prosecution of "drunk and disorderly" and other criminal offenses involving alcohol, together with referral of these individuals to treatment, would have an impact on highway safety. It will be desirable to obtain the support of the Justice Department funding for those communities putting on highway alcohol safety demonstration projects in order to cover costs associated with more intensive law enforcement for alcohol related non-highway offenses.

\section{f. The Department of Housing and Urban Development}

HUD has Eunds to support attacks on various urban problems. Some of these funds can be used to support alcoholism treatment and advisory services, vocational training services and other activities which are necessary adjuncts to the NHSB's community demonstration programs. Once again this may provide a source of support for those areas which it is not appropriate for NHSB to fund. A continuing regular contact with a cesponsible liaison staft member trom HUD would assist the demonstration projects activity in making use of these funds wherever possible, as with Department of Health, Education and Welfare. An agreement to give priority to the Bureau's demonstration project communities will be sought.

\section{g. The Veterans Administration}

The V.A. treats more alcoholics than any other agency. To date this agency has been unwilling to open its records to other agencies concerned with problem drinkers. The NHSB should solicit the V.A.'s participation in the highway safety program in the hope that it will assist in identifying problem drinkers who should not drive.

\section{Private Non-Governmental Organizations}

A number of industry and service organizations are active in the highwaj' safety field. Informal discussions with these groups indicate that they are ready and quite anxious to support the Highway Safety Bureau in its national education campaign. Since a number cf these groups can provide sizeable financial support for mass media advertising, their cooperation will be sought. Moreover, as noted, some of these groups, such as the National Safety Council and the AMA, are sponsoring national information programs which are partially contradictory to the position being taken 
by NHSB. If possible, these programs and the Bureau's program shouldbe reconciled so that they'support rather than counter each other. Among the major groups which need to be involved in the Bureau's program are the following:

\section{a. The National Safety Council}

The National Safety Council can be both specially helpful and a difficult problem. They have been conducting national education campaigns for years. They view this area of activity as very much their orn. They will be sensitive to outside efforts. Further, they have developed a philosophy over the years which is not in accord with the new direction of the National Highway Safety Bureau. Because it has a different emphasis, the Bureau's program, by implication, is critical of what the National Safety Council has done. There has been evidence during the last six months that the National Safety Council is moving away from the "if you drink don't drive" position, but they have not been able to abandon this long established slogan entirely. They must be helped to move towards the position which the Bureau intends to take. During the summer of 1969, the National Safety Council, with the American Medical Association, proposed a national campaign to be conducted in cooperation with the National Highway Safety Bureau and the National Institutes of Health. Both NIH and NHSB expressed interest but declined to participate actively because they could not fully agree with the focus of the Nationai safety Councii. INHsis wiil invite trie National safety CounciI and the AMA to join the Bureau in its program, by inviting them to sit on a working group chaired by a member of the office of Alcohol Countermeasures.

\section{b. The American Medical Association}

Since the focus of the Bureau's program is on the problem drinker, the position of physicians in the United States will be particularly critical. If they support the concept of the program as outlined by the National Highway Safety Bureau, they can be instrumental in mobilizing their membership throughout the country to support the new legislation which will be required. They can also help develop the support for the courts in the diagnosis and treatment of problem drinkers. If, on the other hand, they come into opposition with the Bureau's program their effect could be very damaging.

\section{c. The Insurance Institute}

The Insurance Institute can play an important role in our national education campa:ign since it is supported by the major insurance companies who have large amounts of funds to support advertising campaigns. The Bureau is alrealy benefiting from campaigns by insurance companies urging support of the Bureau's programs. This same type of support will be solicited for the alcohol safety campaign. To ensure that support is forthcoming, the Insurance Institute should participate in the development of the program. 
Figure $10-1$

Interagency Relationships Required To Support the NHSB Alcohol Safety Program

1. Government Agencies

A. Department of Health, Education and Welfare

1. NJMH

2. Public Health Service

3. Office of: Education

B. Department of Defense

1. Aix Force

2. Army

3. Navy

C. Department of Justice

D. Department of Housing and Urban Development:

II. Private Organizations

A. National Safety Council.

B. American Melical Association

C. Insurance Tastitute of America

D. National. Council. on Alcoholism

E. Others Whica May Offer Support 
The national alçohol safety program involves a large number of activities in research; revision of Highway Safety Standards; support of State and community Highway Safety Programs and Annual Work Plans; implementation of alcohol related 402 projects in states and communities; alcohol safety manpower development; coordination with other government agencies in a large scale attack on alcohol pioblems; and a series of comprehensive field action programs at selected cities and local areas around the country. Activities in alcohol safety will be centralized into a single office of Alcohol Countermeasures, reporting to the Associate Director for Traffic Safety Programs as illustrated in Figure 1l-1. The Office of Alcohol Countermeasures will operate with responsibilities, authority and resources commensurate with the top priority, significance and magnitude of the program.

\section{ORGANIZATION AND STAFFING REQUIREMENTS}

Based on a funding level of $\$ 7.6$ million in FY 1971, the proposed staffing for the office of Alcohol Countermeasures (OAC) is 22 positions, 17 professionals and 5 clericals, with ten additional positions assigned to NHSB regional offices. Projected staffing plans will hold the OAC to its 1971 level of 22 positions while increasing alcohol program positions in the regional offices and the NHSB Contracting Division to a total of 65 positions in alcohol for FY 1972 and 100 positions in FY 1973. This level will be maintained until FY 1976 when staffing for alcohol programs will decrease to 65 positions. Thus, personnel resources reflect the buildup and :subsequent drop-off of ASAP projects.

Mission and funcrional statements for the office of Alcohol Countermeasures are shown in Figure 11-3. 


\section{NATIONAL HIGHWAY SAFETY BUREAU TRAFFIC SAFETY PROGRAMS}

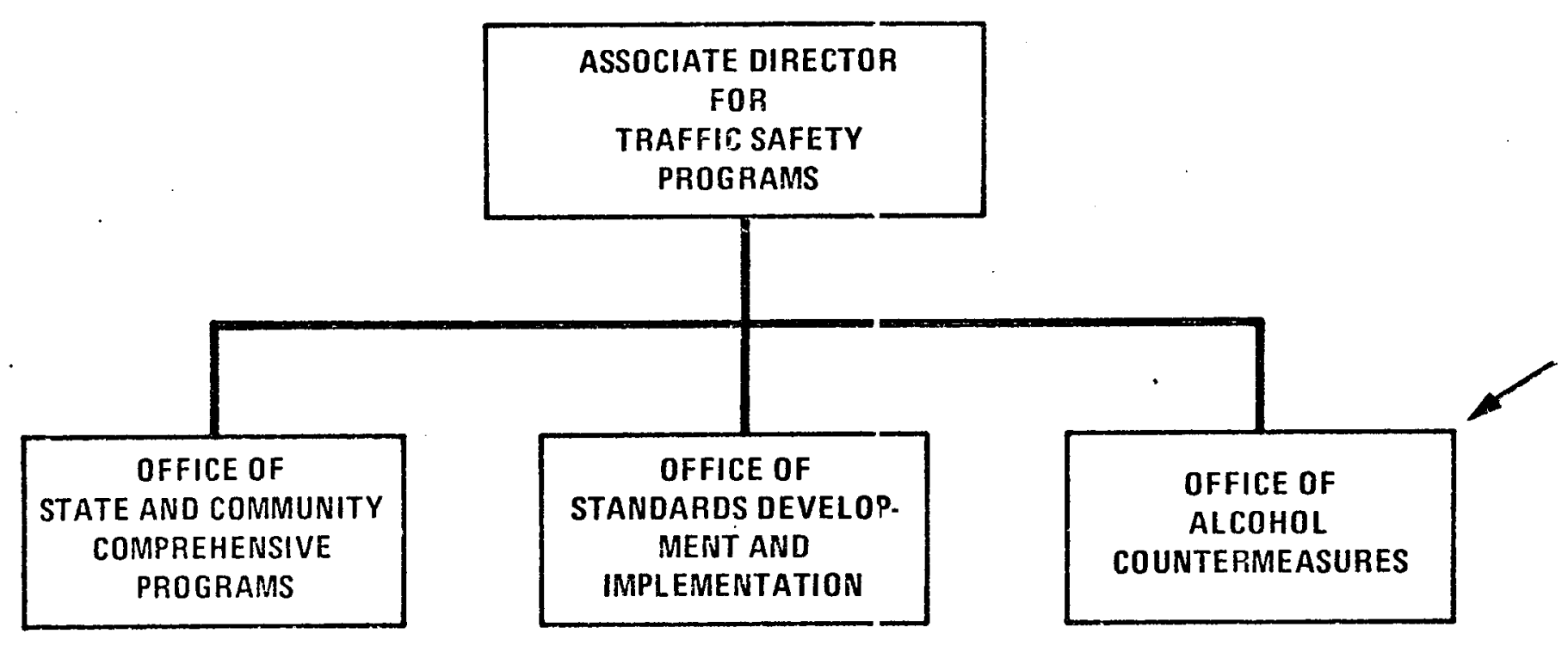


Figure 11-3

OFEICE OF ALCOHOL COUNTERMEASURES

1. MISSION. Provides national leadership in planning, publicizing, and implementing traffic safety programs directed toward reducing traffic accidents and deaths, injuries, and property damage resulting from the improper use of alcohol and drugs.

2. FUNCTIONS.

a. Provides technical assistance and guidance to the regions and the States in the development of the components related to alcohol and drugs in the State-community comprehensive and annual work programs.

b. Designs, implements, and manages alcohol and drug demonstration and start-up projects funded under section 403 of the Highway Safety Act and provides guidance, evaluation, and monitoring of Section 402 projects involving alcohol and drugs.

c. Develops highway safety standards and related material on alcohol and drugs, and assists the ofifice of Standards Development and Implementation in incorporating alcohol and drug aspects into other highway safety standards.

d. Gives technical assistance to the Office of State and Community Comprehensive programs in developing forms, instructions and procedures and in conducting courses of instruction.

e. Reviews and evaluates the alcohol and drug aspects of statecommunity comprehensive and annual work proposals, informs the office of State and Community Compretensive Programs of its findings, and aids that office in apfraising the proposed coordinated programs.

f. Provides guidance to the regions in the monitoring of alcohol and drug program elements, assists the regions as necessary when technical help is required, participates in team, across-theboard monitoring, and performs monituring as an adjunct to its program development and technical assistance work.

g. Assists the states on problems of implementation of their alcohol and drug programs in highway safety. 


\section{NHTSA}

\section{BOX 00001}

$$
\begin{aligned}
& \text { DOT-NHTSA } \\
& \text { PROJECT }
\end{aligned}
$$


h. Evaluates the national manpower needs for alcohol-drug activities related to highway safety; works with the staff of the Associate Director for Research and Technology and other organizations to assure that highway safety manpower needs in alcohol and drugs are incorporated into Bureau plans for highway safety manpower; and develops and implements programs to meet national manpower meeds to carry out community alcohol-drug countermeasure programs for highway safety.

i. Develops requirements for alcohol and drug research, and makes recommendations thereon for incorporation into the total research requirements of the Office of the Associate Director for Traffic Safety Programs.

j. Establishes and maintains liaison with governmental and private agencies involved in alcohol programs to assure correlation and direction of efforts. 